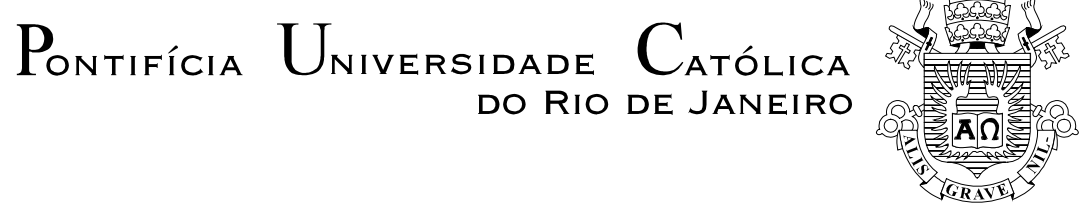

Robson Costa Reis

Análise de Desempenho de Fundos Comportamentais

Dissertação de Mestrado

Dissertação apresentada ao Programa de Pós-Graduação em Administração de Empresas da PUC-Rio como requisito parcial para obtenção do título de Mestre em Administração de Empresas.

Orientador: Prof. Marcelo Cabús Klötzle

Rio de Janeiro

Fevereiro de 2015 


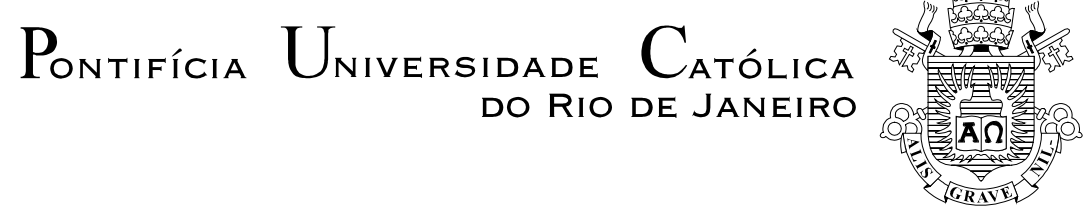

Robson Costa Reis

\section{Análise de Desempenho de Fundos Comportamentais}

Dissertação apresentada como requisito parcial para obtenção do grau de Mestre pelo Programa de PósGraduação em Administração de Empresas da PUC-Rio. Aprovada pela Comissão Examinadora abaixo assinada.

Prof. Marcelo Cabus KIotzle Orientador Departamento de Administração - PUC-Rio

Prof. Antonio Carlos Figueiredo Pinto Departamento de Administração - PUC-Rio

Prof. Roberto Marcos da Silva Montezano

Faculdades Ibmec

Prof ${ }^{a}$. Mônica Herz

Vice-Decana de Pós-Graduação do CCS - PUC-Rio 
Todos os direitos reservados. É proibida a reprodução total ou parcial do trabalho sem autorização da universidade, do autor e do orientador.

\section{Robson Costa Reis}

Possui graduação em Ciências Contábeis pela Universidade Federal do Rio de Janeiro (1998) e pós-graduação em "controladoria e finanças pela Universidade Federal Fluminense (2003)”. Concluindo mestrado em Administração, com Ênfase em finanças pela PUC-Rio (2015). Experiência em análise financeira e sistemas de informações gerenciais, atuando em empresas do setor de petróleo e financeiro."

Ficha Catalográfica

Reis, Robson Costa

Análise de desempenho de fundos comportamentais / Robson Costa Reis; orientador: Marcelo Cabús Klötzle. 2015.

81 f. ; $30 \mathrm{~cm}$

Dissertação (mestrado) - Pontifícia Universidade Católica do Rio de Janeiro, Departamento de Administração, 2015.

Inclui bibliografia

1. Administração - Teses. 2. Finanças comportamentais. 3. Teoria do prospecto. 4. Fundos comportamentais. 5. Indicadores de desempenho. I. Klötzle, Marcelo Cabús. II. Pontifícia Universidade Católica do Rio de Janeiro. Departamento de Administração. III. Título.

CDD: 658 


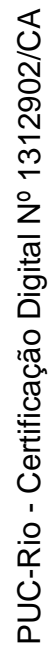

"Que darei eu ao Senhor por todos os benefícios que me tem feito?"

(Salmos, 116) 


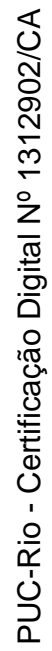

Para Aleteia, Alice e Clara, minha família. 


\section{Agradecimentos}

A Deus. A Ele toda a honra e toda a glória.

Ao BNDES que viabilizou a realização deste mestrado.

Aos amigos da valorosa e unida turma do mestrado.

Aos professores e funcionários do IAG Puc-Rio.

Ao meu orientador, Prof. Dr. Marcelo Klotzle, pelo apoio, disponibilidade e conselho.

Aos meus pais, José Reis e Linda Lúcia. Por tudo.

Por último, mas não menos importante, à minha esposa, Aleteia e minhas filhas, Alice e Clara: sem elas nada seria possível. 


\section{Resumo}

Reis, Robson Costa; Klötzle, Marcelo Cabús (Orientador). Análise de Desempenho de Fundos Comportamentais. Rio de Janeiro, 2015. 81p. Dissertação de Mestrado - Departamento de Administração, Pontifícia Universidade Católica do Rio de Janeiro.

Este trabalho analisou o desempenho de 31 fundos mútuos comportamentais atuantes nos EUA, Europa e Japão descritos em Santoni e Kelshiker (2010). Foram observados os desempenhos dos fundos e seus respectivos Benchmarks em quatro indicadores: Índice de Sharpe, Índice de Sortino, Medida Ômega e Medida de Desempenho Comportamental. O horizonte da análise foi de 10 anos (jan/04 a dez/14) dividido em intervalos de 6, 12, 36, 60 e 120 meses. A partir da consolidação dos indicadores os fundos foram ranqueados e classificados em três faixas de desempenho: superior, intermediário e inferior. No intervalo de 120 meses não houve, na média geral, diferença de desempenho significativa (a 5\%) entre os fundos e os Benchmarks. A análise por intervalos indicou que o desempenho dos fundos em relação aos Benchmarks piora conforme aumenta o prazo de aplicação. Nos intervalos mais curtos (6 e 12 meses) não houve, na média, diferença de desempenho significativa enquanto nos prazos mais longos (36 e 60 meses) o desempenho médio dos fundos foi significativamente inferior aos Benchmarks. Na média de todos os intervalos o desempenho médio dos fundos foi significativamente inferior aos Benchmarks. Dentre os indicadores utilizados, o índice de Sortino foi o que apresentou maior correlação com o desempenho geral dos fundos.

\section{Palavras-chave}

Finanças comportamentais; teoria do prospecto; fundos comportamentais; indicadores de desempenho. 


\section{Abstract}

Reis, Robson Costa; Klötzle, Marcelo Cabús (Advisor). Analysis of the performance of behavioral funds. Rio de Janeiro, 2015. 81p. MSc Dissertation - Departamento de Administração, Pontifícia Universidade Católica do Rio de Janeiro.

This work has analyzed the performance of 31 behavioral mutual funds operating in USA, Europe and Japan, as described in Santoni and Kelshiker (2010). It has been observed the performance of the funds and their respective Benchmarks according to four measures: Sharpe Index, Sortino Index, Omega Measure and Behavioral Performance Measure. The analysis covered a 10-year period (jan-04 to dec-14) split into intervals of 6, 12, 36, 60 and 120 months. Based on the consolidation of the performance measures, the funds have been ranked and classified into three performance categories: upper, intermediate and lower. In the 120-month interval there has not been, on average, a significant difference (at 5\%) in performance between funds and Benchmarks. The analysis by intervals showed that the funds' performance worsens in relation to the Benchmarks as the investment period increases. In shorter intervals (6 and 12 months) there has not been, on average, a significant difference in performance while in the longer intervals (36 and 60 months) the funds average performance was significantly lower than the Benchmarks. Computing the mean of all intervals, the funds average performance was significantly lower than the Benchmarks. Among the performance measures used, the Sortino Index presented the highest correlation with the general performance of the funds.

\section{Keywords}

Behavioral finance; prospect theory; behavioral funds; performance measures. 


\section{Sumário}

$\begin{array}{ll}\text { 1. Introdução } & 14\end{array}$

2. Referencial teórico 16

2.1. Teoria do Prospecto 16

2.1.2. Função valor e função peso 18

2.1.3. Ponto de referência 19

2.1.4. Teoria do prospecto cumulativa 20

2.2. Desenvolvimentos em finanças comportamentais $\quad 22$

$\begin{array}{ll}\text { 2.3. Fundos comportamentais } & 24\end{array}$

3. Metodologia $\quad 27$

3.1. Base de dados $\quad 27$

3.2. Medidas de performance $\quad 28$

3.3. Análise do desempenho 32

3.3.1. Algum fundo apresentou desempenho significativamente
superior ao seu respectivo Benchmark? (P1)

$\begin{array}{ll}\text { 3.3.2. Os fundos apresentaram desempenhos significativamente } & 34 \\ \text { diferentes entre si? (P2) }\end{array}$

3.3.3. Algum indicador se mostrou mais adequado que os demais na medição do desempenho dos fundos? (P3) 41

3.3.4. Como as variáveis analisadas afetaram o desempenho dos fundos? (P4) 42

4. Resultados 46

4.1. Algum fundo apresentou desempenho significativamente superior ao seu respectivo Benchmark? (P1) 46

4.2. Os fundos apresentaram desempenhos significativamente diferentes entre si? (P2) 48

4.3. Algum indicador se mostrou mais adequado que os demais na medição do desempenho dos fundos? (P3) 55

4.4. Como as variáveis analisadas afetaram o desempenho dos fundos? (P4)

4.4.1. Impacto dos Benchmarks $\quad 57$

4.4.2. Impacto dos fundos $\quad 58$

4.4.3. Impacto dos prazos $\quad 61$

4.4.4. Interação prazo vs fundos 63

4.4.5. Impacto do grupo econômico e região foco 70

5. Conclusões

5.1. Desempenho dos fundos $\quad 72$

$\begin{array}{ll}\text { 5.2. Prazos de aplicação } & 73\end{array}$

5.3. Impactos das variáveis $\quad 75$

$\begin{array}{ll}\text { 5.4. Sugestões para estudos futuros } & 76\end{array}$

$\begin{array}{ll}\text { 6. Referências bibliográficas } & 77\end{array}$ 


\section{Lista de quadros}

Quadro 1: Relação dos fundos analisados.

Quadro 2: Esquema de apuração dos zscores dos fatores MDC_OMEGA e IS_ISO por fundo e intervalo.

Quadro 3: Resumo descritivo dos zscores ponderados dos Fatores MDC_OMEGA e IS_ISO.

Quadro 4: Dispersão da variável Fator Geral. 


\section{Lista de tabelas}

Tabela 1: Resumo descritivo das taxas de superação (TS) por fundo.

Tabela 2: Matriz de correlação das taxas de superação (TS) dos indicadores.

Tabela 3: Formação dos fatores MDC_OMEGA e IS_ISO.

Tabela 4: Frequências relativas médias por fundo e prazo de aplicação (em \%).

Tabela 5: Fatores MDC_OMEGA e IS_ISO: Zscores médios ponderados pela frequência relativa por prazo de aplicação.

Tabela 6: Resultados do Teste de Hipótese H1 (H0: TS = 0; Ha: TS > $0)$.

Tabela 7: Contagem dos resultados do Teste de Hipótese H1 (TS > 0, Rejeita H0).

Tabela 8: Fator Geral de superação dos Benchmarks (Fator Geral) por fundo e prazo de aplicação.

Tabela 9: Tabela 9: Resumo dos testes ANOVA - variável: Fator Geral; fator fixo: Fundo

Tabela 10: Testes ANOVA Post-hoc: contagem de diferenças entre médias da variável Fator Geral (sig. 5\%).

Tabela 11: Classificação dos fundos pelos resultados dos testes posthoc (sig. 5\%).

Tabela 12: Resultados das regressões Fator Geral: Zscores das taxas de superação dos indicadores.

Tabela 13: Resumo descritivo dos valores de R2 das regressões Fator Geral: Zscores das taxas de superação dos indicadores por intervalo

Tabela 14: Resumo dos testes post-hoc (sig. 5\%) para os valores de R2 das regressões Fator Geral: Zscores das taxas de superação dos indicadores.

Tabela 15: Coeficiente: Retorno do Benchmark.

Tabela 16: Regressão Fator Geral Excesso: Retorno do Benchmark; dummy=fundo. 
Tabela 17: Coeficientes regressão Fator Geral Excesso: Retorno do Benchmark; dummy=fundos e classificações a partir dos testes post-hoc (sig. 5\%).

Tabela 18: Regressão Fator Geral Excesso: Retorno do Benchmark; dummy=prazo de aplicação.

Tabela 19: Fator Geral Excesso: Resumo descritivo por prazo de aplicação.

Tabela 20: Resumos das regressões de Fator Geral Excesso, por variáveis dummy e dados em painel, por prazo de aplicação.

Tabela 21: Coeficientes das regressões de Fator Geral Excesso, por variáveis dummy e dados em painel, por prazo de aplicação.

Tabela 22: Percentual de intervalos quanto à significância (a 95\%) das médias da variável Fator Geral Excesso - Por prazo de aplicação.

Tabela 23: Regressão Fator Geral Excesso: Retorno do Benchmark; 


\section{Lista de gráficos}

Gráfico 1: Zscores médios dos fatores MDC_OMEGA e IS_ISO ponderados pela frequência relativa.

Gráfico 2: Fator Geral de superação dos Benchmarks (Fator Geral) por fundo e prazo de aplicação (1).

Gráfico 3: Fator Geral de superação dos Benchmarks (Fator Geral) por fundo e prazo de aplicação (2).

Gráfico 4: Fator Geral: Intervalos de confiança das diferenças entre médias (post-hoc a 5\%) - 6 e 60 meses.

Gráfico 5: Retornos mensais dos Benchmarks (em \%).

Gráfico 6: Fator Geral Excesso - Intervalos de confiança (95\%) e tamanho da amostra por prazo de aplicação.

Gráfico 7: Regressão Fator Geral Excesso - dados em painel: efeitos de tempo.

Gráfico 8A: Fator Geral Excesso - Intervalos de confiança (95\%) por intervalo (prazo e data) 6 meses.

Gráfico 8B: Fator Geral Excesso - Intervalos de confiança (95\%) por intervalo (prazo e data) 12 meses.

Gráfico 8C: Fator Geral Excesso - Intervalos de confiança (95\%) por intervalo (prazo e data) 36 meses.

Gráfico 8D: Fator Geral Excesso - Intervalos de confiança (95\%) por intervalo (prazo e data) 60 meses. 


\section{1 \\ Introdução}

O campo de estudo das finanças comportamentais tem como marco inicial a publicação do trabalho "Prospect theory: an analysis of decision under risk" de Kahneman e Tversky (1979). Esse trabalho apresenta a Teoria do Prospecto, uma revisão crítica da Teoria da Utilidade Esperada, desenvolvida por von Neumann \& Morgenstern (1944), uma das bases da moderna teoria de finanças, especialmente quanto à sua premissa de comportamento racional dos indivíduos em decisões arriscadas, traduzido pela busca da maximização da utilidade.

Nesse trabalho, posteriormente atualizado na Teoria do Prospecto Cumulativa (Tversky e Kahneman e (1992)), os autores apontaram importantes divergências entre os resultados empíricos observados nos seus experimentos com escolhas de prospectos e o modelo previsto pela Teoria da Utilidade Esperada. Por suas pesquisas sobre o comportamento humano na tomada de decisões sob risco, integrando psicologia e economia, Kahneman foi laureado com o Prêmio Nobel de Economia em 2002.

Desde a publicação desse trabalho seminal, o interesse pelas finanças comportamentais cresceu enormemente. Uma amostra deste interesse no âmbito acadêmico é que o estudo já ultrapassou a marca de trinta mil citações e o trabalho continua figurando entre os artigos mais citados pelas publicações mais recentes da área.

No âmbito do mercado, um exemplo do interesse pelas finanças comportamentais pode ser observado na indústria de fundos. A partir dos anos 90 gestores de recursos passaram a oferecer os chamados "fundos comportamentais", com apelo de explorar vieses comportamentais e atitudes irracionais do mercado para, desta forma, obter rendimentos superiores. Estes fundos operam principalmente nos Estados Unidos, Europa e Japão.

O objetivo principal do presente trabalho é analisar o desempenho dos fundos comportamentais. Como contribuição à literatura deste campo de estudo pode-se destacar: i) a análise do impacto dos prazos de aplicação sobre o desempenho dos fundos comportamentais; e ii) a utilização inédita de indicadores 
como a Medida de Desempenho Comportamental e a Medida Ômega na análise de fundos comportamentais.

Como objetivos intermediários, as seguintes questões são investigadas:

- P1: Algum fundo apresentou desempenho significativamente superior ao seu respectivo Benchmark?

- P2: Os fundos apresentaram desempenhos significativamente diferentes entre si?

- P3: Algum indicador se mostrou mais adequado que os demais na medição do desempenho dos fundos?

- P4: Como as variáveis analisadas afetaram o desempenho dos fundos?

Como limitação do estudo pode ser citada a pequena quantidade de fundos comportamentais identificados na literatura até o momento. No Brasil, especificamente, não foram encontrados estudos situando a existência de tais fundos no país.

A amostra analisada neste trabalho foi descrita no estudo de Santoni e Kelshiker (2010) intitulado "Behavioral finance: an analysis of the performance of behavioral finance funds". 


\section{Referencial teórico}

\section{1}

\section{Teoria do Prospecto}

A Teoria do Prospecto foi desenvolvida por Kahneman e Tversky (1979) no trabalho "Prospect theory: an analysis of decision under risk" que deu origem ao campo de estudo das finanças comportamentais. Nesse trabalho os autores apresentam uma crítica à Teoria da Utilidade Esperada desenvolvida por von Neumann \& Morgenstern (1944) quanto às suas premissas de comportamento racional dos indivíduos nas tomadas de decisão sob risco.

No estudo os autores propuseram a estudantes universitários uma série de problemas na forma de questionário onde cada respondente, anonimamente, deveria optar entre duas apostas ou prospectos, como por exemplo:
A: $50 \%$ de chance de ganhar 1,000
B: ganhar 450 com certeza
$50 \%$ de chance de ganhar nada

A partir da compilação das escolhas feitas pelos respondentes nos problemas propostos, os autores identificaram uma série de vieses comportamentais que contrariavam a expectativa de comportamento racional, especialmente quanto a três princípios da Teoria da Utilidade Esperada: expectativa, aversão ao risco e integração com os ativos.

Uma descoberta importante do estudo foi o "efeito da certeza": as pessoas tendem a superestimar o peso de eventos certos ou de elevada probabilidade de ocorrência em relação àqueles apenas prováveis de acontecer. Esta constatação viola o princípio da expectativa da Teoria da Utilidade que prevê que a utilidade de um prospecto é a soma da utilidade esperada dos seus componentes. Os resultados dos testes mostraram que prospectos contendo eventos certos ou de elevada probabilidade tinham preferência (ou seja, maior utilidade) sobre 
prospectos com eventos de probabilidades moderadas, ainda que as somas dos valores esperados destes eventos fossem equivalentes, ou até menores.

Os autores argumentam que este efeito contribui para outro fato observado no estudo: a aversão ao risco é positiva em cenários de ganhos e negativa em cenários de perdas. Em outras palavras, as pessoas são menos dispostas a assumir riscos para aumentar ganhos e mais dispostas a assumir riscos para reduzir perdas. A isto os autores chamaram "efeito de reflexo", alusão ao reflexo de uma imagem num espelho. Desta forma, a função de preferência seria côncava na região de ganhos e convexa na região de perdas, o que difere do modelo previsto pela Teoria da Utilidade, em que a aversão ao risco é absoluta e a função utilidade é sempre côncava. Segundo os autores o efeito de reflexo é impulsionado pelo efeito da certeza: as pessoas preferem abrir mão da possibilidade de ganhar mais se já tiverem um ganho garantido mas, por outro lado, preferem se arriscar a perder mais a assumir uma perda certa.

Outro efeito importante observado no estudo é o "efeito de isolamento": para simplificar o processo de escolha, as pessoas tendem a focar sua avaliação apenas no que as alternativas diferem entre si e desprezar os aspectos comuns a todas as alternativas. Esta característica leva a escolhas inconsistentes, uma vez que os prospectos podem ser decompostos entre elementos comuns e exclusivos de várias formas possíveis. Isto é, dependendo da forma como as escolhas (prospectos) são apresentadas, podem apresentar preferências diferentes, ainda que seus resultados finais esperados sejam exatamente os mesmos.

O efeito de isolamento contraria o princípio da integração aos ativos da Teoria da Utilidade, que diz que os indivíduos fazem escolhas avaliando a posição final de riqueza proporcionada por cada alternativa, ou seja, agregando o resultado de cada prospecto à sua posição inicial de riqueza. Os resultados mostraram que, na verdade, as pessoas tendem a avaliar os prospectos considerando apenas seus resultados isoladamente, desprezando da análise sua posição inicial de riqueza por ser este um elemento comum a quaisquer prospectos sob avaliação. Por este princípio, o verdadeiro direcionador das escolhas não é a posição final da riqueza, como prevê a Teoria da Utilidade, mas a variação na posição de riqueza.

Estas descobertas foram o ponto central na elaboração da Teoria do Prospecto. Em resumo, elas demonstravam que, sob certas circunstancias, as pessoas não escolhiam os prospectos de maior valor esperado ou de menor risco, 
contrariando o comportamento racional de maximização da utilidade assumido pela Teoria da Utilidade.

\subsection{2}

\section{Função valor e função peso}

O trabalho introduz a função "V" que calcula o valor total esperado do prospecto e é a principal equação da teoria. A seguir a representação do cálculo do valor de um prospecto de 2 eventos com resultados " $x$ ” e “ $y$ ” com respectivas probabilidades "p" e “q”:

$$
V(x, p ; y, q)=\pi(p) v(x)+\pi(q) v(y)
$$

Onde:

“ $\pi$ ” é a função que exprime o peso associado à probabilidade objetiva do evento; e “v” é a função que exprime o valor atribuído ao resultado do evento

A função V da Teoria do Prospecto é uma generalização da função utilidade (U) da Teoria da Utilidade, em que o princípio da expectativa é relaxado: enquanto na Teoria da Utilidade os valores de cada evento são ponderados pela sua respectiva probabilidade de forma que a soma das probabilidades de todo os eventos do prospecto é igual a $1(\mathrm{p}+\mathrm{q}+\ldots+\mathrm{n}=1)$, na Teoria do Prospecto a função " $\pi$ " atribui pesos às probabilidades sem necessariamente totalizar $1(\pi(p)+\pi(q)$ $+\ldots+\pi(\mathrm{n})<=1)$.

Propriedades da função valor (v):

i. é definida em termos de desvios em torno de um ponto de referência (a referência pode ser a posição inicial de riqueza ou um outro patamar esperado pelo decisor);

ii. é côncava para ganhos e convexa para perdas (aversão ao risco na região de ganhos e propensão ao risco região de perdas);

iii. é mais inclinada na área de perdas do que na área de ganhos (preferência por evitar uma perda a obter um ganho equivalente). 
Propriedades da função peso $(\boldsymbol{\pi})$ :

i. transforma a probabilidade objetiva de um evento em peso de decisão (não é uma probabilidade subjetiva ou percebida pelo decisor quanto à chance de ocorrência do evento);

ii. sua inclinação mede o impacto das variações nas probabilidades objetivas sobre as variações na preferência do prospecto;

iii. varia de $0(\boldsymbol{\pi}(0))$ a $1(\boldsymbol{\pi}(1))$; a soma das funções peso de um prospecto é, geralmente, menor que 1 .

iv. é menor do que a probabilidade objetiva do evento, geralmente (devido ao padrão de concavidade/convexidade da função valor);

v. é maior do que a probabilidade objetiva do evento, para probabilidades muito baixas (nestes casos, há aversão ao risco na região de perdas e propensão ao risco na região de ganhos; ex: seguros e loterias)

\subsection{3}

\section{Ponto de referência}

Pelo efeito de isolamento, as pessoas tendem a avaliar os prospectos em termos de ganhos e perdas mais do que em termos da posição final de riqueza. Os autores destacam algumas implicações das mudanças no ponto de referência na tomada de decisão:

i. mesmo pequenas alterações na forma de apresentação de dois prospectos equivalentes podem levar a mudanças na preferência entre eles, dependendo do ponto de referência usado para calcular os valores dos eventos;

ii. perdas já ocorridas mas ainda não assimiladas ou ganhos ainda não ocorridos mas já esperados pelo decisor podem levar a decisões mais arriscadas por conta da propensão ao risco na área de perdas; 
iii. a forma mais efetiva de evitar propensão ao risco na região de perdas é usar 0 (zero) como ponto de referência e avaliar os resultados em termos da posição final de riqueza proporcionada por cada evento do prospecto.

\subsection{4}

\section{Teoria do prospecto cumulativa}

Em 1992 foi introduzida a Teoria do Prospecto Cumulativa (Tversky e Kahneman e (1992)), como extensão e aperfeiçoamento da teoria original, especialmente no tocante às formulações das funções valor e peso. As principais mudanças em relação à teoria original foram:

i. As funções peso e valor foram expressas matematicamente, diferenciadas entre ganhos e perdas.

ii. A função de valor geral do prospecto foi generalizada para prospectos com qualquer quantidade de resultados e com distribuições contínuas (ao invés de apenas dois resultados).

iii. A função peso foi modificada para transformação de probabilidades cumulativas (ao invés de probabilidades individuais dos resultados).

Foi mantido o padrão de 4 configurações:

iv. Aversão ao risco para ganhos de alta e moderada probabilidade

v. Propensão ao risco para ganhos de baixa probabilidade

vi. Propensão ao risco para perdas de alta e moderada probabilidade

vii. Aversão ao risco para perdas de baixa probabilidade

A teoria incorporou dois novos princípios para explicar os resultados observados: 
- Princípio da sensibilidade decrescente: o impacto das mudanças nos resultados dos eventos sobre a função valor diminui conforme se afasta do ponto de referência; e o impacto das mudanças nas probabilidades dos eventos sobre a função peso aumenta conforme se aproxima de 0 ou 1.

- Princípio da aversão à perda: a função valor é mais inclinada na região de perdas do que na região de ganhos

A partir da compilação dos resultados de novos experimentos envolvendo escolha de prospectos, foram modeladas as funções valor e peso.

O valor geral de um prospecto $\mathbf{f}$, com $\mathbf{m}$ resultados negativos e $\mathbf{n}$ resultados positivos é dado por:

$$
V(f)=\sum_{i=-m}^{n} \pi_{i} v\left(x_{i}\right)
$$

Onde:

$\boldsymbol{\pi}$ é a função peso da probabilidade objetiva do resultado i, sendo $\boldsymbol{\pi}_{\boldsymbol{i}}^{+}$a função peso para resultados positivos e $\boldsymbol{\pi}_{\boldsymbol{i}}^{-}$para resultados negativos $\boldsymbol{v}\left(\boldsymbol{x}_{\boldsymbol{i}}\right)$ é a função valor do resultado $\boldsymbol{x}_{\boldsymbol{i}}$

A função valor do resultado x é dada por:

$$
\boldsymbol{v}= \begin{cases}x^{\alpha} & \text { se } x \geq 0 \\ -\lambda(-x)^{\beta} & \text { se } x<0\end{cases}
$$

Onde

$\boldsymbol{\alpha}$ e $\boldsymbol{\beta}$ são parâmetros estimados pelos autores a partir da compilação dos resultados dos experimentos, sendo $\boldsymbol{\alpha}=\boldsymbol{\beta}=\mathbf{0 , 8 8}$

$\lambda$ é o coeficiente de aversão à perda, também estimado a partir da compilação dos resultados dos experimentos, sendo $\lambda=\mathbf{2 , 2 5}$ 
A função peso da probabilidade p de um resultado positivo $(x \geq 0)$ é dada por:

$$
\boldsymbol{\pi}^{+}=\frac{\boldsymbol{p}^{\gamma}}{\left(\boldsymbol{p}^{\gamma}+(\mathbf{1}-\boldsymbol{p})^{r}\right)^{1 / \gamma}}
$$

A função peso da probabilidade p de um resultado negativo $(x<0)$ é dada por:

$$
\pi^{-}=\frac{p^{\delta}}{\left(p^{\delta}+(1-p)^{\delta}\right)^{1 / \delta}}
$$

$\boldsymbol{\gamma}$ e $\boldsymbol{\delta}$ são parâmetros estimados pelos autores a partir da compilação dos resultados dos experimentos, sendo $\boldsymbol{\gamma}=\mathbf{0 , 6 1}$ e $\boldsymbol{\delta}=\mathbf{0 , 6 9}$

\section{2 \\ Desenvolvimentos em finanças comportamentais}

Os desenvolvimentos no campo das finanças avançam em duas linhas principais: limite à arbitragem e psicologia (Barberis e Thaler (2003)). A primeira é composta pelo conjunto de estudos que contestam a premissa da teoria de eficiência dos mercados de que eventuais distorções nos preços não perduram porque investidores racionais vão comprar os ativos subavaliados e vender os superestimados restabelecendo o equilíbrio: investidores racionais não conseguem eliminar as distorções geradas por investidores irracionais, gerando desequilíbrios duradouros. Na segunda vertente inserem-se os estudos que buscam identificar e investigar os fenômenos associados a esses comportamentos irracionais dos investidores observados empiricamente.

Na linha de limite à arbitragem, Shleifer e Vishny (1997) propõem um modelo que descreve as condições em que a arbitragem profissional não consegue trazer os preços dos ativos de volta aos fundamentos, especialmente em situações extremas de volatilidade ou altas maturidades que, apesar de potencialmente mais lucrativas, são mais arriscadas e podem levar à liquidação antecipada de posições por pressão dos investidores. De Long et. al (1990) analisaram situações em que investidores irracionais (“noise traders”), afetaram a volatilidade e os preços de ativos a tal ponto de eles mesmos obterem retornos mais altos do que os próprios investidores racionais, configurando o chamado “noise traders risk”. D’avolio (2002) investigou os custos de empréstimo de ações, que podem inviabilizar a montagem de posições vendidas, reduzindo arbitragens. Merton (1987) observou 
que a complexidade da operação e a falta de informação podem afetar os custos de uma arbitragem a ponto de eliminar sua atratividade, elevando assim o tempo de duração do desequilíbrio.

Pela vertente da psicologia, heurísticas e vieses cognitivos que afetam o comportamento dos indivíduos nas decisões de investimentos têm sido identificados e estudados, dentre os quais podem ser citados: excesso de confiança, representatividade, disponibilidade, conservadorismo, ancoragem, disponibilidade, contabilidade mental (Tversky e Kahneman (1974), Thaler (2000), Fromlet (2001), Ritter (2003), Moore e Healy (2008), Chan et al (2003), Bailey et. al (2010)).

Vários estudos também analisaram evidências empíricas de anomalias no mercado de ações que contrariam a expectativa de comportamental racional da hipótese de mercados eficientes.

O “efeito janeiro” (Rozeff e Kinney (1976) e Reinganum (1983)), fenômeno pelo qual as ações de pequenas empresas apresentam em janeiro rentabilidade maior do que em qualquer outro mês, continua sendo consistentemente observado (Haug e Hirschey (2006)).

Harris e Gurel (1986) examinaram as 288 mudanças ocorridas na composição do índice SP\&500 entre 1973 e 1983 e constataram que, ao ser anunciada a entrada de uma nova ação no índice, seu preço imediatamente sobe, em média, 3\% revertendo a alta em até 2 semanas.

Shefrin e Statman (1985) estudaram o “efeito disposição”, fenômeno que leva investidores a se desfazerem muito cedo de ações com tendência de alta (vencedoras) e a segurarem por mais tempo ações com tendência de queda (perdedoras).

De Bondt e Thaler (1985) investigaram o efeito da reação exagerada ("overreaction”) do mercado em relação a fatos novos sobre os preços das ações. Eles identificaram que o rendimento das ações mais perdedoras nos últimos 36 meses supera, no acumulado dos 36 meses passados com os 36 meses seguintes, o rendimento das ações mais vencedoras, numa tendência de reversão de longo prazo.

Jegadeesh e Titman (1993) documentaram o "efeito momentum”: as ações mais vencedoras e as ações mais perdedoras dos últimos seis meses tendem a manter seu movimento pelos 3 a 12 meses seguintes, gerando retornos anormais 
(desproporcionais ao risco) para quem assume posições compradas nas vencedoras e vendidas nas perdedoras durante esse período.

Benartzi e Thaler (1993) investigaram o enigma do excesso de retorno das ações (descontado o risco) em relação a títulos de renda fixa ("equity premium puzzle”, Mehra e Prescott (1985)) sob uma perspectiva comportamental. Aplicando fundamentos da teoria do prospecto, chegaram à conclusão que, assumindo que os investidores são avessos à perda e que reavaliam constantemente a alocação de seus recursos (“aversão míope à perda”), o intervalo desta reavaliação compatível com o excesso de retorno observado é de 1 ano.

Além da teoria do prospecto, outras teorias têm sido desenvolvidas relacionando aspectos psicológicos e comportamentais às decisões de risco.

Lopes (1987) e Lopes e Oden (1999) desenvolveram a teoria SP/A, segundo a qual, na formação de seus portfolios, os investidores relacionam a segurança (S) e o potencial (P) de um ativo com a probabilidade de atingir níveis de aspiração (A). De acordo com a teoria, as decisões dos investidores são orientadas por sentimentos de medo e esperança, levando à combinação de ativos muito seguros com ativos muito arriscados em seus portfolios.

Shefrin e Statman (2000) desenvolveram a teoria comportamental das carteiras (BPT behavioral portfolio theory) com base na teoria do prospecto de Kahneman e Tiversky (1979) e na teoria SP/A de Lopes (1987). No trabalho eles discutem as implicações da teoria para a construção de portfolios e apresentam a fronteira eficiente comportamental em contraponto à fronteira eficiente de médiavariância da tradicional teoria das carteiras de Markowitz (1959).

\section{3}

\section{Fundos comportamentais}

Segundo Santoni e Kelshker (2010), os primeiros fundos comportamentais surgiram no início dos anos 90 nos Estados Unidos e Europa, sendo o "Premier Equity Growth” o pioneiro, lançado pela subsidiária inglesa do grupo JPMorgan em 1992. O principal critério de classificação dos fundos na categoria “comportamental” tem sido, geralmente, a autodeclararão, principalmente através do nome do fundo, sua descrição e sua estratégia de promoção. Alguns autores, como Reinhart e Brennan (2003) e Santoni e Kelshker (2010), argumentam que 
tais fundos não seguem propriamente os fundamentos das teorias das finanças comportamentais, mas apenas buscam identificar e explorar vieses comportamentais irracionais observados no mercado para tentar obter ganhos superiores.

Em um dos primeiros estudos sobre fundos comportamentais, Reinhart e Brennan (2004) analisaram a performance (rendimento bruto e algumas medidas de risco-retorno) de nove fundos mútuos comportamentais comparando seu desempenho com Benchmarks e alguns índices de fundos de investimentos para o período entre 1997 e 2004. Ressalvado o tamanho limitado da amostra, uma das conclusões do estudo foi que fundos comportamentais que investem em ações de grandes empresas (large caps) tiveram, em geral, melhor desempenho que os fundos comportamentais investidores de pequenas empresas (small caps): por terem muita liquidez, serem muito conhecidas e terem ampla cobertura da mídia, as ações das grandes empresas seriam mais vulneráveis a comportamentos irracionais dos investidores. Os autores não encontraram evidências de que os fundos comportamentais, na média, superaram significativamente os Benchmarks.

Outro estudo nesta linha foi o de Wright et al (2008) que analisou 16 fundos (incluindo os nove analisados por Reinhart e Brennan (2004)), comparando, além da performance, sua capacidade de captar recursos frente a fundos tradicionais. Apesar de não encontrar evidências de desempenho ajustado pelo risco significantemente superior aos Benchmarks, o estudo constatou que estes fundos conseguiram atrair mais recursos do que concorrentes similares não comportamentais, sugerindo que a classificação “comportamental” funcionou melhor como estratégia de marketing do que na geração de resultados anormais.

A amostra analisada no presente trabalho foi descrita no estudo de Santoni e Kelshiker (2010), que apresenta a amostra mais abrangente de fundos comportamentais registrada na literatura até o momento. O estudo analisou os nove fundos estudados por Reinhart e Brennan (2003), os setes fundos adicionados por Wright et al (2006) e mais 15 fundos adicionados pelos próprios autores, com base na terminologia “comportamental” contida no nome ou na descrição, totalizando 31 fundos. Além da comparação dos retornos brutos, os autores também analisaram outras características tais como: perfil de investimento dos fundos, efeito sazonalidade, desempenho em ciclos de alta e baixa nos mercados ("bull market" e "bear market”), diversificação, consistência e 
antecipação de reversão. O estudo concluiu ser difícil comprovar, com clareza, a capacidade destes fundos em superar, consistentemente, os Benchmarks e prever reversões de tendência do mercado: os fundos foram superiores aos Benchmarks nos períodos de alta e inferiores nos períodos de baixa. Também se observou que os fundos foram eficazes em explorar vieses comportamentais (como o "efeito janeiro”) e apresentaram menor volatilidade que os Benchmarks.

Podem ser citados outros estudos investigativos do desempenho de fundos comportamentais, como segue.

Sjøberg (2011) comparou o desempenho de fundos comportamentais com índices e fundos convencionais na Noruega entre 1993 e 2010. Apesar de não haver fundos noruegueses autodeclarados como “comportamentais” o autor classificou, a partir da análise dos prospectos de 67 fundos, 6 fundos nesta categoria para os quais examinou a ocorrência ou não de retornos anormais descontado o risco. Três fundos da amostra apresentaram retornos anormais positivos.

Philippas (2014) analisou a performance de 22 fundos comportamentais norte-americanos durante o período de jan/07 a mar/13 com foco na investigação do comportamento destes fundos durante e após o período de crise internacional. O estudo comparou o desempenho dos fundos com Benchmarks, retornos de mercado e fundos de administração passiva (ETFs, fundos de índice) através de indicadores de retorno ajustado ao risco. O estudo não encontrou evidências de desempenho superior dos fundos em relação aos comparativos e, para alguns fundos, constatou desempenho significativamente inferior.

Gonzales Fernández e Gonzales Velasco (2013) compararam os desempenhos de três categorias de fundos do mercado norte-americano entre 1994 a 2011: 6 fundos comportamentais, 6 fundos socialmente responsáveis e 1 fundo de vício (de investimentos em setores como bebidas, cigarros, atividades poluentes, etc.). $\mathrm{O}$ estudo não encontrou evidências de desempenho significativamente diferente entre os três tipos de fundo.

Goodfellow et. al (2013) compararam o desempenho de fundos comportamentais com Benchmarks de mercado e correspondentes fundos mútuos ativamente gerenciados de diferentes regiões do globo entre 1990 e 2010, avaliando o retorno bruto e medidas de risco-retorno. O estudo não encontrou evidências de diferenças significativas de desempenho. 
3

\section{Metodologia}

\section{1}

\section{Base de dados}

Neste trabalho foram analisados todos os $\mathbf{3 1}$ fundos descritos no estudo de Santoni e Kelshiker (2010). O quadro 1 mostra a relação dos fundos analisados:

Quadro 1: Relação dos fundos analisados.

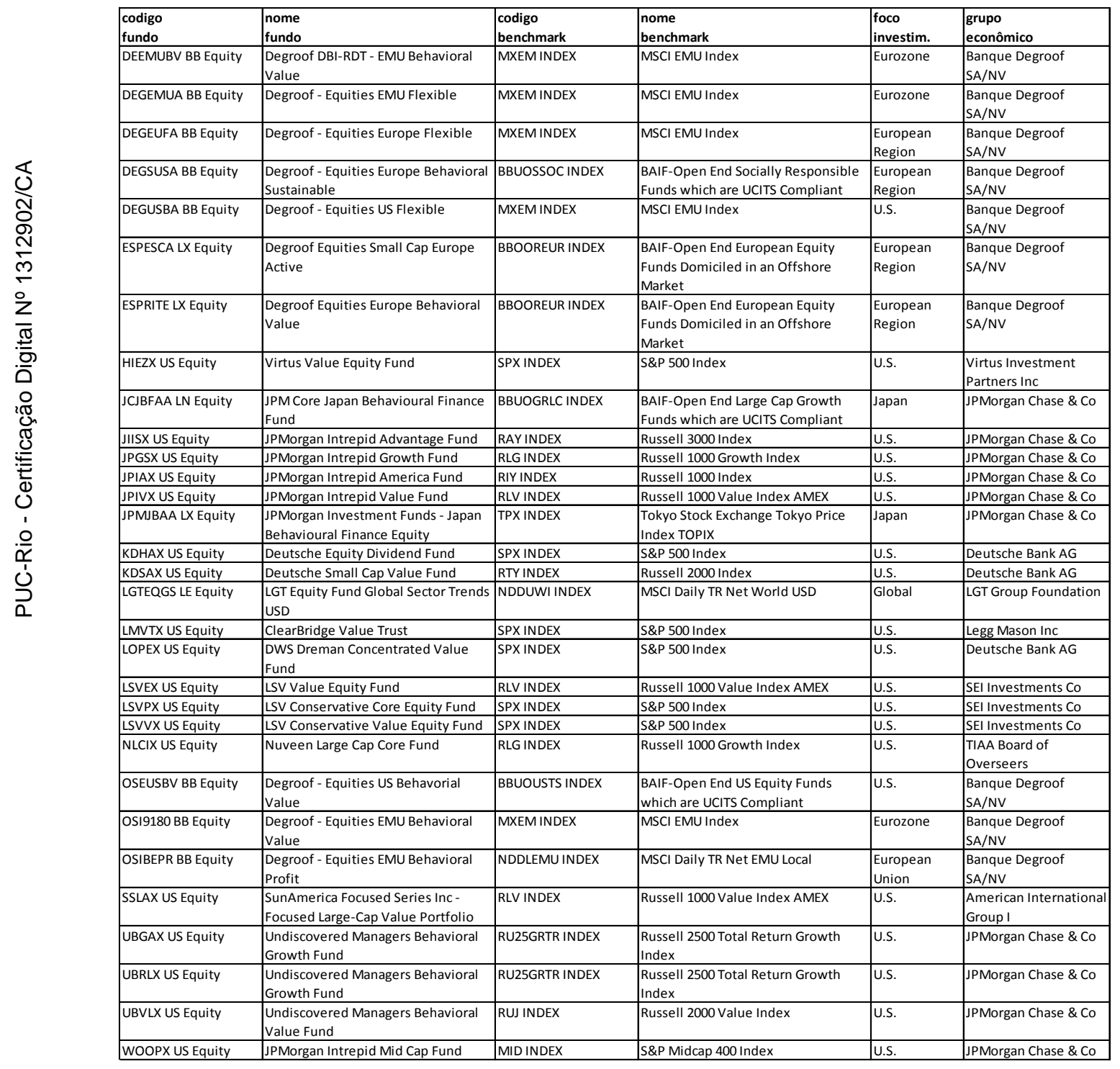

Fonte: Santoni e Kelshiker (2010) e Bloomberg. 
O presente estudo se diferencia em dois aspectos principais:

i) o período de análise foi estendido de 5 para 10 anos e dividido em intervalos de 6, 12, 36, 60 e 120 meses, possibilitando a análise do desempenho dos fundos para diferentes prazos de aplicação;

ii) foram utilizados não apenas os retornos brutos, mas indicadores de desempenho que relacionam os retornos com uma medida de risco, com destaque para a Medida de Desempenho Comportamental e a Medida Ômega, cuja utilização na análise de desempenho de fundos comportamentais não foi registrada na literatura até o momento.

Neste trabalho foram utilizados os retornos aritméticos mensais dos fundos e dos seus respectivos Benchmarks no período entre JAN/2004 e DEZ/2013, contemplando 120 meses. Os dados foram extraídos da Bloomberg.

\section{2}

\section{Medidas de performance}

A avaliação de performance de investimentos com base no seu retorno e seu risco tem suas origens no trabalho de Markowitz (1959), destacadamente na Teoria do Portfolio ou Teoria das Carteiras, desenvolvida a partir da Teoria da Utilidade Esperada de von Neumann-Morgenstern, que buscava uma alocação ótima de ativos numa carteira de modo a maximizar a relação entre o retorno dessa carteira e seu nível de risco, alcançando a chamada fronteira eficiente.

A partir dos dados coletados foram computados os seguintes indicadores de performance: Índice de Sharpe (IS), Índice de Sortino (ISO), Medida Ômega (Ômega) e Medida de Desempenho Comportamental (MDC). A seguir um breve resumo dos quatro indicadores de performance utilizados no estudo:

\section{1) Índice de Sharpe (IS)}

Desenvolvido por William Sharpe (1966), foi o primeiro indicador de performance a relacionar o retorno e o risco do investimento, tomando como base 
a teoria das carteiras de Markowitz (1959). A medida de risco utilizada é o desvio padrão dos retornos do investimento. O índice calcula o excesso de retorno gerado por determinado investimento em relação à taxa livre de risco, por unidade de risco.

Pela facilidade de cálculo e de interpretação é amplamente utilizado na avaliação de aplicações financeiras, especialmente de fundos de investimentos.

Calculado pela seguinte fórmula:

$$
I S=\frac{R-R f}{\sigma}
$$

Onde:

$\mathbf{R}$ é a taxa de retorno média gerada pelo investimento num dado período

Rf é a taxa de juros livre de risco

$\boldsymbol{\sigma}$ é o desvio padrão dos retornos gerados pelo investimento no período

\section{2) Índice de Sortino (ISO)}

Apresentado por Sortino e Price (1994), diferencia-se do Índice de Sharpe por usar no denominador como medida de risco não o desvio padrão dos retornos, mas apenas os desvios negativos, ou seja, as variações negativas em relação ao retorno mínimo exigido, que é o conceito de “downside risk”. O indicador de “downside risk” utilizado no denominador do índice é a raiz quadrada de um momento parcial inferior de ordem 2 (Bawa (1975) e Fishburn (1977)).

Calculado pela seguinte fórmula:

$$
I S O=\frac{R-R t}{\sqrt{\int_{-\infty}^{R t}(R t-R)^{2} d F(R)}}
$$

Onde:

$\mathbf{R}$ é a taxa de retorno média gerada pelo investimento num dado período Rt é a taxa mínima de retorno exigida pelo investidor; neste estudo foi usada a taxa de juros livre de risco (Rf) 
$\mathbf{F ( R ) ~ e ́ ~ a ~ f u n c ̧ a ̃ o ~ d e ~ d i s t r i b u i c ̧ a ̃ o ~ d e ~ p r o b a b i l i d a d e s ~ d o s ~ r e t o r n o s ~ d o ~}$ investimento.

\section{3) Medida Omega (Omega)}

A medida ômega foi desenvolvida por Keating e Shadwic (2002) com a proposta de ser um indicador universal de performance de investimentos, diferenciando-se dos tradicionais indicadores em um aspecto fundamental: enquanto os indicadores tradicionais contemplam apenas a média e a variância (com ajustes, a exemplo do índice Sortino), a medida Omega contempla, além da média e da variância, também os momentos superiores da distribuição como a curtose e a assimetria. O índice consiste na razão entre a distribuição dos retornos ocorridos na região acima da taxa mínima requerida e a distribuição dos retornos ocorridos na região abaixo da taxa mínima requerida.

É calculada pela formula:

$$
\text { Omega }=\frac{\int_{r}^{\infty} 1-F(x) d x}{\int_{-\infty}^{r} F(x) d x}
$$

\footnotetext{
Onde:

$\mathbf{x}$ é o retorno do investimento

r é a taxa mínima de retorno exigida pelo investidor; neste estudo foi usada a taxa de juros livre de risco (Rf)
}

$\mathbf{F}(\mathbf{x})$ é a distribuição de frequência dos retornos

\section{4) Medida de Desempenho Comportamental (MDC)}

Desenvolvida por Klotzle et al (2012) a medida de desempenho comportamental se difere dos demais indicadores utilizados neste trabalho, fundamentalmente, por se basear na Teoria do Prospecto de Kahneman e Tversky (1979) e na Teoria do Prospecto Cumulativa de Tversky e Kahneman (1992).

A exemplo da medida Omega, contempla todos os momentos da distribuição dos retornos, diferente dos modelos de média-variância sendo, da 
mesma forma, calculada como a razão entre a distribuição dos retornos ocorridos na região de ganhos e a distribuição dos retornos ocorridos na região de perdas. Entretanto, apresenta duas distinções principais principais: i) a distribuição de probabilidade dos retornos não é a probabilidade objetiva (caso da Omega) mas sim a probabilidade ajustada pela função peso prevista na Teoria da Probabilidade Cumulativa; ii) a distribuição de probabilidade na região de perdas é ajustada pelo coeficiente de aversão a perdas também previsto na Teoria da Probabilidade Cumulativa.

É calculado pela seguinte fórmula:

$$
\boldsymbol{M D C}=\frac{\int_{M}^{\infty}(p) E((R A-M))^{\alpha} d \pi^{+}(p)}{\int_{-\infty}^{M}(p) \lambda E((M-R A))^{\beta} d \pi^{-}(p)}
$$

Onde:

RA é o retorno alcançado pelo investimento

M é a meta de retorno; neste estudo foi usada a taxa de juros livre de risco (Rf)

p é a probabilidade objetiva de ocorrência de um retorno

$\boldsymbol{\alpha}$ é o coeficiente de aversão/propensão ao risco na área de ganhos

$\boldsymbol{\beta}$ é o coeficiente de aversão/propensão ao risco na área de perdas

$\lambda$ é o coeficiente de aversão à perda.

$\pi+(p)$ é a função peso na área de ganhos

$\pi-(\mathbf{p})$ é a função peso na área de perdas.

A função peso reflete a distorção das probabilidades objetivas na percepção dos tomadores de decisão diante de cenários de ganhos e perdas, conforme prevê a Teoria do Prospecto Cumulativa.

As funções-peso nas regiões de ganhos e perdas são dadas pelas fórmulas:

$$
\begin{gathered}
\boldsymbol{\pi}^{+}(\boldsymbol{p})=\frac{p^{\gamma}}{\left(p^{\gamma}+(1-p)^{\gamma}\right)^{\frac{1}{\gamma}}} \\
\boldsymbol{\pi}^{-}(\boldsymbol{p})=\frac{p^{\delta}}{\left(p^{\delta}+(1-p)^{\delta}\right)^{\frac{1}{\delta}}}
\end{gathered}
$$


No presente trabalho, os valores dos parâmetros utilizados no cálculo do MDC foram as estimativas obtidas a partir de observações empíricas contidas em Tversky e Kahneman (1992), como segue:

$$
\alpha=0,88, \beta=0,88, \lambda=2,25, \quad \gamma=0,61 \text { e } \delta=0,69 \text {. }
$$

No presente estudo, para o cálculo de todos os quatro índices foram utilizadas, como proxy da taxa de juros livre de risco para os fundos e seus Benchmarks, as taxas LIBOR de um mês relativas às moedas da região foco de cada fundo: dólar americano, euro e iene. As cotações das taxas LIBOR foram obtidas no site do Federal Reserve (FED).

Mais informações sobre os índices em Nawrocki (1999), Pedersen e Satchell (2000), Zakamouline e Koekebakker (2009), Kaplan e Knowles (2004), Bertrand e Prigent (2011), Kane et al (2009).

\section{3}

\section{Análise do desempenho}

Os dados mensais de cada fundo foram agrupados por prazo de aplicação (6 meses, 12 meses, 36 meses, 60 meses e 120 meses) e subdivididos em intervalos. Cada combinação de mês e prazo de aplicação constitui um intervalo, com mês de início, prazo de aplicação (duração do intervalo em meses) e mês de encerramento. Exemplos de intervalos: início em jul/05 com prazo de aplicação de 6 meses encerrando em dez/05; início em abr/08 com prazo de aplicação de 12 meses encerrando em mar/09; início em ago/12 com prazo de aplicação de 60 meses encerrando em jul/17. A quantidade total de intervalos para cada prazo de aplicação é dada por $(\mathbf{1 2 0}-\mathbf{P}+\mathbf{1})$, sendo $\mathbf{P}$ o prazo de aplicação em meses, totalizando $\mathbf{3 7 1}$ intervalos analisados no estudo:

Total de Intervalos $=(120-6+1)+(120-12+1)+(120-36+1)+(120-60+1)+$ $(120-120+1)=371$

Os indicadores de desempenho listados na seção anterior foram apurados para cada fundo e seu Benchmark. A partir dos valores apurados em cada índice 
foi calculada a taxa de superação (TS) do fundo em relação a seu respectivo Benchmark, expressa como proporção do valor obtido pelo Benchmark no índice, através da fórmula:

Taxa de Superação $(T S)=\frac{\text { Índice do Fundo- } \text { Índice do Benchmark }}{\mid \text { Índice do Benchmark } \mid}$

A taxa de superação em cada índice foi calculada para todos os fundos em cada intervalo.

A Tabela 1 apresenta o resumo descritivo das taxas de superação dos fundos para cada índice:

Tabela 1: Resumo descritivo das taxas de superação (TS) por fundo.

\begin{tabular}{|c|c|c|c|c|c|c|c|c|c|c|c|c|}
\hline \multirow[t]{2}{*}{ Fundo: } & \multicolumn{4}{|c|}{ Observações (N) } & \multicolumn{4}{|c|}{ Média } & \multicolumn{4}{|c|}{ Desvio Padrão } \\
\hline & MDC & OMEGA & IS & ISO & MDC & OMEGA & IS & ISO & MDC & OMEGA & IS & ISO \\
\hline DEEMUBV BB Equity & 307 & 308 & 319 & 308 & $-0,108$ & 0,163 & $-0,730$ & $-0,694$ & 0,257 & 4,073 & 3,336 & 3,452 \\
\hline DEGEMUA BB Equity & 253 & 254 & 263 & 260 & $-0,089$ & 0,014 & $-0,777$ & $-0,683$ & 0,182 & 1,260 & 3,190 & 2,966 \\
\hline DEGEUFA BB Equity & 248 & 249 & 260 & 252 & $-0,052$ & $-0,092$ & 1,245 & 1,504 & 0,240 & 0,254 & 14,666 & 16,751 \\
\hline DEGSUSA BB Equity & 147 & 147 & 161 & 149 & 0,253 & 0,644 & $-0,006$ & $-0,228$ & 0,680 & 0,759 & 0,938 & 0,630 \\
\hline DEGUSBA BB Equity & 247 & 248 & 263 & 254 & 1,773 & 2,008 & 6,194 & 9,678 & 4,278 & 5,453 & 47,069 & 61,022 \\
\hline ESPESCA LX Equity & 352 & 353 & 361 & 354 & 0,103 & 1,840 & 0,043 & 1,480 & 0,771 & 29,149 & 3,711 & 20,318 \\
\hline ESPRITE LX Equity & 351 & 351 & 361 & 352 & $-0,120$ & $-0,078$ & $-0,335$ & $-0,076$ & 0,540 & 0,616 & 3,586 & 4,833 \\
\hline HIEZX US Equity & 350 & 350 & 359 & 352 & 0,145 & 0,146 & $-0,764$ & 0,013 & 0,421 & 0,462 & 18,755 & 21,883 \\
\hline JCJBFAA LN Equity & 184 & 184 & 203 & 185 & $-0,024$ & $-0,036$ & $-1,341$ & $-0,915$ & 1,085 & 1,000 & 4,843 & 3,377 \\
\hline JIISX US Equity & 362 & 362 & 371 & 362 & 0,003 & 0,002 & $-0,774$ & $-0,703$ & 0,175 & 0,181 & 6,508 & 6,229 \\
\hline JPGSX US Equity & 365 & 365 & 371 & 365 & 0,021 & 0,019 & $-0,155$ & $-0,086$ & 0,237 & 0,250 & 2,274 & 2,432 \\
\hline JPIAX US Equity & 361 & 361 & 371 & 361 & 0,014 & 0,009 & $-0,332$ & $-0,259$ & 0,189 & 0,213 & 2,842 & 2,838 \\
\hline JPIVX US Equity & 365 & 365 & 371 & 366 & 0,077 & 0,074 & 0,049 & 0,129 & 0,201 & 0,233 & 1,336 & 1,360 \\
\hline JPMJBAA LX Equity & 288 & 288 & 302 & 292 & 0,461 & 0,519 & 3,004 & 9,186 & 2,774 & 3,700 & 16,724 & 61,649 \\
\hline KDHAX US Equity & 364 & 364 & 371 & 364 & $-0,121$ & $-0,049$ & $-2,506$ & $-2,547$ & 0,265 & 0,288 & 31,685 & 35,973 \\
\hline KDSAX US Equity & 366 & 366 & 371 & 366 & 0,047 & 0,062 & 0,282 & 0,494 & 0,340 & 0,379 & 2,437 & 2,812 \\
\hline LGTEQGS LE Equity & 356 & 356 & 363 & 357 & $-0,090$ & $-0,060$ & $-0,935$ & $-0,841$ & 0,197 & 0,214 & 3,464 & 3,224 \\
\hline LMVTX US Equity & 365 & 365 & 371 & 365 & $-0,181$ & $-0,049$ & $-6,269$ & $-6,387$ & 0,404 & 0,613 & 48,641 & 49,826 \\
\hline LOPEX US Equity & 220 & 220 & 240 & 220 & $-0,013$ & 0,147 & 0,965 & 1,672 & 0,377 & 0,444 & 11,313 & 18,933 \\
\hline LSVEX US Equity & 364 & 364 & 371 & 365 & 0,089 & 0,121 & $-0,217$ & $-0,179$ & 0,299 & 0,327 & 2,790 & 3,013 \\
\hline LSVPX US Equity & 289 & 289 & 296 & 292 & $-0,087$ & $-0,046$ & $-0,477$ & $-0,430$ & 0,316 & 0,349 & 2,310 & 2,341 \\
\hline LSVVX US Equity & 295 & 295 & 302 & 295 & $-0,108$ & $-0,040$ & $-1,093$ & $-1,036$ & 0,329 & 0,389 & 7,295 & 7,512 \\
\hline NLCIX US Equity & 21 & 21 & 25 & 21 & $-0,162$ & $-0,169$ & $-0,131$ & $-0,270$ & 0,072 & 0,079 & 0,072 & 0,055 \\
\hline OSEUSBV BB Equity & 350 & 350 & 361 & 350 & 0,477 & 0,648 & 2,962 & 9,048 & 3,185 & 4,658 & 33,731 & 96,745 \\
\hline OSI9180 BB Equity & 361 & 363 & 371 & 363 & $-0,056$ & 0,562 & $-1,058$ & $-1,087$ & 0,300 & 10,971 & 5,111 & 5,510 \\
\hline OSIBEPR BB Equity & 187 & 187 & 197 & 188 & $-0,189$ & $-0,122$ & $-0,475$ & $-0,426$ & 0,424 & 0,663 & 1,458 & 1,150 \\
\hline SSLAX US Equity & 243 & 243 & 272 & 244 & $-0,045$ & $-0,069$ & 0,205 & 0,150 & 0,339 & 0,342 & 2,846 & 3,106 \\
\hline UBGAX US Equity & 343 & 343 & 358 & 347 & 0,198 & 0,242 & $-1,087$ & $-0,247$ & 1,757 & 2,090 & 3,366 & 7,743 \\
\hline UBRLX US Equity & 346 & 346 & 359 & 348 & 0,235 & 0,283 & $-0,949$ & $-0,056$ & 1,895 & 2,251 & 3,230 & 8,267 \\
\hline UBVLX US Equity & 358 & 358 & 371 & 358 & 0,168 & 0,248 & 1,284 & 2,967 & 0,405 & 0,438 & 12,222 & 29,291 \\
\hline WOOPX US Equity & 364 & 364 & 371 & 364 & 0,043 & 0,020 & $-0,632$ & $-0,430$ & 1,051 & 0,772 & 2,223 & 2,055 \\
\hline Total & 9372 & 9379 & 9706 & 9419 & 0,084 & 0,230 & $-0,241$ & 0,543 & 1,269 & 6,313 & 16,730 & 28,555 \\
\hline
\end{tabular}

Fonte: elaboração própria 


\subsection{1}

\section{Algum fundo apresentou desempenho significativamente superior ao seu respectivo Benchmark? (P1)}

Para responder à pergunta P1 foram aplicados testes T (Black, 2011) para verificar se a média das taxas de superação (TS) de cada fundo, em cada indicador, foi significativamente positiva, como segue:

$$
\begin{aligned}
& \text { H0: TS }=0 \\
& \text { Ha: } \text { TS }>0
\end{aligned}
$$

\subsection{2}

\section{Os fundos apresentaram desempenhos significativamente diferentes} entre si? (P2)

Os quatro indicadores analisados podem ser classificados em dois tipos: indicadores de média-variância (IS e ISO) e indicadores de momentos superiores (MDC e OMEGA).

Esta relação pode ser observada na Tabela 2 que mostra a matriz de correlação entre as taxas de superação dos indicadores: os indicadores IS e ISO apresentam correlação de 0,808 enquanto os indicadores MDC e OMEGA apresentam correlação de 0,985. A correlação cai quando se compara MDC com IS e ISO $(0,062$ e 0,166) e OMEGA com IS e ISO $(0,052$ e 0,158).

\begin{tabular}{|c|c|c|c|c|c|}
\hline & & MDC & OMEGA & IS & ISO \\
\hline \multirow[t]{4}{*}{ Correlação } & TS_MDC & 1 & 0,985 & 0,062 & 0,166 \\
\hline & TS_OMEGA & 0,985 & 1 & 0,052 & 0,158 \\
\hline & TS_IS & 0,062 & 0,052 & 1 & 0,808 \\
\hline & TS_ISO & 0,166 & 0,158 & 0,808 & 1 \\
\hline \multirow{4}{*}{$\begin{array}{l}\text { Significância } \\
\text { (unicaudal) }\end{array}$} & TS_MDC & 0,000 & 0,000 & 0,000 & 0,000 \\
\hline & TS_OMEGA & 0,000 & 0,000 & 0,000 & 0,000 \\
\hline & TS_IS & 0,000 & 0,000 & 0,000 & 0,000 \\
\hline & TS_ISO & 0,000 & 0,000 & 0,000 & 0,000 \\
\hline
\end{tabular}

Tabela 2: Matriz de correlação das taxas de superação (TS) dos indicadores.

Fonte: elaboração própria 
Por isso, para melhor análise do desempenho dos fundos, foi aplicada análise fatorial (Hair et al, 2006) agrupando os quatro índices em duas variáveis representativas de cada tipo de indicador: Fator MDC_OMEGA e Fator IS_ISO. Os dois fatores foram gerados por regressão conforme resumo na Tabela 3:

Tabela 3: Formação dos fatores

\begin{tabular}{|c|c|c|c|}
\hline \begin{tabular}{|l} 
Variável \\
Dependente
\end{tabular} & $\begin{array}{l}\text { Variável } \\
\text { Independente }\end{array}$ & Beta & $\begin{array}{l}\text { Beta } \\
\text { Padronizado }\end{array}$ \\
\hline \multirow{4}{*}{\begin{tabular}{|l} 
Fator \\
MDC_OMEGA
\end{tabular}} & Intercepto & $\begin{array}{l}0,076 \\
\end{array}$ & \\
\hline & TS_MDC & 0,396 & 0,502 \\
\hline & TS_OMEGA & 0,307 & 0,502 \\
\hline & R2 Ajustado & 1,000 & \\
\hline \multirow[t]{4}{*}{ Fator IS_ISO } & Intercepto & $\begin{array}{l}-\quad 0,002 \\
\end{array}$ & \\
\hline & TS_IS & 0,031 & 0,527 \\
\hline & TS_ISO & 0,018 & 0,527 \\
\hline & R2 Ajustado & 1,000 & \\
\hline
\end{tabular}

Fonte: elaboração própria

Os fatores são expressos pelas fórmulas:

$$
\begin{aligned}
& \text { Fator MDC_OMEGA }=\text { TS_MDC * 0,396 + TS_OMEGA * 0,307 - 0,076 } \\
& \text { Fator IS_ISO = TS_IS * } 0,031+\text { TS_ISO } * 0,018-0,002
\end{aligned}
$$

Os dois fatores (MDC_OMEGA e IS_ISO) foram normalizados por intervalo e então apurados os zscores (Black, 2011) de cada fundo em cada intervalo. Ou seja, para cada fator, em cada um dos 371 intervalos, foi apurado o zscore de cada um dos 31 fundos conforme resumo no quadro 2: 
Quadro 2: Esquema de apuração dos zscores dos fatores MDC_OMEGA e IS_ISO por fundo e intervalo.

\begin{tabular}{|l|r|r|r|r|r|r|}
\hline \multirow{2}{*}{ Fundos: } & \multicolumn{7}{|c|}{ Intervalos: } \\
\cline { 2 - 7 } & Int. 1 & Int. 2 & Int. 3 & Int. 4 & $\begin{array}{c}\text { (...) } \\
\text { Int. 371 }\end{array}$ & Média \\
\hline Fundo 1 & $Z_{1-1}$ & $Z_{1-2}$ & $Z_{1-3}$ & $Z_{1-4}$ & $Z_{1-371}$ & $Z_{1}$ \\
\hline Fundo 2 & $Z_{2-1}$ & $Z_{2-2}$ & $Z_{2-3}$ & $Z_{2-4}$ & $Z_{2-371}$ & $Z_{2}$ \\
\hline Fundo 3 & $Z_{3-1}$ & $Z_{3-2}$ & $Z_{3-3}$ & $Z_{3-4}$ & $Z_{3-371}$ & $Z_{3}$ \\
\hline (...) Fundo 31 & $Z_{31-1}$ & $Z_{31-2}$ & $Z_{31-3}$ & $Z_{31-4}$ & $Z_{31-371}$ & $Z_{31}$ \\
\hline Média & $\mathbf{0}$ & $\mathbf{0}$ & $\mathbf{0}$ & $\mathbf{0}$ & $\mathbf{0}$ & $\mathbf{0}$ \\
\hline Desvio Padrão & $\mathbf{1}$ & $\mathbf{1}$ & $\mathbf{1}$ & $\mathbf{1}$ & $\mathbf{1}$ & $\sim \mathbf{1}$ \\
\hline
\end{tabular}

Fonte: elaboração própria

Como se pode observar na Tabela 1 o número de observações $(\mathrm{N})$ varia entre os fundos. Isto ocorre por dois motivos: i) nem todos os fundos estiveram ativos durante todo o período analisado no estudo: alguns só começaram a operar depois de jan/04 e outros deixaram de operar antes de dez/13; ii) mesmo durante o período de operação, os dados relativos aos retornos de alguns fundos em alguns meses não estavam disponíveis.

Para corrigir este efeito os zscores dos fatores MDC_OMEGA e IS_ISO foram ponderados pela frequência relativa (FR) de cada fundo em cada intervalo, sendo a frequência relativa obtida pela seguinte fórmula:

Frequencia Relativa $($ FR $)=\frac{\text { Número de meses em que o fundo atuou no intervalo }}{\text { Número total de meses do intervalo }}$

Desta forma:

$$
\text { Zscore Ponderado }=\text { Zscore }{ }^{*} \text { FR }
$$

A Tabela 4 mostra a frequência relativa média dos fundos para cada prazo de aplicação. 
Tabela 4: Frequências relativas médias por fundo e prazo de aplicação (em \%).

\begin{tabular}{|c|c|c|c|c|c|c|}
\hline \multirow[b]{2}{*}{ Fundos: } & \multicolumn{6}{|c|}{ Prazos de Aplicação (meses): } \\
\hline & 6 & 12 & 36 & 60 & 120 & Total \\
\hline DEEMUBV BB Equity & 73 & 74 & 81 & 84 & 72 & 80 \\
\hline DEGEMUA BB Equity & 56 & 56 & 58 & 61 & 56 & 59 \\
\hline DEGEUFA BB Equity & 55 & 56 & 57 & 59 & 55 & 58 \\
\hline DEGSUSA BB Equity & 14 & 15 & 19 & 24 & 13 & 20 \\
\hline DEGUSBA BB Equity & 56 & 56 & 58 & 61 & 56 & 59 \\
\hline ESPESCA LX Equity & 91 & 93 & 97 & 98 & 89 & 96 \\
\hline ESPRITE LX Equity & 91 & 93 & 97 & 98 & 89 & 96 \\
\hline HIEZX US Equity & 90 & 92 & 97 & 97 & 88 & 96 \\
\hline JCJBFAA LN Equity & 26 & 28 & 35 & 42 & 25 & 36 \\
\hline JIISX US Equity & 100 & 100 & 100 & 100 & 100 & 100 \\
\hline JPGSX US Equity & 100 & 100 & 100 & 100 & 100 & 100 \\
\hline JPIAX US Equity & 100 & 100 & 100 & 100 & 100 & 100 \\
\hline JPIVX US Equity & 100 & 100 & 100 & 100 & 100 & 100 \\
\hline JPMJBAA LX Equity & 66 & 68 & 73 & 77 & 63 & 73 \\
\hline KDHAX US Equity & 100 & 100 & 100 & 100 & 100 & 100 \\
\hline KDSAX US Equity & 100 & 100 & 100 & 100 & 100 & 100 \\
\hline LGTEQGS LE Equity & 92 & 94 & 97 & 98 & 90 & 97 \\
\hline LMVTX US Equity & 100 & 100 & 100 & 100 & 100 & 100 \\
\hline LOPEX US Equity & 42 & 44 & 51 & 55 & 40 & 51 \\
\hline LSVEX US Equity & 100 & 100 & 100 & 100 & 100 & 100 \\
\hline LSVPX US Equity & 66 & 67 & 71 & 75 & 65 & 72 \\
\hline LSVVX US Equity & 67 & 68 & 74 & 78 & 67 & 74 \\
\hline NLCIX US Equity & 3 & 2 & 1 & 1 & 5 & 1 \\
\hline OSEUSBV BB Equity & 91 & 93 & 97 & 98 & 89 & 96 \\
\hline OSI9180 BB Equity & 100 & 100 & 100 & 100 & 100 & 100 \\
\hline OSIBEPR BB Equity & 24 & 26 & 33 & 40 & 23 & 34 \\
\hline SSLAX US Equity & 59 & 59 & 62 & 65 & 58 & 63 \\
\hline UBGAX US Equity & 87 & 91 & 96 & 97 & 83 & 95 \\
\hline UBRLX US Equity & 90 & 92 & 97 & 97 & 88 & 96 \\
\hline UBVLX US Equity & 100 & 100 & 100 & 100 & 100 & 100 \\
\hline WOOPX US Equity & 100 & 100 & 100 & 100 & 100 & 100 \\
\hline
\end{tabular}

Fonte: elaboração própria

A Tabela 5 mostra os zscores médios dos fatores MDC_OMEGA e IS_ISO ponderados pela frequência relativa, por prazo de aplicação: 
Tabela 5: Fatores MDC_OMEGA e IS_ISO: Zscores médios ponderados pela frequência relativa por prazo de aplicação.

\begin{tabular}{|c|c|c|c|c|c|c|c|c|c|c|c|c|}
\hline \multirow[b]{2}{*}{ Fundos: } & \multicolumn{6}{|c|}{ Fator MDC_OMEGA } & \multicolumn{6}{|c|}{ Fator IS_ISO } \\
\hline & 6 & 12 & 36 & 60 & 120 & Total & 6 & 12 & 36 & 60 & 120 & Total \\
\hline $\begin{array}{l}\text { DEEMUBV } \\
\text { BB Equity }\end{array}$ & $\begin{array}{l}- \\
0,093\end{array}$ & $\begin{array}{l}- \\
0,150\end{array}$ & $\begin{array}{l}- \\
0,106\end{array}$ & $\begin{array}{l}- \\
0,142\end{array}$ & $\begin{array}{l}- \\
0,259\end{array}$ & $\begin{array}{l}- \\
0,122\end{array}$ & $\begin{array}{l}- \\
0,083\end{array}$ & $-\overline{0,068}$ & $\begin{array}{l}- \\
0,207\end{array}$ & 0,101 & $\begin{array}{l}- \\
0,447\end{array}$ & $\begin{array}{l}- \\
0,077\end{array}$ \\
\hline $\begin{array}{l}\text { DEGEMUA } \\
\text { BB Equity }\end{array}$ & $\begin{array}{l}- \\
0,121\end{array}$ & $\begin{array}{l} \\
0,236\end{array}$ & - & $\begin{array}{l}- \\
0,382\end{array}$ & $\begin{array}{l}- \\
0,379\end{array}$ & $\begin{array}{l}- \\
0,242 \\
\end{array}$ & $\begin{array}{l}- \\
0,109\end{array}$ & $\begin{array}{l}- \\
0,163 \\
\end{array}$ & $\begin{array}{l}- \\
0,293 \\
\end{array}$ & $\begin{array}{l}- \\
0,016 \\
\end{array}$ & $\begin{array}{l}- \\
0,952 \\
\end{array}$ & $\begin{array}{l}- \\
0,154\end{array}$ \\
\hline $\begin{array}{l}\text { DEGEUFA BB } \\
\text { Equity }\end{array}$ & 0,024 & - & $\begin{array}{l}- \\
0,146\end{array}$ & $\begin{array}{l}- \\
0,199\end{array}$ & 0,136 & 0,103 & 0,119 & 0,043 & 0,119 & 0,205 & $\begin{array}{l}- \\
0,019\end{array}$ & 0,110 \\
\hline $\begin{array}{l}\text { DEGSUSA BB } \\
\text { Equity }\end{array}$ & 0,010 & 0,125 & 0,431 & 0,613 & 0,309 & 0,243 & $\begin{array}{l}- \\
0,031 \\
\end{array}$ & 0,083 & 0,189 & 0,124 & 0,005 & 0,078 \\
\hline $\begin{array}{l}\text { DEGUSBA BB } \\
\text { Equity }\end{array}$ & 0,439 & 0,874 & 1,167 & 0,958 & 1,503 & 0,833 & 0,425 & 0,500 & 1,336 & 0,820 & 2,853 & 0,735 \\
\hline $\begin{array}{l}\text { ESPESCA LX } \\
\text { Equity }\end{array}$ & 0,206 & 0,147 & 0,514 & 0,591 & 0,186 & 0,326 & 0,053 & 0,082 & $\begin{array}{l}- \\
0,011\end{array}$ & $\begin{array}{l}- \\
0,383 \\
\end{array}$ & $\begin{array}{l}- \\
0,213 \\
\end{array}$ & $\begin{array}{l}- \\
0,027\end{array}$ \\
\hline $\begin{array}{l}\text { ESPRITE LX } \\
\text { Equity }\end{array}$ & 0,253 & 0,403 & $\begin{array}{l}- \\
0,693\end{array}$ & 1,045 & 0,981 & 0,538 & $\begin{array}{l}- \\
0,130\end{array}$ & 0,031 & $\begin{array}{l}- \\
0,271\end{array}$ & 0,598 & $\begin{array}{l}- \\
0,207\end{array}$ & $\begin{array}{l}- \\
0,194\end{array}$ \\
\hline $\begin{array}{l}\text { HIEZX US } \\
\text { Equity }\end{array}$ & 0,367 & 0,220 & 0,097 & $\begin{array}{l}- \\
0,050\end{array}$ & 0,577 & 0,190 & 0,295 & 0,210 & 0,066 & $\begin{array}{l}- \\
0,062\end{array}$ & 0,051 & 0,156 \\
\hline $\begin{array}{l}\text { JCJBFAA LN } \\
\text { Equity }\end{array}$ & 0,059 & $\begin{array}{l}- \\
0,039 \\
\end{array}$ & $\begin{array}{l}- \\
0,321 \\
\end{array}$ & $\begin{array}{l}- \\
0,522 \\
\end{array}$ & $\begin{array}{l}- \\
0,418 \\
\end{array}$ & $\begin{array}{l}- \\
0,157\end{array}$ & 0,052 & $\begin{array}{l}- \\
0,002 \\
\end{array}$ & $\begin{array}{l}- \\
0,106 \\
\end{array}$ & 0,103 & $\begin{array}{l}- \\
0,047\end{array}$ & 0,009 \\
\hline $\begin{array}{l}\text { JIISX US } \\
\text { Equity }\end{array}$ & $\begin{array}{l}- \\
0,041\end{array}$ & 0,003 & $\begin{array}{l}- \\
0,097\end{array}$ & $\begin{array}{l}- \\
0,234\end{array}$ & 0,149 & 0,073 & - 0,031 & 0,035 & $\begin{array}{l}- \\
0,333\end{array}$ & - & $\begin{array}{l}- \\
0,059\end{array}$ & $\begin{array}{l}- \\
0,149\end{array}$ \\
\hline $\begin{array}{l}\text { JPGSX US } \\
\text { Equity }\end{array}$ & 0,009 & 0,014 & 0,006 & $\begin{array}{l}- \\
0,037\end{array}$ & 0,300 & 0,003 & 0,040 & 0,126 & 0,059 & $\begin{array}{l} \\
0,088\end{array}$ & $\begin{array}{l}- \\
0,032\end{array}$ & 0,048 \\
\hline $\begin{array}{l}\text { JPIAX US } \\
\text { Equity }\end{array}$ & $\begin{array}{l}- \\
0,022\end{array}$ & 0,016 & $\begin{array}{l}- \\
0,062\end{array}$ & $\begin{array}{l}- \\
0,094\end{array}$ & 0,172 & $\begin{array}{l}- \\
0,032\end{array}$ & - & $\begin{array}{l}- \\
0,031\end{array}$ & $\begin{array}{l}- \\
0,054\end{array}$ & 0,015 & $\begin{array}{l}- \\
0,045\end{array}$ & $\begin{array}{l}- \\
0,030\end{array}$ \\
\hline $\begin{array}{l}\text { JPIVX US } \\
\text { Equity }\end{array}$ & 0,122 & 0,080 & 0,233 & 0,411 & 0,686 & 0,185 & 0,095 & 0,032 & 0,306 & 0,464 & 0,004 & 0,186 \\
\hline $\begin{array}{l}\text { JPMJBAA LX } \\
\text { Equity }\end{array}$ & 0,157 & 0,210 & 0,145 & 0,246 & 0,118 & 0,185 & 0,229 & 0,313 & 0,510 & 0,523 & 0,035 & 0,368 \\
\hline $\begin{array}{l}\text { KDHAX US } \\
\text { Equity }\end{array}$ & $\begin{array}{l}- \\
0,262\end{array}$ & 0,250 & $\begin{array}{l}- \\
0,400\end{array}$ & $\begin{array}{l}- \\
0,697\end{array}$ & $\begin{array}{l}- \\
0,860\end{array}$ & 0,365 & $\begin{array}{l}- \\
0,145\end{array}$ & 0,193 & $\begin{array}{l}- \\
0,489\end{array}$ & $\begin{array}{l}- \\
0,944\end{array}$ & $\begin{array}{l}- \\
0,215\end{array}$ & $\begin{array}{l}- \\
0,374\end{array}$ \\
\hline $\begin{array}{l}\text { KDSAX US } \\
\text { Equity }\end{array}$ & 0,059 & 0,001 & 0,143 & 0,293 & 0,739 & 0,102 & 0,073 & 0,279 & 0,835 & 0,773 & 0,021 & 0,428 \\
\hline $\begin{array}{l}\text { LGTEQGS LE } \\
\text { Equity }\end{array}$ & $\begin{array}{l}- \\
0,274 \\
\end{array}$ & $\begin{array}{l}- \\
0,267 \\
\end{array}$ & $\begin{array}{l}- \\
0,222 \\
\end{array}$ & $\begin{array}{l}- \\
0,150 \\
\end{array}$ & $\begin{array}{l}- \\
0,371 \\
\end{array}$ & $\begin{array}{l}- \\
0,239 \\
\end{array}$ & $\begin{array}{l}- \\
0,210 \\
\end{array}$ & $\begin{array}{l}- \\
0,241 \\
\end{array}$ & $\begin{array}{l}- \\
0,068 \\
\end{array}$ & $\begin{array}{l}- \\
0,188 \\
\end{array}$ & $\begin{array}{l}- \\
0,253 \\
\end{array}$ & $\begin{array}{l}- \\
0,182 \\
\end{array}$ \\
\hline $\begin{array}{l}\text { LMVTX US } \\
\text { Equity }\end{array}$ & - & 0,429 & $\begin{array}{l}- \\
0,568\end{array}$ & - & 1,432 & 0,515 & $\begin{array}{l}- \\
0,465\end{array}$ & 0,522 & $\begin{array}{l}- \\
0,936\end{array}$ & 1,508 & $\begin{array}{l}- \\
0,313\end{array}$ & $\begin{array}{l}- \\
0,766\end{array}$ \\
\hline $\begin{array}{l}\text { LOPEX US } \\
\text { Equity }\end{array}$ & 0,014 & 0,052 & 0,217 & 0,383 & 0,187 & 0,136 & $\begin{array}{l}- \\
0,017\end{array}$ & $\begin{array}{l}- \\
0,010 \\
\end{array}$ & 0,074 & 0,177 & $\begin{array}{l}- \\
0,019 \\
\end{array}$ & 0,040 \\
\hline $\begin{array}{l}\text { LSVEX US } \\
\text { Equity }\end{array}$ & 0,174 & 0,156 & 0,280 & 0,455 & 0,881 & 0,242 & 0,125 & 0,052 & 0,164 & 0,299 & $\begin{array}{l}- \\
0,027\end{array}$ & 0,141 \\
\hline $\begin{array}{l}\text { LSVPX US } \\
\text { Equity }\end{array}$ & - & $\begin{array}{l}- \\
0,042\end{array}$ & $\begin{array}{l}- \\
0,131\end{array}$ & $\begin{array}{l}- \\
0,111\end{array}$ & 0,022 & 0,074 & $\begin{array}{l}- \\
0,006\end{array}$ & 0,018 & 0,007 & 0,090 & $\begin{array}{l}- \\
0,054\end{array}$ & 0,020 \\
\hline $\begin{array}{l}\text { LSVVX US } \\
\text { Equity }\end{array}$ & $\begin{array}{l}- \\
0,092 \\
\end{array}$ & $\begin{array}{l}- \\
0,046 \\
\end{array}$ & $\begin{array}{l}- \\
0,316\end{array}$ & $\begin{array}{l}- \\
0,451 \\
\end{array}$ & $\begin{array}{l}- \\
0,316 \\
\end{array}$ & $\begin{array}{l}- \\
0,191\end{array}$ & $\begin{array}{l}- \\
0,069\end{array}$ & $\begin{array}{l}- \\
0,050 \\
\end{array}$ & $\begin{array}{l}- \\
0,248 \\
\end{array}$ & $\begin{array}{l}- \\
0,142 \\
\end{array}$ & $\begin{array}{l}- \\
0,119 \\
\end{array}$ & $\begin{array}{l}- \\
0,117\end{array}$ \\
\hline $\begin{array}{l}\text { NLCIX US } \\
\text { Equity }\end{array}$ & $\begin{array}{l}- \\
0,026\end{array}$ & $\begin{array}{l}- \\
0,013\end{array}$ & $\begin{array}{l}- \\
0,005\end{array}$ & $\begin{array}{l}- \\
0,005\end{array}$ & $\begin{array}{l}- \\
0,056\end{array}$ & $\begin{array}{l}- \\
0,014\end{array}$ & $\begin{array}{l}- \\
0,027\end{array}$ & $\begin{array}{l}- \\
0,016\end{array}$ & $\begin{array}{l}- \\
0,001\end{array}$ & $\begin{array}{l}- \\
0,002\end{array}$ & $\begin{array}{l}- \\
0,004\end{array}$ & $\begin{array}{l}- \\
0,013\end{array}$ \\
\hline $\begin{array}{l}\text { OSEUSBV BB } \\
\text { Equity }\end{array}$ & 0,244 & 0,307 & 0,179 & $\begin{array}{l}- \\
0,049\end{array}$ & 0,284 & 0,198 & 0,239 & 0,470 & 0,354 & 0,471 & 0,006 & 0,373 \\
\hline $\begin{array}{l}\text { OSI9180 BB } \\
\text { Equity }\end{array}$ & $\begin{array}{l}- \\
0,127 \\
\end{array}$ & $\begin{array}{l}- \\
0,224 \\
\end{array}$ & $\begin{array}{l}- \\
0,063 \\
\end{array}$ & $\begin{array}{l}- \\
0,059 \\
\end{array}$ & 0,178 & $\begin{array}{l}- \\
0,129 \\
\end{array}$ & $\begin{array}{l}- \\
0,133 \\
\end{array}$ & $\begin{array}{l}- \\
0,128 \\
\end{array}$ & $\begin{array}{l}- \\
0,256 \\
\end{array}$ & $\begin{array}{l}- \\
0,610 \\
\end{array}$ & $\begin{array}{l}- \\
0,143 \\
\end{array}$ & $\begin{array}{l}- \\
0,240 \\
\end{array}$ \\
\hline $\begin{array}{l}\text { OSIBEPR BB } \\
\text { Equity }\end{array}$ & 0,016 & 0,088 & $\begin{array}{l}- \\
0,221\end{array}$ & $\begin{array}{l}- \\
0,322\end{array}$ & 0,236 & 0,136 & $\begin{array}{l}- \\
0,020\end{array}$ & 0,047 & $\begin{array}{l}- \\
0,012\end{array}$ & 0,109 & $\begin{array}{l}- \\
0,017\end{array}$ & 0,004 \\
\hline $\begin{array}{l}\text { SSLAX US } \\
\text { Equity }\end{array}$ & 0,158 & $\begin{array}{l}- \\
0,177 \\
\end{array}$ & $\begin{array}{l}- \\
0,069\end{array}$ & $\begin{array}{l}- \\
0,019 \\
\end{array}$ & $\begin{array}{l}- \\
0,332 \\
\end{array}$ & $\begin{array}{l}- \\
0,119\end{array}$ & $\begin{array}{l}- \\
0,056\end{array}$ & $\begin{array}{l}- \\
0,048 \\
\end{array}$ & 0,112 & 0,223 & $\begin{array}{l}- \\
0,073 \\
\end{array}$ & 0,034 \\
\hline $\begin{array}{l}\text { UBGAX US } \\
\text { Equity }\end{array}$ & $\begin{array}{l}- \\
0,045\end{array}$ & $\begin{array}{l}- \\
0,086\end{array}$ & $\begin{array}{l}- \\
0,171\end{array}$ & $\begin{array}{l}- \\
0,278 \\
\end{array}$ & $\begin{array}{l}- \\
0,574\end{array}$ & 0,129 & $\begin{array}{l}- \\
0,206\end{array}$ & $\begin{array}{l}- \\
0,504\end{array}$ & $\begin{array}{l}- \\
0,360\end{array}$ & $\begin{array}{l}- \\
0,612 \\
\end{array}$ & $\begin{array}{l}- \\
0,217\end{array}$ & $\begin{array}{l}- \\
0,401\end{array}$ \\
\hline $\begin{array}{l}\text { UBRLX US } \\
\text { Equity }\end{array}$ & $\begin{array}{l}- \\
0,012 \\
\end{array}$ & - & $\begin{array}{l}- \\
0,113 \\
\end{array}$ & $\begin{array}{l}- \\
0,175\end{array}$ & $\begin{array}{l}- \\
0,600\end{array}$ & 0,077 & $\begin{array}{l}- \\
0,162\end{array}$ & $\begin{array}{l}- \\
0,456 \\
\end{array}$ & $\begin{array}{l}- \\
0,289\end{array}$ & $\begin{array}{l}- \\
0,457 \\
\end{array}$ & $\begin{array}{l}- \\
0,201\end{array}$ & $\begin{array}{l}- \\
0,331\end{array}$ \\
\hline $\begin{array}{l}\text { UBVLX US } \\
\text { Equity }\end{array}$ & 0,022 & 0,397 & 1,314 & 1,860 & 1,744 & 0,761 & 0,219 & 0,467 & 0,543 & 0,752 & $\begin{array}{l}- \\
0,044\end{array}$ & 0,462 \\
\hline $\begin{array}{l}\text { WOOPX US } \\
\text { Equity }\end{array}$ & 0,117 & 0,038 & - & $\begin{array}{l}- \\
0,698\end{array}$ & $\begin{array}{l}- \\
0,422\end{array}$ & 0,181 & 0,068 & 0,008 & $\begin{array}{l}- \\
0,607\end{array}$ & 0,668 & $\begin{array}{l}- \\
0,041\end{array}$ & $\begin{array}{l}- \\
0,236\end{array}$ \\
\hline
\end{tabular}

Fonte: elaboração própria 
O Gráfico 1 mostra os zscores médios dos fatores MDC_OMEGA e IS_ISO ponderados pela frequência relativa, na média de todos os prazos de aplicação:

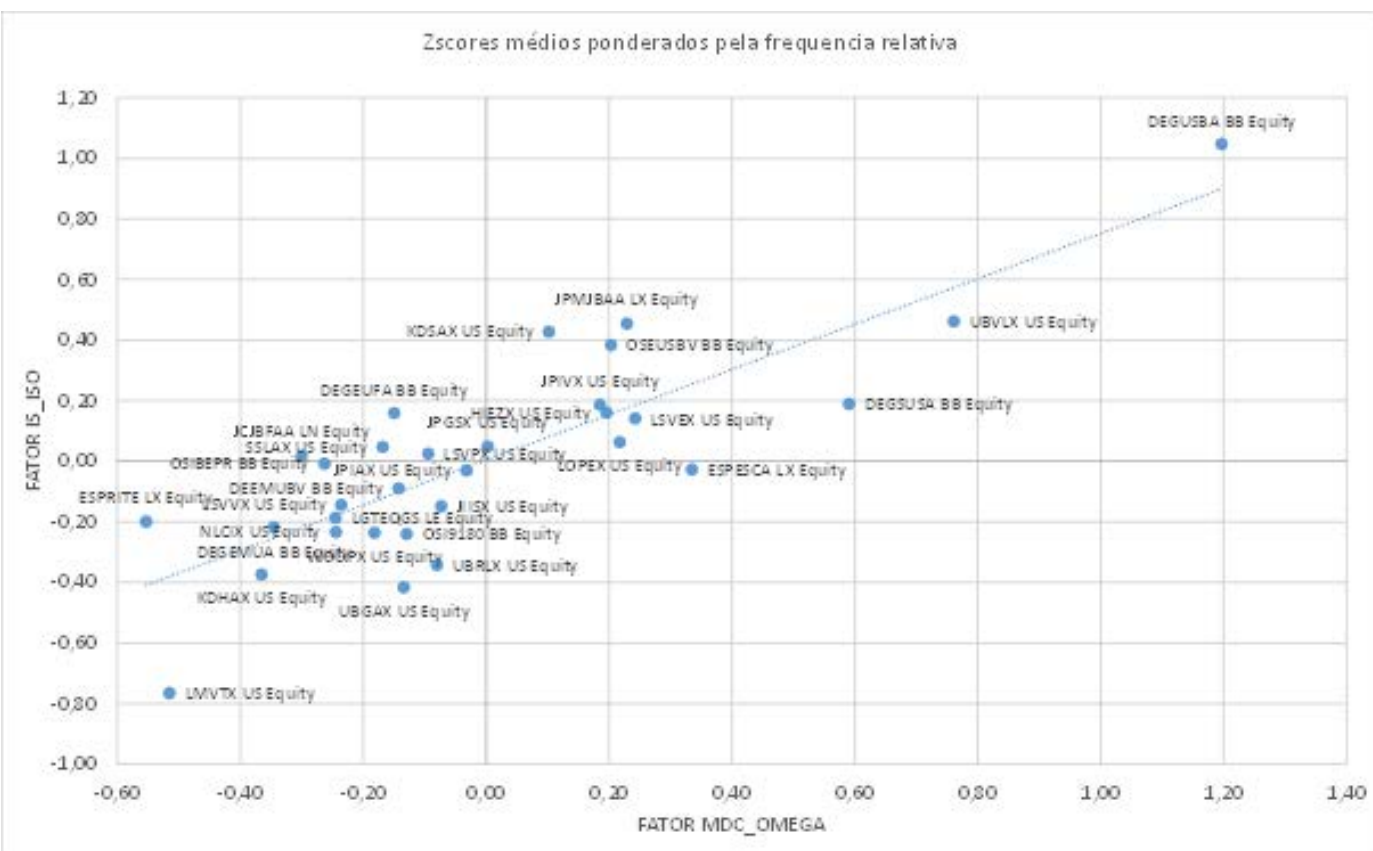

Gráfico 1: Zscores médios dos fatores MDC_OMEGA e IS_ISO ponderados pela frequência relativa.

Apurados os zscores ponderados dos fatores MDC_OMEGA e IS_ISO, chega-se ao Fator Geral de Superação dos Benchmarks ou Fator Geral (FG) pela fórmula:

Fator Geral (FG) =

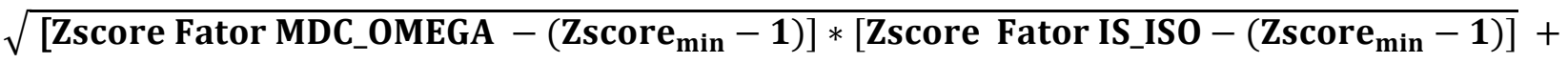
$\left(\right.$ Zscore $\left._{\min }-1\right)$

O Fator Geral é a média geométrica dos zscores dos fatores MDC_OMEGA e IS_ISO ponderados pela frequência relativa. Valores positivos indicam fundos com desempenho acima da média e valores negativos fundos com desempenho abaixo da média do período.

Para evitar números negativos e zeros no cálculo da média geométrica, os zscores foram expressos como distância em relação ao ponto equivalente ao zscore mínimo - 1. O zscore mínimo utilizado no cálculo foi -5,27169, por ter 
sido o menor valor registrado dentre todos os zscores ponderados, conforme Quadro 3:

Quadro 3: Resumo descritivo dos zscores ponderados dos Fatores MDC_OMEGA e IS_ISO.

\begin{tabular}{|l|r|r|}
\hline & $\begin{array}{c}\text { Zscore Ponderado } \\
\text { Fator MDC_OMEGA }\end{array}$ & $\begin{array}{c}\text { Zscore Ponderado } \\
\text { Fator IS_ISO }\end{array}$ \\
\hline Média & $-0,00212$ & $-0,00465$ \\
\hline Mediana & $-0,17529$ & $-0,01893$ \\
\hline Desvio Padrão & 0,85587 & 0,92274 \\
\hline Mínimo & $-2,95632$ & $-\mathbf{5 , 2 7 1 6 9}$ \\
\hline Máximo & 4,79009 & 5,29346 \\
\hline N & 9.372 & 9.419 \\
\hline
\end{tabular}

Fonte: elaboração própria

Na perspectiva espacial do Gráfico 1, o Fator Geral corresponde ao lado do quadrado de área equivalente à do retângulo delimitado pelas coordenadas ( $\mathrm{x}+$ 6,27169; y 6,27169) deduzido o valor de 6,27169.

Para avaliar a significância estatística das diferenças de desempenho entre os fundos foi aplicada análise de variância (ANOVA) (Black, 2011) para a variável Fator Geral usando como fator fixo a variável Fundo. Apesar de robusta quanto à não normalidade dos dados (especialmente para amostras suficientemente grandes como a deste estudo), a ANOVA não é robusta contra a violação da premissa de homogeneidade das variâncias. Como a hipótese de homogeneidade das variâncias foi rejeitada pelo teste de Levene (Lim e Loh, 1996), foram aplicados os testes de Welch (Keselman et al, 2004) e BrownForsythe (Brown e Forsythe, 1974), robustos contra esta violação.

Para classificar os fundos quanto ao desempenho, foram aplicados os testes post-hoc Games-Howell, Dunnett T3, Dunnett C e Tamhane, também robustos contra heteroscedasticidade (Wilcox, 1987), com significância a 5\%. Nos testes post-hoc as médias da variável Fator Geral de todos os 31 fundos foram comparadas entre si, 2 a 2, totalizando 465 comparações (31*30 / 2). A partir dos resultados destas comparações os fundos foram ranqueados conforme a quantidade de diferenças positivas e negativas (significativas a 5\%) identificadas nos testes: quanto maior o número de diferenças positivas e menor o número de diferenças negativas registradas, melhor a classificação do fundo. 
Sendo “pos” o número de diferenças positivas e “neg” o número de diferenças negativas registradas por cada fundo nos testes post-hoc (numa escala de 0 a 30), os fundos foram classificados em três categorias de desempenho, conforme segue:
i) Superiores:
pos - neg $>+10$
ii) Intermediários:
$-\mathbf{1 0} \leq$ pos - neg $\leq+10$
iii) Inferiores:
pos - neg $<-10$

\subsection{3}

\section{Algum indicador se mostrou mais adequado que os demais na medição do desempenho dos fundos? (P3)}

Para responder a esta pergunta foram realizadas regressões lineares simples pelo método de mínimos quadrados (Brooks, 2008), relacionando o Fator Geral de Superação dos Benchmarks e as taxas de superação em cada um dos quatro indicadores de desempenho analisados (MDC, Omega, Sharpe e Sortino).

Para realizar as regressões foram apurados, para cada um dos 4 indicadores, os respectivos valores normalizados por intervalo (zscores), analogamente ao procedimento já descrito no cálculo dos zscores dos fatores IS_ISO e MDC_OMEGA

O Fator Geral foi utilizado como variável dependente e os zscores das taxas de superação em cada indicador (MDC, Omega, Sharpe e Sortino) como variáveis independentes, comparando-se então os ajustes de cada regressão.

Foram utilizadas 9.372 observações em cada uma das quatro regressões. Além das quatro regressões gerais, abrangendo toda a amostra, o procedimento foi repetido para cada um dos 371 intervalos, totalizando 1.453 regressões.

Sobre os valores de R2 obtidos nas regressões de cada indicador em cada intervalo foi aplicado teste de ANOVA para identificar diferenças entre as médias. Como a homogeneidade de variância das médias dos valores de R2 foi rejeitada pelo teste de Levene, foram aplicados testes robustos contra a heteroscedasticidade (Welch e Brown-Forsythe) que confirmaram diferenças significativas a $0,1 \%$. Adicionalmente, foram aplicados testes post-hoc também robustos contra variâncias heterogêneas (Dunnett C, Dunnett T3, Games-Howell e Tamhane) comparando individualmente as diferenças entre os indicadores. 


\subsection{4}

\section{Como as variáveis analisadas afetaram o desempenho dos fundos?} (P4)

Na pergunta P2 o foco era apurar as diferenças de desempenho entre os fundos. Para isso foi utilizada a medida Fator Geral, que representa a média geométrica dos zscores dos fatores IS_ISO e MDC_OMEGA, normalizados por intervalo e ponderados pela frequência relativa.

Para investigar os elementos que afetaram o desempenho dos fundos foi criada uma nova variável, chamada Fator Geral Excesso, a partir da medida Fator Geral.

O cálculo da variável Fator Geral Excesso foi feito em 2 etapas:

i) primeiramente foi calculado, em cada intervalo, o Fator Geral que seria obtido por um fundo hipotético cujo desempenho tivesse sido exatamente igual ao seu Benchmark. O procedimento para o cálculo do Fator Geral para o fundo hipotético foi exatamente o mesmo já descrito na pergunta P2, com uma única diferença: a taxa de superação nos 4 indicadores foi fixada em zero (TS_MDC = TS_OMEGA $=$ TS_IS $=$ TS_ISO $=0$ );

ii) em seguida, foi deduzido do Fator Geral de cada fundo, em cada intervalo, o valor correspondente ao Fator Geral apurado para o fundo hipotético, como descrito na fórmula:

FATOR_GERAL_EXCESSO ${ }_{(\text {FUNDO, INTERVALO) }}=$

\section{FATOR_GERAL(FUNDO, INTERVALO) ( - ) FATOR_GERAL DO FUNDO HIPOTÉTICO (INTERVALO)}

O Fator Geral calculado para o fundo hipotético reflete a posição em que um fundo estaria caso tivesse apresentado desempenho rigorosamente igual ao de seu Benchmark. Portanto, a variável Fator Geral Excesso é uma medida do desvio do fundo em relação ao Benchmark: valores positivos na variável indicam fundos com desempenho acima do seu Benchmark e valores negativos fundos com desempenho abaixo do seu Benchmark. 
O Fator Geral calculado para o fundo hipotético (que é deduzido do Fator Geral de cada fundo para o cômputo do Fator Geral Excesso) é único por intervalo, ou seja, o mesmo valor é deduzido de todos os fundos dentro de um mesmo intervalo. Por isso, os fundos mantem as mesmas distâncias relativas entre si tanto na variável Fator Geral como na variável Fator Geral Excesso.

Foram então realizadas regressões lineares simples pelos métodos dos mínimos quadrados (Brooks, 2008), tomando como variável dependente a variável Fator Geral Excesso.

A primeira variável independente analisada foi o Retorno do Benchmark: tudo o mais constante, quanto melhor o desempenho do benchmark menor deve ser o excesso de retorno do fundo em relação a ele e vice-versa. Após descontado o efeito benchmark, foram realizadas novas regressões para avaliar os impactos das variáveis categóricas sobre o desempenho medido pela variável Fator Geral Excesso, a saber:

\section{i) Fundo}

ii) Prazo de aplicação

iii) Fundo e Prazo de aplicação

iv) Grupo econômico e Região foco

Equações das regressões:

$$
\begin{aligned}
& y=\beta\left(r_{b}\right)+e \\
& y=\beta\left(r_{b}\right)+u_{i}\left(f_{i}\right)+e \\
& y=\beta\left(r_{b}\right)+u_{j}\left(p_{j}\right)+e \\
& y=\beta\left(r_{b}\right)+u_{i, j}\left(f p_{i, j}\right)+e \\
& y=\beta\left(r_{b}\right)+u_{k, l}\left(g r_{k, l}\right)+e
\end{aligned}
$$

Onde:

y é a variável dependente Fator Geral Excesso

$\boldsymbol{\beta}$ é o coeficiente (beta) da variável independente retorno do benchmark

$\boldsymbol{r}_{\boldsymbol{b}}$ é o retorno do benchmark

$\boldsymbol{u}_{\boldsymbol{N}}$ é o conjunto dos coeficientes das variáveis “dummy” 
$\boldsymbol{f}$ é o conjunto das variáveis “dummy” relativas aos $\boldsymbol{i}$ fundos

$\boldsymbol{p}$ é o conjunto das variáveis “dummy” relativas aos $\boldsymbol{j}$ prazos de aplicação

$\boldsymbol{f p}$ é o conjunto das variáveis “dummy” de interação dos $\boldsymbol{i}$ fundos com os $\boldsymbol{j}$ prazos de aplicação

gr é o conjunto das variáveis “dummy” de interação dos $\boldsymbol{k}$ grupos econômicos com as $\boldsymbol{l}$ regiões foco

e são os resíduos não explicados pela regressão.

Os coeficientes obtidos para as variáveis relativas aos fundos foram comparados com o ranqueamento dos fundos descrito na seção 3.3.2 (P2).

A análise dos coeficientes relativos aos prazos de aplicação e à interação entre fundos e prazos buscou investigar como as diferenças de desempenho entre os fundos variam ao longo do tempo. Para esta análise, além da regressão com variáveis dummy, também foi utilizada a técnica de regressão por dados em painel com efeitos fixos não balanceados, que combina características de regressão por série temporal e de regressão cross section. Esta técnica é indicada para análises de amostras como a estudada neste trabalho, que envolvem o acompanhamento de vários objetos de estudo ao longo do tempo (Brooks, 2008). Foram realizadas 4 regressões de dados em painel, uma para cada prazo de aplicação: 6, 12, 36 e 60 meses (o período de 120 meses não foi incluído por conter apenas uma observação por fundo), com os seguintes componentes:

- Variável Dependente : $\quad$ Fator Geral Excesso

- Variável Independente : Retorno Aritmético do Benchmark

- Efeito Fixo cross section : : Fundo

- Efeito Fixo temporal : : Mês de encerramento do intervalo

A equação geral da regressão por dados em painel aqui aplicada é descrita por:

$$
y=\beta\left(r_{b}\right)+u_{i}\left(f_{i}\right)+\lambda_{m}\left(t_{m}\right)+e
$$

y é a variável dependente Fator Geral Excesso 
$\boldsymbol{\beta}$ é o coeficiente (beta) da variável independente retorno do benchmark $\boldsymbol{r}_{\boldsymbol{b}}$ é o retorno do benchmark

$\boldsymbol{u}_{\boldsymbol{i}}$ é o conjunto dos coeficientes das variáveis “dummy” relativas aos fundos

$\boldsymbol{f}$ é o conjunto das variáveis “dummy” relativas aos $\boldsymbol{i}$ fundos (efeito fixo cross-section)

$\lambda_{m}$ é o conjunto dos coeficientes das variáveis “dummy” relativas aos meses

$\boldsymbol{t}$ é o conjunto das variáveis “dummy” relativas aos $\boldsymbol{m}$ meses (efeito fixo temporal)

Finalmente, a análise das variáveis dummy relativas à interação entre o grupo econômico e a região foco dos investimentos teve como objetivo avaliar se o desempenho dos fundos variou, significativamente, em função do seu grupo gestor ou local de atuação. 


\section{Resultados}

\section{1}

\section{Algum fundo apresentou desempenho significativamente superior ao seu respectivo Benchmark? (P1)}

A Tabela 6 mostra os resultados dos testes de hipótese para as taxas de superação (TS) de cada fundo em cada índice.

Tabela 6: Resultados do Teste de Hipótese H1 $\left(\mathrm{H}_{0}: \mathrm{TS}=0 ; \mathrm{H}_{\mathrm{a}}: \mathrm{TS}>0\right)$

\begin{tabular}{|c|c|c|c|c|c|c|c|c|}
\hline \multirow[b]{3}{*}{ Fundos } & \multicolumn{8}{|c|}{$\begin{array}{c}\text { Valor de Teste }=0 \\
\text { Intervalos de Confiança (95\%) }\end{array}$} \\
\hline & \multicolumn{4}{|c|}{ Inferior } & \multicolumn{4}{|c|}{ Superior } \\
\hline & MDC & OMEGA & IS & ISO & MDC & OMEGA & IS & ISO \\
\hline DEEMUBV BB Equity & $-0,137$ & $-0,294$ & $-1,098$ & $-1,081$ & $-0,080$ & 0,620 & $-0,363$ & $-0,307$ \\
\hline DEGEMUA BB Equity & $-0,111$ & $-0,141$ & $-1,164$ & $-1,046$ & $-0,066$ & 0,170 & $-0,389$ & $-0,321$ \\
\hline DEGEUFA BB Equity & $-0,082$ & $-0,123$ & $-0,546$ & $-0,574$ & $-0,022$ & $-0,060$ & 3,036 & 3,582 \\
\hline DEGSUSA BB Equity & 0,142 & 0,520 & $-0,152$ & $-0,330$ & 0,363 & 0,768 & 0,140 & $-0,126$ \\
\hline DEGUSBA BB Equity & 1,237 & 1,326 & 0,479 & 2,137 & 2,309 & 2,690 & 11,909 & 17,218 \\
\hline ESPESCA LX Equity & 0,022 & $-1,212$ & $-0,341$ & $-0,644$ & 0,184 & 4,891 & 0,427 & 3,604 \\
\hline ESPRITE LX Equity & $-0,176$ & $-0,143$ & $-0,706$ & $-0,583$ & $-0,063$ & $-0,013$ & 0,036 & 0,430 \\
\hline HIEZX US Equity & 0,101 & 0,098 & $-2,711$ & $-2,281$ & 0,190 & 0,195 & 1,182 & 2,306 \\
\hline JCJBFAA LN Equity & $-0,182$ & $-0,181$ & $-2,011$ & $-1,405$ & 0,133 & 0,110 & $-0,670$ & $-0,425$ \\
\hline JIISX US Equity & $-0,015$ & $-0,016$ & $-1,438$ & $-1,347$ & 0,021 & 0,021 & $-0,109$ & $-0,059$ \\
\hline JPGSX US Equity & $-0,003$ & $-0,006$ & $-0,387$ & $-0,336$ & 0,046 & 0,045 & 0,077 & 0,164 \\
\hline JPIAX US Equity & $-0,006$ & $-0,013$ & $-0,623$ & $-0,552$ & 0,033 & 0,031 & $-0,042$ & 0,035 \\
\hline JPIVX US Equity & 0,056 & 0,050 & $-0,087$ & $-0,011$ & 0,097 & 0,098 & 0,186 & 0,269 \\
\hline JPMJBAA LX Equity & 0,140 & 0,090 & 1,110 & 2,086 & 0,783 & 0,948 & 4,897 & 16,287 \\
\hline KDHAX US Equity & $-0,148$ & $-0,079$ & $-5,740$ & $-6,255$ & $-0,093$ & $-0,020$ & 0,729 & 1,161 \\
\hline KDSAX US Equity & 0,012 & 0,023 & 0,034 & 0,205 & 0,082 & 0,101 & 0,531 & 0,783 \\
\hline LGTEQGS LE Equity & $-0,110$ & $-0,083$ & $-1,293$ & $-1,177$ & $-0,069$ & $-0,038$ & $-0,578$ & $-0,506$ \\
\hline LMVTX US Equity & $-0,223$ & $-0,112$ & $-11,235$ & 11,516 & $-0,139$ & 0,015 & $-1,303$ & $-1,259$ \\
\hline LOPEX US Equity & $-0,063$ & 0,088 & $-0,474$ & $-0,843$ & 0,037 & 0,206 & 2,403 & 4,188 \\
\hline LSVEX US Equity & 0,059 & 0,087 & $-0,502$ & $-0,489$ & 0,120 & 0,155 & 0,068 & 0,131 \\
\hline LSVPX US Equity & $-0,124$ & $-0,087$ & $-0,741$ & $-0,700$ & $-0,051$ & $-0,006$ & $-0,212$ & $-0,161$ \\
\hline LSVVX US Equity & $-0,146$ & $-0,085$ & $-1,919$ & $-1,896$ & $-0,071$ & 0,004 & $-0,267$ & $-0,175$ \\
\hline NLCIX US Equity & $-0,195$ & $-0,205$ & $-0,161$ & $-0,295$ & $-0,129$ & $-0,133$ & $-0,101$ & $-0,245$ \\
\hline OSEUSBV BB Equity & 0,142 & 0,159 & $-0,529$ & $-1,123$ & 0,811 & 1,138 & 6,454 & 19,219 \\
\hline OSI9180 BB Equity & $-0,087$ & $-0,571$ & $-1,580$ & $-1,656$ & $-0,025$ & 1,694 & $-0,537$ & $-0,519$ \\
\hline OSIBEPR BB Equity & $-0,250$ & $-0,218$ & $-0,679$ & $-0,591$ & $-0,128$ & $-0,027$ & $-0,270$ & $-0,260$ \\
\hline SSLAX US Equity & $-0,088$ & $-0,112$ & $-0,134$ & $-0,242$ & $-0,002$ & $-0,026$ & 0,545 & 0,542 \\
\hline UBGAX US Equity & 0,011 & 0,020 & $-1,437$ & $-1,064$ & 0,384 & 0,464 & $-0,737$ & 0,571 \\
\hline UBRLX US Equity & 0,035 & 0,045 & $-1,284$ & $-0,928$ & 0,436 & 0,521 & $-0,614$ & 0,815 \\
\hline
\end{tabular}




\begin{tabular}{|l|r|r|r|r|r|r|r|r|}
\hline UBVLX US Equity & 0,126 & 0,202 & 0,036 & $-0,077$ & 0,210 & 0,293 & 2,532 & 6,012 \\
\hline WOOPX US Equity & $-0,066$ & $-0,060$ & $-0,859$ & $-0,641$ & 0,151 & 0,099 & $-0,405$ & $-0,218$ \\
\hline Total & $\mathbf{0 , 0 5 9}$ & $\mathbf{0 , 1 0 2}$ & $\mathbf{- 0 , 5 7 5}$ & $\mathbf{- 0 , 0 3 6}$ & $\mathbf{0 , 1 1 0}$ & $\mathbf{0 , 3 5 8}$ & $\mathbf{0 , 0 9 3}$ & $\mathbf{1 , 1 2 1}$ \\
\hline
\end{tabular}

Fonte: elaboração própria

A Tabela 7 apresenta a contagem dos resultados dos testes de hipótese em que foi rejeitada a hipótese nula, ou seja, em quais indicadores cada fundo apresentou resultado significativamente superior ao seu respectivo Benchmark.

Tabela 7: Contagem dos resultados do Teste de Hipótese H1 (TS > 0, Rejeita $\mathrm{H}_{0}$ ).

\begin{tabular}{|c|c|c|c|c|c|}
\hline Fundo: & MDC & OMEGA & IS & ISO & Contagem \\
\hline DEGUSBA BB Equity & $x$ & $x$ & $x$ & $x$ & 4 \\
\hline JPMJBAA LX Equity & $x$ & $x$ & $x$ & $x$ & 4 \\
\hline KDSAX US Equity & $\mathrm{x}$ & $\mathbf{x}$ & $\mathrm{x}$ & $\mathbf{x}$ & 4 \\
\hline UBVLX US Equity & $\mathbf{x}$ & $\mathbf{x}$ & $\mathrm{X}$ & & 3 \\
\hline DEGSUSA BB Equity & $x$ & $x$ & & & 2 \\
\hline HIEZX US Equity & $x$ & 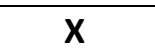 & & & 2 \\
\hline JPIVX US Equity & $x$ & $x$ & & & 2 \\
\hline LSVEX US Equity & $x$ & $x$ & & & 2 \\
\hline OSEUSBV BB Equity & $x$ & $x$ & & & 2 \\
\hline UBGAX US Equity & $x$ & $x$ & & & 2 \\
\hline UBRLX US Equity & $\mathbf{x}$ & $x$ & & & 2 \\
\hline ESPESCA LX Equity & $\mathrm{x}$ & & & & 1 \\
\hline LOPEX US Equity & & $\mathbf{x}$ & & & 1 \\
\hline DEEMUBV BB Equity & & & & & - \\
\hline DEGEMUA BB Equity & & & & & - \\
\hline DEGEUFA BB Equity & & & & & - \\
\hline ESPRITE LX Equity & & & & & - \\
\hline JCJBFAA LN Equity & & & & & - \\
\hline JIISX US Equity & & & & & - \\
\hline JPGSX US Equity & & & & & - \\
\hline JPIAX US Equity & & & & & - \\
\hline KDHAX US Equity & & & & & - \\
\hline LGTEQGS LE Equity & & & & & - \\
\hline LMVTX US Equity & & & & & - \\
\hline LSVPX US Equity & & & & & - \\
\hline LSVVX US Equity & & & & & - \\
\hline NLCIX US Equity & & & & & - \\
\hline OSI9180 BB Equity & & & & & - \\
\hline OSIBEPR BB Equity & & & & & - \\
\hline SSLAX US Equity & & & & & - \\
\hline WOOPX US Equity & & & & & - \\
\hline MÉDIA GERAL & $x$ & $\mathbf{x}$ & & & 2 \\
\hline
\end{tabular}

Fonte: elaboração própria 
De acordo com a Tabela 7, dos 31 fundos, 13 apresentaram desempenho médio superior ao respectivo Benchmark em pelo menos um indicador, num intervalo de confiança de 95\%. No total, 18 fundos não superaram o Benchmark em nenhum dos quatro indicadores analisados e apenas 3 fundos superaram seus Benchmarks em todos os quatro indicadores. Na média geral, os fundos superaram os Benchmarks apenas nos indicadores MDC e OMEGA.

\section{2}

\section{Os fundos apresentaram desempenhos significativamente diferentes entre si? (P2)}

A Tabela 8 e o Gráfico 2 mostram o Fator Geral por fundo e prazo de aplicação.

Tabela 8: Fator Geral de superação dos Benchmarks (Fator Geral) por fundo e prazo de aplicação

\begin{tabular}{|l|r|r|r|r|r|r|}
\hline \multirow{2}{*}{ Fundos: } & \multicolumn{7}{|c|}{ Prazo de Aplicação (meses) } \\
\cline { 2 - 7 } & $\mathbf{6}$ & $\mathbf{1 2}$ & $\mathbf{3 6}$ & $\mathbf{6 0}$ & $\mathbf{1 2 0}$ & \multicolumn{1}{c|}{ Total } \\
\hline DEEMUBV BB Equity & $-0,122$ & $-0,143$ & $-0,159$ & $-0,023$ & $-0,354$ & $-0,119$ \\
\hline DEGEMUA BB Equity & $-0,210$ & $-0,336$ & $-0,390$ & $-0,204$ & $-0,673$ & $-0,289$ \\
\hline DEGEUFA BB Equity & 0,084 & $-0,046$ & $-0,021$ & $-0,001$ & $-0,078$ & 0,001 \\
\hline DEGSUSA BB Equity & $-0,149$ & 0,468 & 0,528 & 0,363 & 0,155 & 0,379 \\
\hline DEGUSBA BB Equity & 0,782 & 1,096 & 1,603 & 0,874 & 2,151 & 1,109 \\
\hline ESPESCA LX Equity & 0,107 & 0,098 & 0,219 & 0,062 & $-0,016$ & 0,123 \\
\hline ESPRITE LX Equity & $-0,219$ & $-0,205$ & $-0,503$ & $-0,855$ & $-0,607$ & $-0,395$ \\
\hline HIEZX US Equity & 0,355 & 0,217 & 0,076 & $-0,066$ & 0,308 & 0,173 \\
\hline JCJBFAA LN Equity & 0,083 & $-0,137$ & $-0,293$ & $-0,221$ & $-0,236$ & $-0,182$ \\
\hline JIISX US Equity & $-0,040$ & $-0,021$ & $-0,230$ & $-0,279$ & 0,044 & $-0,119$ \\
\hline JPGSX US Equity & 0,015 & 0,063 & 0,029 & $-0,084$ & 0,132 & 0,016 \\
\hline JPIAX US Equity & $-0,030$ & $-0,009$ & $-0,059$ & $-0,046$ & 0,063 & $-0,033$ \\
\hline JPIVX US Equity & 0,102 & 0,054 & 0,267 & 0,436 & 0,336 & 0,182 \\
\hline JPMJBAA LX Equity & 0,227 & 0,314 & 0,326 & 0,372 & 0,076 & 0,308 \\
\hline KDHAX US Equity & $-0,207$ & $-0,224$ & $-0,454$ & $-0,840$ & $-0,547$ & $-0,377$ \\
\hline KDSAX US Equity & 0,059 & 0,133 & 0,473 & 0,514 & 0,370 & 0,254 \\
\hline LGTEQGS LE Equity & $-0,261$ & $-0,264$ & $-0,148$ & $-0,197$ & $-0,313$ & $-0,224$ \\
\hline LMVTX US Equity & $-0,414$ & $-0,483$ & $-0,774$ & $-1,255$ & $-0,901$ & $-0,660$ \\
\hline LOPEX US Equity & $-0,010$ & 0,035 & 0,188 & 0,279 & 0,083 & 0,137 \\
\hline LSVEX US Equity & 0,143 & 0,096 & 0,221 & 0,375 & 0,412 & 0,187 \\
\hline LSVPX US Equity & $-0,040$ & $-0,019$ & $-0,068$ & $-0,012$ & $-0,016$ & $-0,036$ \\
\hline LSVVX US Equity & $-0,123$ & $-0,069$ & $-0,303$ & $-0,302$ & $-0,218$ & $-0,194$ \\
\hline NLCIX US Equity & $-0,610$ & $-0,305$ & $-0,046$ & $-0,039$ & $-0,030$ & $-0,239$ \\
\hline OSEUSBV BB Equity & 0,238 & 0,377 & 0,248 & 0,196 & 0,143 & 0,275 \\
\hline
\end{tabular}




\begin{tabular}{|l|r|r|r|r|r|r|}
\hline OSI9180 BB Equity & $-0,134$ & $-0,180$ & $-0,162$ & $-0,424$ & 0,016 & $-0,203$ \\
\hline OSIBEPR BB Equity & $-0,079$ & $-0,204$ & $-0,163$ & $-0,111$ & $-0,127$ & $-0,141$ \\
\hline SSLAX US Equity & $-0,211$ & $-0,189$ & 0,024 & 0,100 & $-0,204$ & $-0,067$ \\
\hline UBGAX US Equity & $-0,151$ & $-0,323$ & $-0,275$ & $-0,475$ & $-0,398$ & $-0,293$ \\
\hline UBRLX US Equity & $-0,105$ & $-0,280$ & $-0,208$ & $-0,336$ & $-0,404$ & $-0,225$ \\
\hline UBVLX US Equity & 0,093 & 0,419 & 0,904 & 1,277 & 0,794 & 0,589 \\
\hline WOOPX US Equity & 0,087 & $-0,027$ & $-0,515$ & $-0,731$ & $-0,234$ & $-0,226$ \\
\hline
\end{tabular}

Fonte: elaboração própria

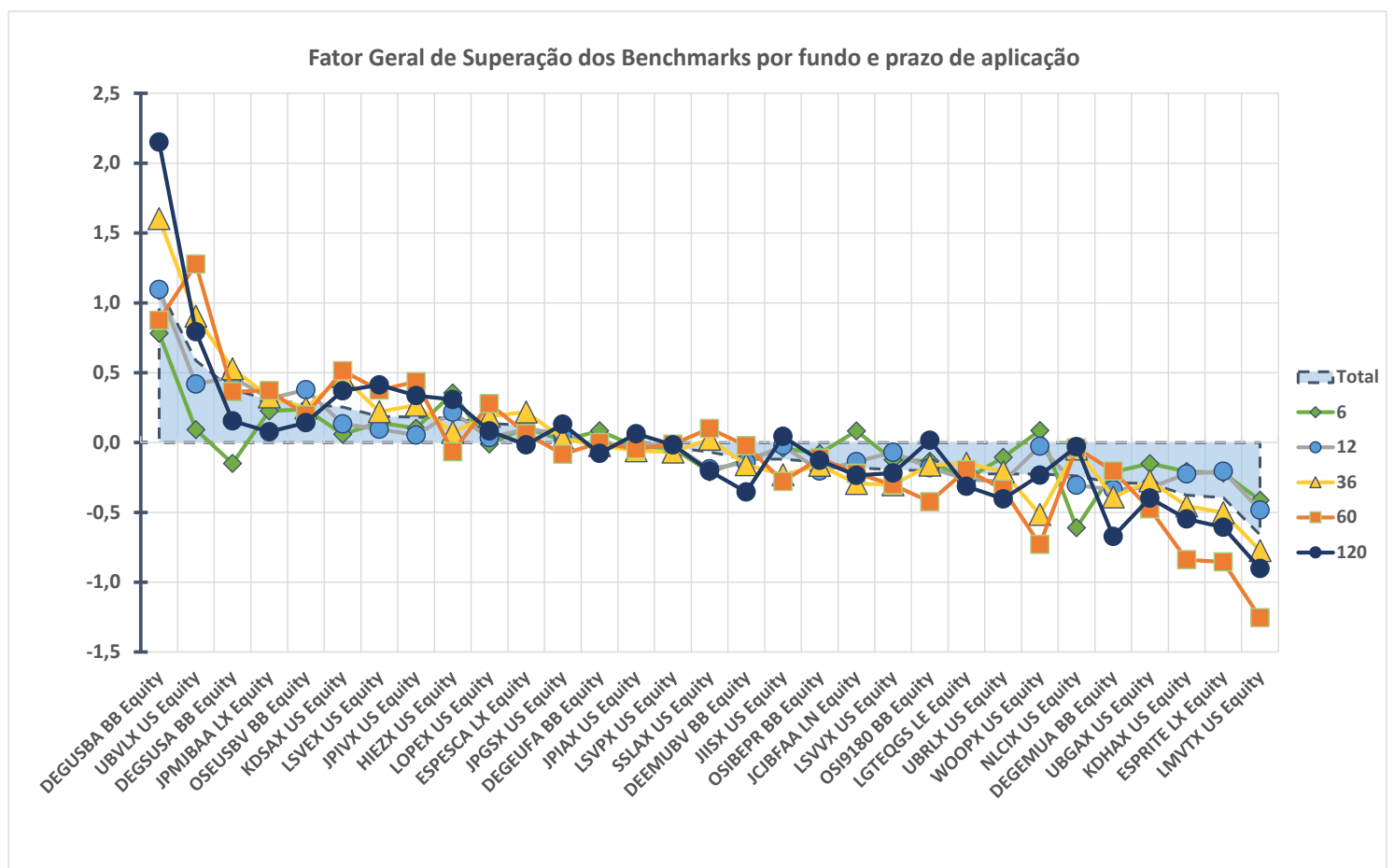

Gráfico 2: Fator Geral de superação dos Benchmarks (Fator Geral) por fundo e prazo de aplicação (1).

Conforme a Tabela 8 e o Gráfico 2, alguns fundos se destacaram acima da média (ex: "DEGUSBA BB Equity” e "UBVLX US Equity”) e alguns se destacaram nas posições inferiores (ex: "ESPRITE LX Equity” e "LMVTX US Equity”).

Entretanto, o que se verifica de maneira geral é uma grande semelhança entre os demais fundos. No Gráfico 1, por exemplo, vê-se que 12 fundos estão a uma distância máxima entre si de 0,4 zscore. Esta semelhança também pode ser vista no Gráfico 2, pela oscilação em torno do zero verificada no intervalo entre os fundos “DEGSUSA BB Equity” e “UBGAX US Equity”).

Considerando os prazos de aplicação, nota-se que nos melhores fundos a performance é melhor (ou seja, acima da média do fundo) nos prazos mais longos 
(36 e 60 meses), enquanto a tendência se reverte nos piores fundos, ficando os prazos mais curtos (6 e 12 meses) acima da média do fundo. Em outras palavras, os fundos com maiores médias melhoram ainda mais com o tempo, enquanto os fundos com médias inferiores se saem melhor no curto prazo. Isto significa que a distância entre os melhores e os piores fundos aumenta ao longo do tempo. Nos fundos intermediários a relação com os prazos é menos definida.

Esta tendência pode ser mais bem observada no Gráfico 3. As diferenças entre os melhores e os piores fundos aumentam conforme aumenta o prazo de aplicação, enquanto os fundos intermediários se mantem a uma distância máxima entre si razoavelmente constante, independente do prazo de aplicação.

Fator Geral de Superação dos Benchmarks por fundo e prazo de aplicação

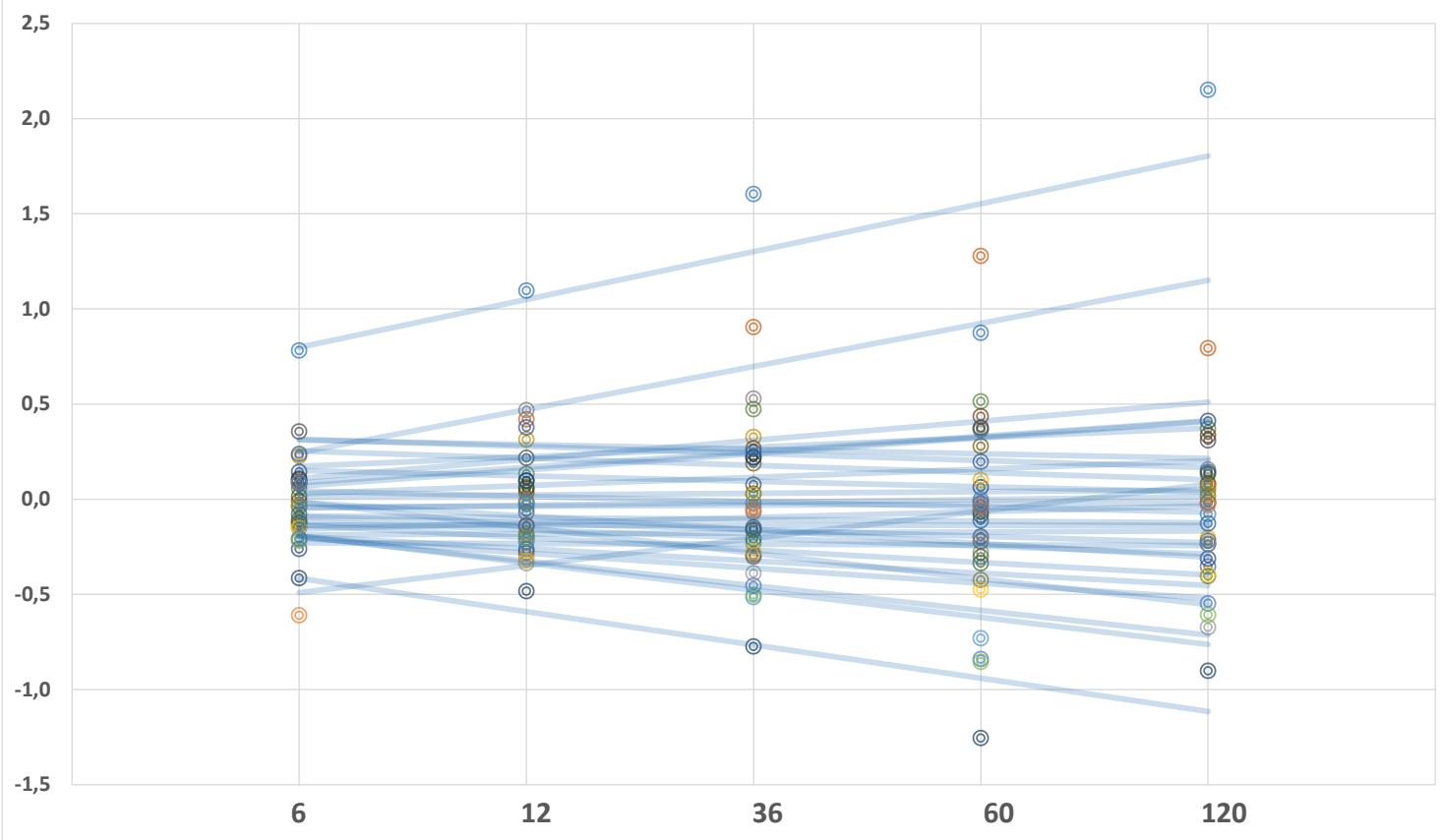

Gráfico 3: Fator Geral de superação dos Benchmarks (Fator Geral) por fundo e prazo de aplicação (2).

Este padrão também pode ser observado no Quadro 4, que mostra a dispersão da variável Fator Geral para cada prazo de aplicação: enquanto a diferença entre o melhor e o pior fundo (representada pela amplitude) aumenta conforme o prazo de aplicação, a distância máxima entre os fundos intermediários (representada pelo intervalo interquartil) se mantem razoavelmente constante, independente do prazo. 
Quadro 4: Dispersão da variável Fator Geral.

\begin{tabular}{|r|c|c|c|c|c|}
\cline { 2 - 6 } \multicolumn{1}{c|}{} & \multicolumn{5}{c|}{ Prazo de Aplicação } \\
\cline { 2 - 6 } \multicolumn{1}{c|}{} & $\mathbf{6}$ & $\mathbf{1 2}$ & $\mathbf{3 6}$ & $\mathbf{6 0}$ & $\mathbf{1 2 0}$ \\
\hline Amplitude: & 1,391 & 1,579 & 2,377 & 2,532 & 3,052 \\
\hline Intervalo Interquartil: & 0,242 & 0,302 & 0,484 & 0,554 & 0,434 \\
\hline Diferença: & $\mathbf{1 , 1 5 0}$ & $\mathbf{1 , 2 7 7}$ & $\mathbf{1 , 8 9 3}$ & $\mathbf{1 , 9 7 8}$ & $\mathbf{2 , 6 1 8}$ \\
\hline
\end{tabular}

Fonte: elaboração própria

O prazo de aplicação de 120 meses é um caso especial pois cada fundo tem apenas uma observação nesse prazo, sendo que apenas 11 fundos estiveram ativos durante todo o período, o que dificulta a avaliação da significância estatística da tendência para esse prazo. Destaque para o fundo “DEGUSBA BB Equity” que apresentou a maior distância para o segundo colocado (1,4 zscore) justamente nesse prazo, mesmo operando em apenas 56\% do período (Tabela 4).

Confirmando a significância estatística das diferenças entre as médias dos fundos na variável Fator Geral, em ambos os testes de ANOVA realizados (Welch e Brown-Forsythe) foi observada significância a 0,1\% para todos os prazos de aplicação (exceto para o prazo de 120 meses por conter apenas uma observação por fundo) como mostra a Tabela 9:

Tabela 9: Resumo dos testes ANOVA - variável: Fator Geral; fator fixo: Fundo.

\begin{tabular}{|r|r|r|r|r|}
\hline \multirow{2}{*}{ Prazo: } & \multicolumn{2}{|c|}{ Welch } & \multicolumn{2}{c|}{ Brown-Forsythe } \\
\cline { 2 - 6 } & Estat. & \multicolumn{1}{|c|}{ Sig. } & \multicolumn{1}{c|}{ Estat. } & \multicolumn{1}{c|}{ Sig. } \\
\hline Todos & 50,617 &, 000 & 59,858 &, 000 \\
\hline $\mathbf{6}$ & 5,363 &, 000 & 4,515 &, 000 \\
\hline $\mathbf{1 2}$ & 11,013 &, 000 & 10,758 &, 000 \\
\hline $\mathbf{3 6}$ & 34,881 &, 000 & 38,481 &, 000 \\
\hline $\mathbf{6 0}$ & 65,789 &, 000 & 54,909 &, 000 \\
\hline $\mathbf{1 2 0}$ & \multicolumn{1}{|c|}{ N/A } & N/A & N/A & N/A \\
\hline
\end{tabular}

Fonte: elaboração própria

Dentre as 465 comparações efetuadas nos testes post-hoc, foram identificadas as seguintes diferenças significativas a 5\%: 
Tabela 10: Testes ANOVA Post-hoc: contagem de diferenças entre médias da variável Fator Geral (sig. 5\%).

\begin{tabular}{|c|r|r|r|r|}
\hline \multirow{2}{*}{ Prazo (meses) } & \multicolumn{5}{|c|}{ Teste } \\
\cline { 2 - 5 } & \multicolumn{1}{|c|}{ Tamhane } & \multicolumn{1}{|c|}{ Dunnett T3 } & Games-Howell & Dunnett C \\
\hline $\mathbf{6}$ & 31 & 32 & 35 & 31 \\
\hline $\mathbf{1 2}$ & 105 & 106 & 117 & 113 \\
\hline $\mathbf{3 6}$ & 253 & 254 & 262 & 258 \\
\hline $\mathbf{6 0}$ & 291 & 292 & 300 & 297 \\
\hline Todos & 293 & 294 & 300 & 300 \\
\hline
\end{tabular}

Fonte: elaboração própria

Os resultados dos testes post-hoc confirmam a tendência apontada nos Gráficos 1 e 2. Como mostra a Tabela 10, a quantidade de diferenças significativas (a 5\%) aumenta com o prazo de aplicação, saindo de cerca de 30 no prazo de 6 meses e chegando a 300 no prazo de 60 meses.

Chega-se então à classificação dos fundos de acordo com o Fator Geral de superação dos Benchmarks, com base na contagem das diferenças positivas e negativas apuradas nas comparações 2 a 2 dos testes post-hoc, conforme mostra a Tabela 11.

Tabela 11: Classificação dos fundos pelos resultados dos testes post-hoc (sig. 5\%).

\begin{tabular}{|c|c|c|c|c|c|c|c|c|c|c|c|c|c|c|c|}
\hline \multirow{3}{*}{ Fundos } & \multicolumn{15}{|c|}{ Prazo de Aplicação (meses) } \\
\hline & \multicolumn{3}{|c|}{ TOTAL } & \multicolumn{3}{|c|}{6} & \multicolumn{3}{|c|}{12} & \multicolumn{3}{|c|}{36} & \multicolumn{3}{|c|}{60} \\
\hline & $\begin{array}{c}\text { po } \\
\text { s }\end{array}$ & $\begin{array}{c}\text { ne } \\
\text { g }\end{array}$ & dif & pos & neg & dif & pos & neg & dif & pos & neg & dif & pos & neg & Dif \\
\hline 1) DEGUSBA BB Equity & 30 & 0 & 30 & 6 & 0 & 6 & 25 & 0 & 25 & 29 & 0 & 29 & 27 & 0 & 27 \\
\hline 2) UBVLX US Equity & 27 & 1 & 26 & 1 & 0 & 1 & 18 & 0 & 18 & 27 & 0 & 27 & 29 & 0 & 29 \\
\hline 3) DEGSUSA BB Equity & 23 & 1 & 22 & 0 & 0 & 0 & 6 & 0 & 6 & 23 & 1 & 22 & 21 & 2 & 19 \\
\hline 4) KDSAX US Equity & 20 & 2 & 18 & 1 & 0 & 1 & 8 & 1 & 7 & 20 & 1 & 19 & 20 & 1 & 19 \\
\hline 4) OSEUSBV BB Equity & 20 & 2 & 18 & 1 & 0 & 1 & 11 & 0 & 11 & 17 & 2 & 15 & 12 & 2 & 10 \\
\hline 6) JPMJBAA LX Equity & 19 & 1 & 18 & 0 & 0 & 0 & 1 & 0 & 1 & 15 & 2 & 13 & 20 & 2 & 18 \\
\hline 7) JPIVX US Equity & 20 & 3 & 17 & 4 & 0 & 4 & 6 & 1 & 5 & 18 & 2 & 16 & 22 & 1 & 21 \\
\hline 7) LSVEX US Equity & 20 & 3 & 17 & 4 & 0 & 4 & 8 & 1 & 7 & 18 & 3 & 15 & 21 & 2 & 19 \\
\hline 9) HIEZX US Equity & 16 & 2 & 14 & 12 & 0 & 12 & 10 & 1 & 9 & 5 & 3 & 2 & 4 & 7 & -3 \\
\hline 10) LOPEX US Equity & 16 & 3 & 13 & 0 & 0 & 0 & 2 & 1 & 1 & 18 & 3 & 15 & 20 & 2 & 18 \\
\hline 11) ESPESCA LX Equity & 14 & 2 & 12 & 0 & 0 & 0 & 2 & 1 & 1 & 9 & 2 & 7 & 6 & 3 & 3 \\
\hline 12) JPGSX US Equity & 11 & 7 & 4 & 1 & 0 & 1 & 4 & 1 & 3 & 6 & 4 & 2 & 4 & 8 & -4 \\
\hline $\begin{array}{l}\text { 13) DEGEUFA BB } \\
\text { Equity }\end{array}$ & 11 & 8 & 3 & 1 & 0 & 1 & 2 & 2 & 0 & 9 & 7 & 2 & 11 & 8 & 3 \\
\hline 14) JPIAX US Equity & 11 & 10 & 1 & 1 & 0 & 1 & 2 & 2 & 0 & 6 & 8 & -2 & 7 & 8 & -1 \\
\hline 14) LSVPX US Equity & 11 & 10 & 1 & 1 & 1 & 0 & 2 & 2 & 0 & 6 & 9 & -3 & 11 & 9 & 2 \\
\hline 16) SSLAX US Equity & 4 & 8 & -4 & 0 & 0 & 0 & 0 & 2 & -2 & 6 & 4 & 2 & 14 & 6 & 8 \\
\hline 17) JIISX US Equity & 4 & 11 & -7 & 1 & 1 & 0 & 2 & 2 & 0 & 1 & 10 & -9 & 4 & 15 & -11 \\
\hline $\begin{array}{l}\text { 17) DEEMUBV BB } \\
\text { Equity }\end{array}$ & 4 & 11 & -7 & 0 & 1 & -1 & 2 & 6 & -4 & 4 & 9 & -5 & 10 & 8 & 2 \\
\hline 19) JCJBFAA LN Equity & 1 & 8 & -7 & 0 & 0 & 0 & 0 & 0 & 0 & 1 & 10 & -9 & 4 & 14 & -10 \\
\hline 20) NLCIX US Equity & 1 & 11 & -10 & 0 & 2 & -2 & 0 & 4 & -4 & 8 & 8 & 0 & 11 & 9 & 2 \\
\hline 21) OSIBEPR BB Equity & 4 & 15 & -11 & 0 & 0 & 0 & 0 & 7 & -7 & 4 & 11 & -7 & 6 & 13 & -7 \\
\hline 22) OSI9180 BB Equity & 3 & 15 & -12 & 0 & 1 & -1 & 2 & 7 & -5 & 4 & 11 & -7 & 1 & 10 & -9 \\
\hline 22) LSVVX US Equity & 3 & 15 & -12 & 0 & 1 & -1 & 2 & 2 & 0 & 1 & 16 & -15 & 4 & 17 & -13 \\
\hline
\end{tabular}




\begin{tabular}{|l|r|r|r|r|r|r|r|r|r|r|r|r|r|r|r|}
\hline 24) WOOPX US Equity & 1 & 15 & -14 & 1 & 0 & $\mathbf{1}$ & 2 & 2 & $\mathbf{0}$ & 0 & 17 & -17 & 0 & 23 & -23 \\
\hline 24) UBRLX US Equity & 1 & 15 & -14 & 0 & 0 & 0 & 0 & 4 & -4 & 1 & 9 & -8 & 3 & 14 & -11 \\
\hline 24) UBGAX US Equity & 1 & 15 & -14 & 0 & 1 & -1 & 0 & 7 & -7 & 1 & 11 & -10 & 1 & 17 & -16 \\
\hline 24) LGTEQGS LE Equity & 1 & 15 & -14 & 0 & 4 & -4 & 0 & 9 & -9 & 2 & 9 & -7 & 3 & 8 & -5 \\
\hline $\begin{array}{l}\text { 28) DEGEMUA BB } \\
\text { Equity }\end{array}$ & 1 & 19 & -18 & 0 & 4 & -4 & 0 & 19 & -19 & 1 & 20 & -19 & 4 & 14 & -10 \\
\hline 29) ESPRITE LX Equity & 1 & 21 & -20 & 0 & 2 & -2 & 0 & 4 & -4 & 1 & 21 & -20 & 0 & 25 & -25 \\
\hline 29) KDHAX US Equity & 1 & 21 & -20 & 0 & 4 & -4 & 0 & 9 & -9 & 1 & 20 & -19 & 0 & 25 & -25 \\
\hline 31) LMVTX US Equity & 0 & 30 & -30 & 0 & 13 & -13 & 0 & 20 & -20 & 0 & 29 & -29 & 0 & 27 & -27 \\
\hline
\end{tabular}

Fonte: elaboração própria

A coluna 'pos' indica a quantidade de diferenças positivas registradas pelo fundo, ou seja, a quantidade de fundos com médias significativamente (a 5\%) inferiores a ele, enquanto a coluna 'neg' indica a quantidade de diferenças negativas, ou seja, a quantidade de fundos com médias superiores. Quanto maior a diferença entre a coluna ‘pos' e a coluna 'neg’ melhor a classificação do fundo.

O fundo "DEGUSBA BB Equity” liderou a classificação geral obtendo média superior a todos os demais fundos considerando todos os prazos de aplicação. Liderou também nos prazos de 12 e 36 meses e ficou em segundo lugar nos prazos de 6 e 60 meses. O fundo "LMVTX US Equity" registrou a pior média em todos os prazos de aplicações.

Confirmando a tendência de menor diferenciação entre os fundos nos prazos mais curtos, a quantidade de fundos em posições intermediárias $(-\mathbf{1 0} \leq$ pos - neg $\leq+10$ ) cai conforme aumenta o prazo de aplicação: 29 fundos em 6 meses contra 15 em 60 meses. Outro indicativo é que houve 28 empates no prazo de aplicação de 6 meses, caindo para 17 em 12 meses e para 10 nos prazos de 36 e 60 meses. Outra evidência desta maior semelhança entre os fundos no curto prazo é que enquanto no prazo de 6 meses o fundo líder (“HIEZX US Equity”) foi superior a apenas 12 fundos, no prazo de 60 meses o líder (“UBVLX US Equity”) superou 29 fundos. 


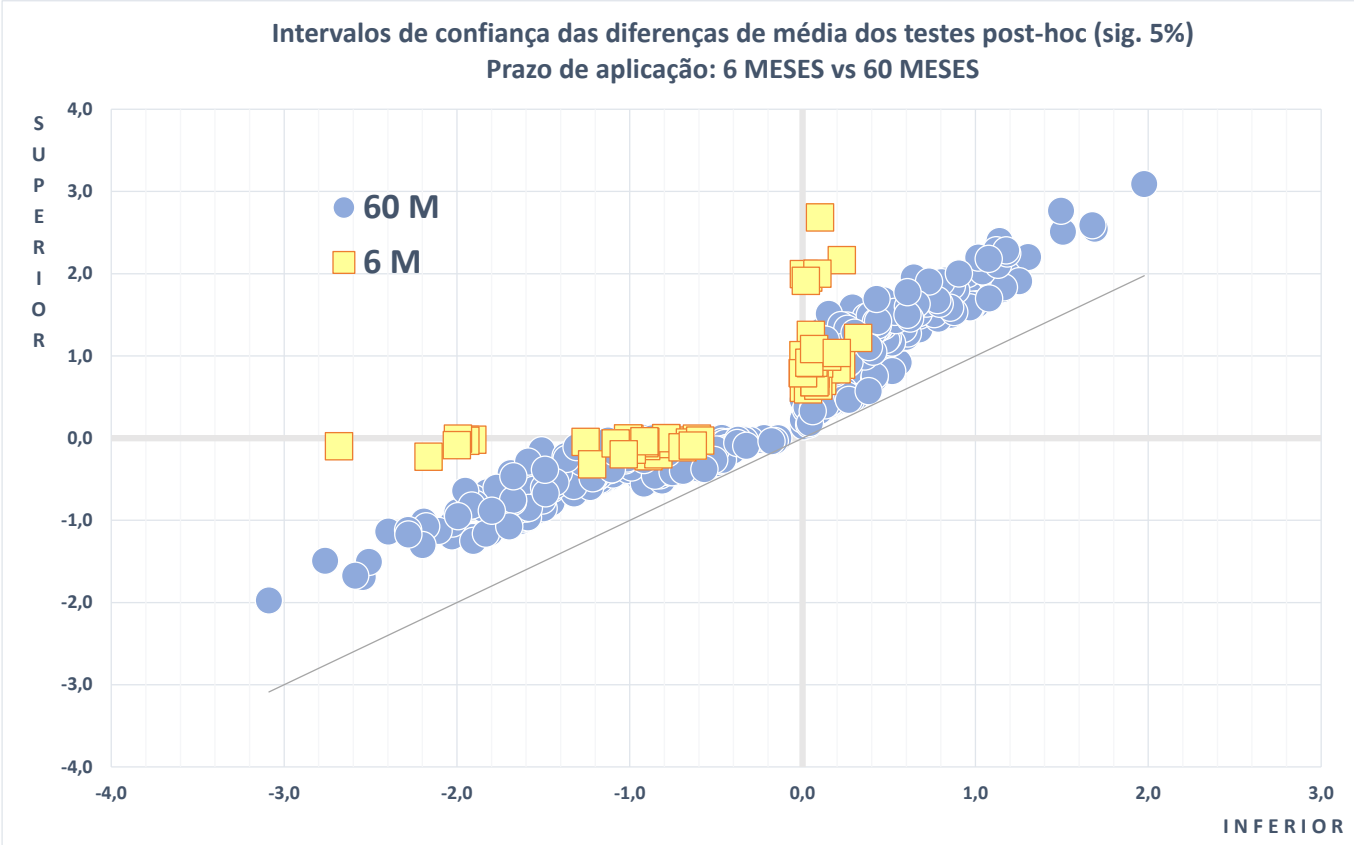

Gráfico 4: Fator Geral: Intervalos de confiança das diferenças entre médias (post-hoc a $5 \%)-6$ e 60 meses.

Esta tendência também pode ser visualizada no Gráfico 4, que compara os intervalos de confiança obtidos nos testes post-hoc (sig. 5\%) para as diferenças entre as médias dos fundos na variável Fator Geral nos prazos de 6 meses e 60 meses. Cada ponto representa uma diferença entre dois fundos, sendo que o eixo horizontal mostra o limite inferior do intervalo de confiança da diferença e o eixo vertical o limite superior. Nota-se que, para o prazo de 60 meses, o limite inferior do intervalo de confiança da diferença entre o melhor e o pior fundo, representada pelo ponto mais à direita do Gráfico, é de 1,97, enquanto no prazo de 6 meses esta diferença é de apenas 0,32 . Isto é mais um indicativo de que a diferença entre os melhores e os piores fundos é mais acentuada no longo prazo do que no curto prazo.

Também pode ser observado no Gráfico que a distribuição dos pontos relativos ao prazo de 6 meses é mais afastada da linha diagonal do que no prazo de 60 meses. Isto significa que a amplitude (distância entre o limite inferior e o limite superior) dos intervalos de confiança das diferenças entre os fundos é maior no curto prazo do que no longo prazo. Esta característica ajuda a entender os resultados da Tabela 11, especialmente o grande número de empates e a elevada quantidade de fundos nas posições intermediárias no prazo de 6 meses: para uma dada diferença entre as médias de dois fundos, quanto mais amplo o intervalo de 
confiança maior a chance de o intervalo superior desta diferença se sobrepor ao intervalo inferior da diferença subsequente e, portanto, menores as chances de ocorrência de diferenças significativas entre os fundos. Isto explica, também, o contraste na quantidade de diferenças significativas registradas pelos testes posthoc no prazo de 6 meses (cerca de 30) em comparação ao prazo de 60 meses (cerca de 300).

\section{3}

\section{Algum indicador se mostrou mais adequado que os demais na medição do desempenho dos fundos? (P3)}

A Tabela 12 mostra os resultados das regressões usando a variável Fator Geral como variável dependente e os zscores das taxas de superação (TS) em cada um dos quatro indicadores (MDC, Ômega, Sharpe e Sortino) como variáveis independentes:

Tabela 12: Resultados das regressões Fator Geral: Zscores das Taxas de superação dos indicadores.

\begin{tabular}{|c|c|c|}
\hline Variável Dependente: & Fator Geral & \\
\hline Observações: & 9.372 & \\
\hline Variância: & 0,662 & \\
\hline Variável Independente & Coeficiente & p-valor \\
\hline Zscore_ISO & 0,729 & $0,00 \%$ \\
\hline Intercepto & $-0,015$ & $0,03 \%$ \\
\hline $\mathrm{R} 2$ & 0,771 & \\
\hline Zscore_IS & 0,703 & $0,00 \%$ \\
\hline Intercepto & $-0,013$ & $0,54 \%$ \\
\hline R2 & 0,714 & \\
\hline Zscore_MDC & 0,683 & $0,00 \%$ \\
\hline Intercepto & $-0,016$ & $0,07 \%$ \\
\hline $\mathrm{R} 2$ & 0,677 & \\
\hline Zscore_OMEGA & 0,638 & $0,00 \%$ \\
\hline Intercepto & $-0,015$ & $0,41 \%$ \\
\hline $\mathrm{R} 2$ & 0,589 & \\
\hline
\end{tabular}

Fonte: elaboração própria

Todos os indicadores apresentaram alta correlação com a variável dependente, com valores de R2 acima de 0,6 e coeficientes significativos a 5\%. Esta elevada correlação era esperada, uma vez que o Fator Geral é uma 
composição dos quatro indicadores. O objetivo das regressões era identificar o indicador com melhor ajuste em relação ao Fator Geral.

Como se pode observar na Tabela 12, o Índice de Sortino (ISO) apresentou maior valor de R2 $(0,77)$ dentre os indicadores analisados. Isto significa que os resíduos da regressão utilizando os zscores da taxa de superação do indicador ISO como preditores do Fator Geral apresentaram menor variância do que os demais indicadores. Pode-se concluir, portanto, que o indicador ISO apresentou melhor ajuste que os demais para explicar as variações do Fator Geral da taxa de superação dos fundos em relação a seus Benchmarks. O segundo melhor indicador foi o Índice de Sharpe (IS) com R2 de 0,71, seguido da Medida de Desempenho Comportamental (MDC) com R2 de 0,68 e, finalmente, a Medida Ômega (OMEGA) com R2 de 0,59.

As diferenças entre os valores de R2 dos quatro indicadores podem parecer pouco materiais mas são consistentes. A Tabela 13 mostra o resumo descritivo dos valores de R2 obtidos nas regressões por intervalo:

Tabela 13: Resumo descritivo dos valores de R2 das regressões Fator Geral: Zscores das Taxas de superação (TS) dos indicadores por intervalo.

\begin{tabular}{|c|c|c|c|c|c|}
\hline Indicador & $\mathbf{N}$ & Média & $\begin{array}{c}\text { Desvio } \\
\text { Padrão }\end{array}$ & \multicolumn{2}{|c|}{$\begin{array}{c}\text { Intervalo de Confiança } \\
\text { (95\%) }\end{array}$} \\
\cline { 5 - 6 } & & & & Inferior & Superior \\
\hline Zscore_ISO & 370 & 0,802 & 0,166 & 0,786 & 0,820 \\
\hline Zscore_IS & 368 & 0,755 & 0,183 & 0,736 & 0,774 \\
\hline Zscore_MDC & 363 & 0,726 & 0,222 & 0,704 & 0,749 \\
\hline Zscore_OMEGA & 352 & 0,675 & 0,271 & 0,647 & 0,704 \\
\hline Total & $\mathbf{1 . 4 5 3}$ & $\mathbf{0 , 7 4 1}$ & $\mathbf{0 , 2 1 8}$ & $\mathbf{0 , 7 2 9}$ & $\mathbf{0 , 7 5 2}$ \\
\hline
\end{tabular}

Fonte: elaboração própria

Além de apresentar a maior média, o índice ISO também teve o menor desvio padrão.

Tabela 14: Resumo dos testes post-hoc (sig. 5\%) para os valores de R2 das regressões Fator Geral: Zscores das Taxas de superação dos indicadores.

\begin{tabular}{|l|r|r|r|}
\hline Indicador & Pos. & Neg. & Dif. \\
\hline Zscore_ISO & 3 & 0 & $\mathbf{3}$ \\
\hline Zscore_IS & 1 & 1 & $\mathbf{0}$ \\
\hline Zscore_MDC & 1 & 1 & $\mathbf{0}$ \\
\hline Zscore_OMEGA & 0 & 3 & $\mathbf{- 3}$ \\
\hline
\end{tabular}

Fonte: elaboração própria 
Como se observa na Tabela 14, confirmando a significância estatística das diferenças entre os indicadores, consideradas todas as regressões executadas para cada indicador, o Índice de Sortino apresentou R2 médio superior a todos os 3 demais indicadores, enquanto a Medida Omega apresentou R2 médio inferior a todos os demais. Os indicadores IS e MDC não apresentaram valores de R2 significativamente diferentes entre si.

\section{4}

Como as variáveis analisadas afetaram o desempenho dos fundos? (P4)

\subsection{1}

\section{Impacto dos Benchmarks}

A Tabela 15 mostra as informações relativas ao coeficiente da variável independente Retorno do Benchmark

Tabela 15: Coeficiente: Retorno do Benchmark. Variável Dependente: Fator Geral Excesso

\begin{tabular}{|c|r|r|r|r|}
\hline Variável & Coeficiente & Erro Padrão & Estatística t & P valor \\
\hline RETORNO DO BENCHMARK & 0.016557 & 0.034082 & 0.485814 & 0.6271 \\
\hline
\end{tabular}

Fonte: elaboração própria

Como se pode observar a variável não apresentou poder de explicação sobre a variável Fator Geral Excesso: O R2 foi desprezível, o que demonstra não haver correlação significativa entre as duas variáveis, e a variável independente não apresentou coeficiente significativo ( $\mathrm{p}$-valor $=0,63$ ). Era esperado que $o$ retorno do Benchmark e o Fator Geral Excesso fossem inversamente proporcionais, como já comentado.

Isto significa que, na amostra analisada neste estudo, o retorno do Benchmark não teve impacto significativo sobre as variações nas taxas de superação entre os fundos. Isto pode ser atribuído a dois fatores:

i) dentre os fundos analisados, alguns compartilham os mesmos Benchmarks (são 17 Benchmarks para 31 fundos); 
ii) a maioria dos Benchmarks analisados apresentou retornos muito semelhantes durante o período estudado, o que pode ser observado no Gráfico 5:

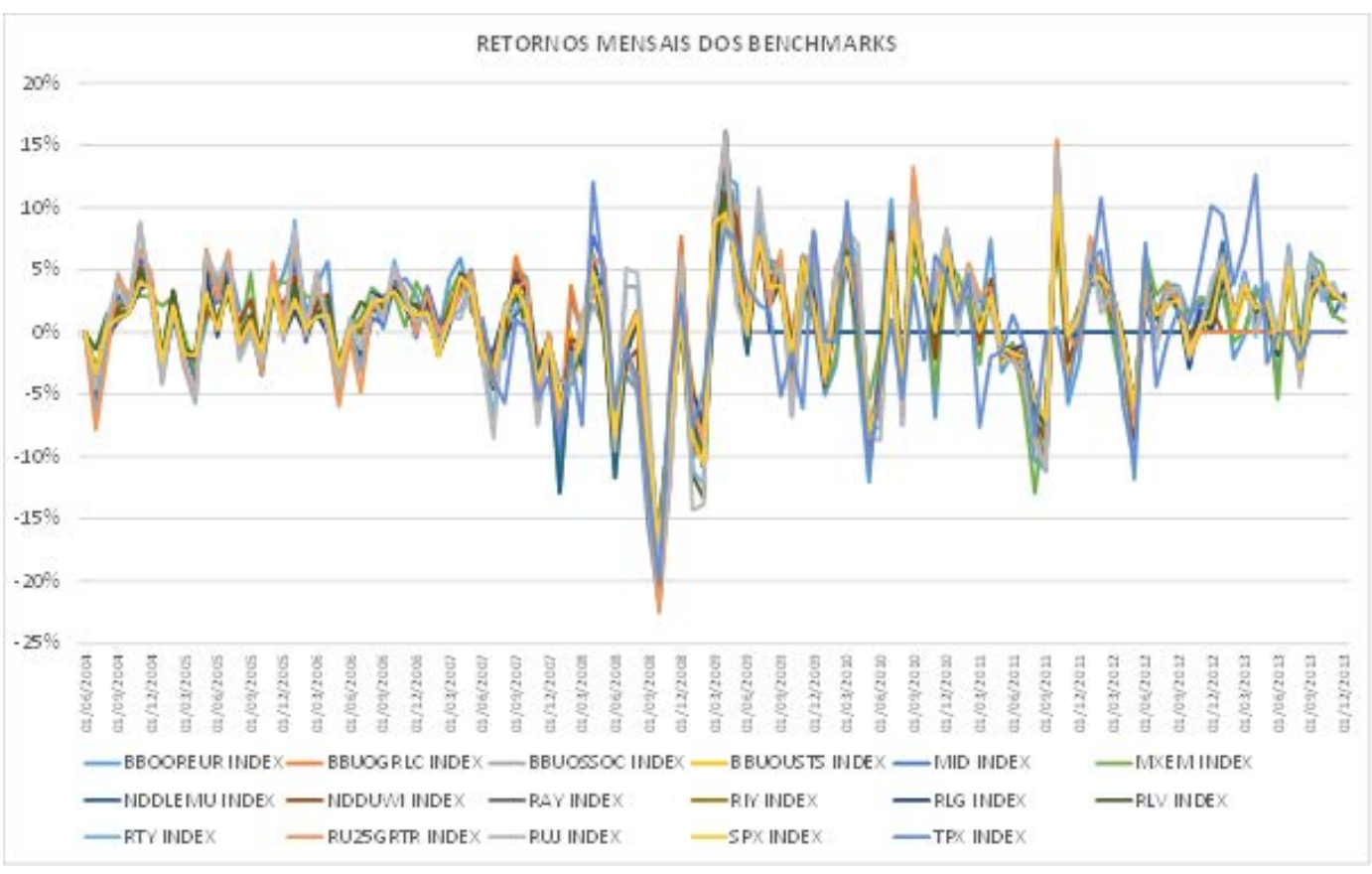

Gráfico 5: Retornos mensais dos Benchmarks (em \%).

\subsection{2}

\section{Impacto dos fundos}

Este resultado indica que as variações nas taxas de superação dos Benchmarks podem ser atribuídas mais a fatores inerentes aos fundos do que aos Benchmarks.

Como se pode verificar na Tabela 16, quando se incluem na regressão as variáveis dummy correspondentes aos fundos, o poder de explicação cresce significativamente, com o R2 ajustado passando de zero para 0,14.

Tabela 16: Regressão Fator Geral Excesso: Retorno do Benchmark; dummy=fundo.

Variável Dependente: Fator Geral Excesso

\begin{tabular}{|l|r|r|r|r|}
\hline \multicolumn{1}{|c|}{ Variável } & Coeficiente & Erro Padrão & Estatística t & P valor \\
\hline RETORNO DO BENCHMARK & 0,094136 & 0,033796 & 2,785407 & 0,0054 \\
\hline DEEMUBV BB EQUITY & $-0,226153$ & 0,046450 & $-4,868765$ & 0,0000 \\
\hline DEGEMUA BB EQUITY & $-0,350723$ & 0,051174 & $-6,853515$ & 0,0000 \\
\hline DEGEUFA BB EQUITY & $-0,066693$ & 0,051664 & $-1,290898$ & 0,1968 \\
\hline DEGSUSA BB EQUITY & 0,197073 & 0,067713 & 2,910440 & 0,0036 \\
\hline
\end{tabular}




\begin{tabular}{|c|c|c|c|c|}
\hline DEGUSBA BB EQUITY & 1,042615 & 0,051794 & 2,013004 & 0,0000 \\
\hline ESPESCA LX EQUITY & 0,041235 & 0,043434 & 0,094937 & 0,3425 \\
\hline ESPRITE LX EQUITY & $-0,475917$ & 0,043496 & $-10,094152$ & 0,0000 \\
\hline HIEZX US EQUITY & 0,096181 & 0,043566 & 2,207690 & 0,0273 \\
\hline JCJBFAA LN EQUITY & $-0,370857$ & 0,060035 & $-6,177298$ & 0,0000 \\
\hline JIISX US EQUITY & $-0,190430$ & 0,042928 & $-4,436072$ & 0,0000 \\
\hline JPGSX US EQUITY & $-0,057865$ & 0,042809 & $-1,351694$ & 0,1765 \\
\hline JPIAX US EQUITY & $-0,103696$ & 0,042982 & $-2,412549$ & 0,0159 \\
\hline JPIVX US EQUITY & 0,118696 & 0,042703 & 2,779592 & 0,0055 \\
\hline JPMJBAA LX EQUITY & 0,204781 & 0,048170 & 4,251215 & 0,0000 \\
\hline KDHAX US EQUITY & $-0,445052$ & 0,042786 & $-1,040173$ & 0,0000 \\
\hline KDSAX US EQUITY & 0,181282 & 0,042755 & 4,239997 & 0,0000 \\
\hline LGTEQGS LE EQUITY & $-0,296999$ & 0,043195 & $-6,875742$ & 0,0000 \\
\hline LMVTX US EQUITY & $-0,728560$ & 0,042728 & $-1,705107$ & 0,0000 \\
\hline LOPEX US EQUITY & $-0,016756$ & 0,054963 & $-0,030487$ & 0,7605 \\
\hline LSVEX US EQUITY & 0,123586 & 0,042760 & 2,890195 & 0,0039 \\
\hline LSVPX US EQUITY & $-0,153742$ & 0,047884 & $-3,210745$ & 0,0013 \\
\hline LSVVX US EQUITY & $-0,308362$ & 0,047398 & $-6,505738$ & 0,0000 \\
\hline NLCIX US EQUITY & $-0,207930$ & 0,177588 & $-1,170860$ & 0,2417 \\
\hline OSEUSBV BB EQUITY & 0,192574 & 0,043522 & 4,424781 & 0,0000 \\
\hline OSI9180 BB EQUITY & $-0,273225$ & 0,042864 & $-6,374178$ & 0,0000 \\
\hline OSIBEPR BB EQUITY & $-0,316690$ & 0,059901 & $-5,286858$ & 0,0000 \\
\hline SSLAX US EQUITY & $-0,160500$ & 0,052218 & $-3,073651$ & 0,0021 \\
\hline UBGAX US EQUITY & $-0,380411$ & 0,044162 & $-8,613915$ & 0,0000 \\
\hline UBRLX US EQUITY & $-0,311104$ & 0,043974 & $-7,074718$ & 0,0000 \\
\hline UBVLX US EQUITY & 0,515111 & 0,043159 & 1,193508 & 0,0000 \\
\hline WOOPX US EQUITY & $-0,301908$ & 0,043048 & $-7,013286$ & 0,0000 \\
\hline R2 Ajustado & 0,135310 & & & \\
\hline
\end{tabular}

Fonte: elaboração própria

Além do aumento no R2, também vale destacar na regressão os coeficientes das variáveis dummy relativas aos fundos. Os coeficientes destas variáveis podem ser separados em três grupos: significativos (a 5\%) positivos, significativos negativos e não significativos, como segue:

Tabela 17: Coeficientes regressão Fator Geral Excesso: Retorno do Benchmark; dummy=fundos e classificações a partir dos testes post-hoc (sig. 5\%).

\begin{tabular}{|l|l|r|r|r|}
\cline { 2 - 5 } \multicolumn{1}{c|}{} & \multicolumn{1}{c|}{ Fundo } & Coeficiente & sig & Class \\
\hline \multirow{4}{*}{$\begin{array}{l}\text { Significativos } \\
\text { Positivos }\end{array}$} & DEGUSBA BB EQUITY & 1,0426 & $0 \%$ & 1 \\
\cline { 2 - 5 } & UBVLX US EQUITY & 0,5151 & $0 \%$ & 2 \\
\cline { 2 - 5 } & DEGSUSA BB EQUITY & 0,1971 & $0 \%$ & 3 \\
\cline { 2 - 5 } & JPMJBAA LX EQUITY & 0,2048 & $0 \%$ & 4 \\
\hline
\end{tabular}




\begin{tabular}{|c|c|c|c|c|}
\hline & OSEUSBV BB EQUITY & 0,1926 & $0 \%$ & 4 \\
\hline & KDSAX US EQUITY & 0,1813 & $0 \%$ & 4 \\
\hline & LSVEX US EQUITY & 0,1236 & $0 \%$ & 7 \\
\hline & JPIVX US EQUITY & 0,1187 & $1 \%$ & 7 \\
\hline & HIEZX US EQUITY & 0,0962 & $3 \%$ & 9 \\
\hline \multirow[t]{5}{*}{ Não Significativos } & LOPEX US EQUITY & $-0,0168$ & $76 \%$ & 10 \\
\hline & ESPESCA LX EQUITY & 0,0412 & $34 \%$ & 11 \\
\hline & JPGSX US EQUITY & $-0,0579$ & $18 \%$ & 12 \\
\hline & DEGEUFA BB EQUITY & $-0,0667$ & $20 \%$ & 13 \\
\hline & NLCIX US EQUITY & $-0,2079$ & $24 \%$ & 20 \\
\hline \multirow{17}{*}{$\begin{array}{l}\text { Significativos } \\
\text { Negativos }\end{array}$} & JPIAX US EQUITY & $-0,1037$ & $2 \%$ & 14 \\
\hline & LSVPX US EQUITY & $-0,1537$ & $0 \%$ & 14 \\
\hline & SSLAX US EQUITY & $-0,1605$ & $0 \%$ & 16 \\
\hline & JIISX US EQUITY & $-0,1904$ & $0 \%$ & 17 \\
\hline & DEEMUBV BB EQUITY & $-0,2262$ & $0 \%$ & 17 \\
\hline & JCJBFAA LN EQUITY & $-0,3709$ & $0 \%$ & 17 \\
\hline & OSIBEPR BB EQUITY & $-0,3167$ & $0 \%$ & 21 \\
\hline & OSI9180 BB EQUITY & $-0,2732$ & $0 \%$ & 22 \\
\hline & LSVVX US EQUITY & $-0,3084$ & $0 \%$ & 22 \\
\hline & LGTEQGS LE EQUITY & $-0,2970$ & $0 \%$ & 24 \\
\hline & WOOPX US EQUITY & $-0,3019$ & $0 \%$ & 24 \\
\hline & UBRLX US EQUITY & $-0,3111$ & $0 \%$ & 24 \\
\hline & UBGAX US EQUITY & $-0,3804$ & $0 \%$ & 24 \\
\hline & DEGEMUA BB EQUITY & $-0,3507$ & $0 \%$ & 28 \\
\hline & KDHAX US EQUITY & $-0,4451$ & $0 \%$ & 29 \\
\hline & ESPRITE LX EQUITY & $-0,4759$ & $0 \%$ & 29 \\
\hline & LMVTX US EQUITY & $-0,7286$ & $0 \%$ & 31 \\
\hline
\end{tabular}

Fonte: elaboração própria

Conforme a Tabela 17, a distribuição dos fundos entre estes três grupos é muito semelhante à classificação dos fundos feita a partir dos testes post-hoc da ANOVA mostrada na Tabela 11: os fundos com coeficientes significativos positivos foram os mesmos fundos que obtiveram as melhores colocações de acordo com as comparações 2 a 2 dos testes post-hoc, alcançando as primeiras posições, de 1 a 9; os fundos sem coeficientes significativos ficaram nas posições seguintes, de 10 a 13; e, finalmente, os fundos com coeficientes significativos negativos ficaram nas últimas posições pelos testes post-hoc, de 14 a 31 . A exceção foi o fundo "NLCIX US EQUITY” que, devido ao reduzido número de observações, apresentou coeficiente não significativo na regressão mas obteve classificação 20 pelos testes post-hoc, correspondente à faixa dos fundos com coeficientes significativos negativos. Conforme a Tabela 4, este fundo atuou em apenas $1 \%$ dos intervalos analisados. 


\subsection{3}

\section{Impacto dos prazos}

A Tabela 18 mostra os dados da regressão utilizando prazo de aplicação como variável dummy.

Tabela 18: Regressão Fator Geral Excesso: Retorno do Benchmark; dummy=prazo de aplicação.

Variável Dependente: Fator Geral Excesso

\begin{tabular}{|c|c|c|c|c|}
\hline Variável & Coeficiente & Erro Padrão & Estatística t & P valor \\
\hline RETORNO DO BENCHMARK & 0,007063 & 0,034345 & 0,205655 & 0,8371 \\
\hline 6 & 0,015850 & 0,017335 & 0,914303 & 0,3606 \\
\hline 12 & $-0,014153$ & 0,016948 & $-0,835037$ & 0,4037 \\
\hline 36 & $-0,161913$ & 0,018280 & $-88,574160$ & 0,0000 \\
\hline 60 & $-0,293337$ & 0,020243 & $-14,490870$ & 0,0000 \\
\hline 120 & $-0,084552$ & 0,156961 & $-0,538680$ & 0,5901 \\
\hline R2 Ajustado & 0,017724 & & & \\
\hline
\end{tabular}

Fonte: elaboração própria

Seria esperado que, com os recursos aplicados por prazos maiores, o gestor do fundo teria mais tempo e oportunidades para superar o Benchmark, o que compensaria a exposição mais prolongada ao risco e à falta de liquidez enfrentadas pelo investidor disposto a manter os recursos aplicados por mais tempo. Entretanto, a relação observada na amostra analisada foi no sentido contrário: os coeficientes relativos aos prazos mais longos (36 e 60 meses) foram negativos, indicando um prêmio negativo para aplicações mais longas. Ou seja, quanto maior o prazo de aplicação, mais difícil para os fundos superarem o Benchmark. Dado o baixo valor do R2, esta observação deve ser vista com parcimônia. A interação entre prazos e fundos (próxima seção) mostra mais claramente esta tendência.

Por outro lado, as observações de Fator Geral Excesso confirmaram uma tendência esperada: quanto maior o prazo de aplicação, menor a volatilidade nos níveis de superação dos Benchmarks pelos fundos. Isto é, quanto mais longa a aplicação, mais claramente definida a capacidade ou incapacidade de os fundos superarem seus Benchmarks. 
Estas tendências podem ser observadas de duas formas: i) na regressão, os prazos mais longos (36 e 60 meses) têm coeficientes significativos a 5\% (negativos), enquanto os coeficientes dos prazos mais curtos (6 e 12 meses) não apresentam significância; ii) no resumo descritivo por prazo da variável Fator Geral excesso (Tabela 19), os prazos de 6 e 12 meses não apresentam médias significativamente (a 5\%) diferentes do Benchmark, enquanto os prazos de 36, 60 e total geral apresentam intervalos de confiança negativos significativos a 5\%. Nota-se também que o desvio padrão (volatilidade) diminui conforme o prazo aumenta. O prazo de 120 meses, devido ao reduzido número de observações, não tem média significativamente diferente do Benchmark.

Tabela 19: Fator Geral Excesso: Resumo descritivo por prazo de aplicação

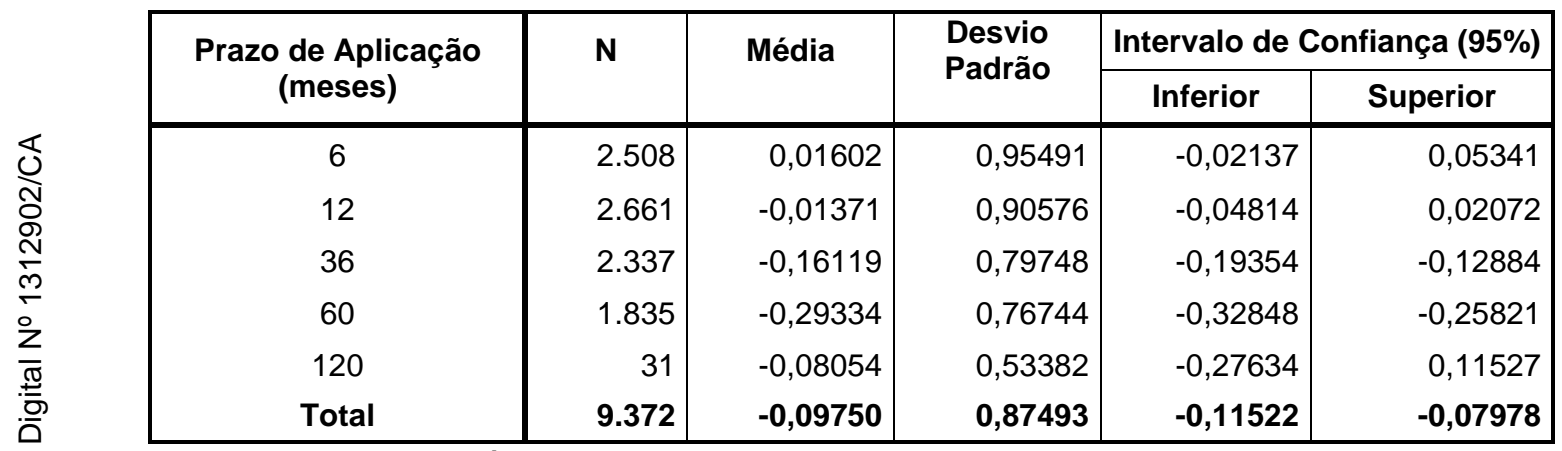

Fonte: elaboração própria 


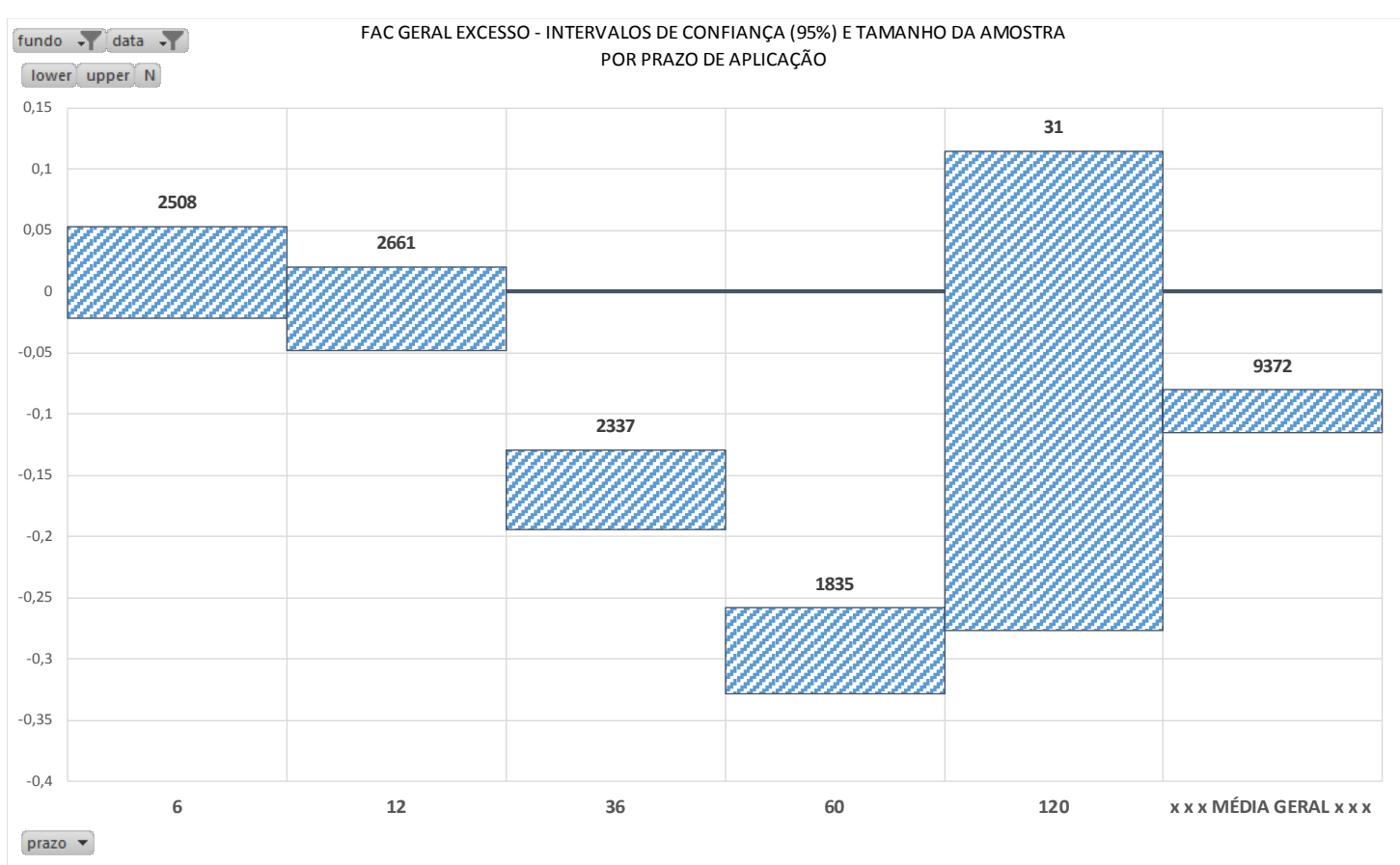

Gráfico 6: Fator Geral Excesso - Intervalos de confiança (95\%) e tamanho da amostra por prazo de aplicação.

A tendência de piora no desempenho conforme se alongam os prazos de aplicação também pode ser observada no Gráfico 6. Nos intervalos de 6 e 12 meses o desempenho médio não diferiu significativamente do Benchmark, enquanto nos prazos de 36 e 60 meses a média foi significantemente negativa, indicando desempenho inferior ao Benchmark. No prazo de 120 meses, devido ao reduzido número de 31 observações (1 por fundo), o intervalo de confiança é mais amplo e, consequentemente, a média foi negativa mas não significativa. Já a média geral, computados todos os cinco prazos de aplicação, foi praticamente igual à do intervalo de 120 meses, mas com significância a 5\%.

\subsection{4}

\section{Interação prazo vs fundos}

A relação entre o prazo de aplicação e a capacidade de superação dos fundos foi investigada de duas formas: i) com o uso de variáveis dummy para a integração entre os fundos e os prazos de aplicação na mesma regressão; e ii) com a aplicação de dados em painel de efeito fixo não balanceado, utilizando os fundos como efeitos cross section e a data fim do intervalo como efeito temporal. 
A Tabela 20 mostra os resumos dos resultados das regressões.

Tabela 20: Resumos das regressões de Fator Geral Excesso, por variáveis dummy e dados em painel, por prazo de aplicação.

\begin{tabular}{|c|c|c|c|c|c|c|c|c|c|c|}
\hline & Var.c & Immy & & & & Dados e & n painel & & & \\
\hline & (prazo & fundo) & & & & & 36 & & 60 & \\
\hline & Coef & pvalor & Coef & sig & Coef & sig & Coef & sig & Coef & sig \\
\hline INTERCEPTO & $N / A$ & $\mathrm{~N} / \mathrm{A}$ & 0,1221 & $0 \%$ & 0,1557 & $0 \%$ & $-0,0648$ & $0 \%$ & $-0,2940$ & $0 \%$ \\
\hline $\begin{array}{l}\text { RETORNO DO } \\
\text { BENCHMARK }\end{array}$ & 0,1700 & $0 \%$ & $-4,3436$ & $0 \%$ & $-2,6920$ & $0 \%$ & $-0,9399$ & $0 \%$ & $-0,6956$ & $0 \%$ \\
\hline R2 AJUSTADO & 0,1845 & & 0,1885 & & 0,2414 & & 0,3774 & & 0,4964 & \\
\hline
\end{tabular}

Fonte: elaboração própria

A Tabela 21, com os coeficientes das regressões, traz mais evidências das duas tendências relacionadas ao prazo de aplicação já identificadas neste trabalho: i) aumento, nos prazos mais longos, do número de betas significativos a $5 \%$ (menos volatilidade no longo prazo); ii) aumento, nos prazos mais longos, da incidência de coeficientes negativos (desempenho inferior aos Benchmarks no longo prazo)

A tendência de maior volatilidade nos prazos mais curtos, também detectada e comentada nas investigações da pergunta P2, pode ser explicada pelo fato de, quanto menor o período da aplicação, maior o impacto exercido pelo resultado de um único mês sobre o resultado total do período. Em outras palavras, é mais provável que um eventual mês com resultado ruim ou negativo, por exemplo, comprometa o retorno total de uma aplicação de 6 meses do que de uma aplicação de 60 meses. Consequentemente, a distinção entre melhores e piores fundos é mais nebulosa no curto prazo e mais definida no longo prazo. 
Tabela 21: Coeficientes das regressões de Fator Geral Excesso, por variáveis dummy e dados em painel, por prazo de aplicação.

\begin{tabular}{|c|c|c|c|c|c|c|c|c|}
\hline \multirow[b]{2}{*}{ Fundo } & \multicolumn{4}{|c|}{ Betas variáveis dummy * } & \multicolumn{4}{|c|}{ Efeitos cross section ** } \\
\hline & 6 & 12 & 36 & 60 & 6 & 12 & 36 & 60 \\
\hline DEEMUBV BB Equity & & $-0,20$ & $-0,31$ & $-0,23$ & $-0,03$ & $-0,03$ & $-0,19$ & $-0,19$ \\
\hline DEGEMUA BB Equity & & $-0,30$ & $-0,50$ & $-0,42$ & $-0,08$ & $-0,12$ & $-0,27$ & $-0,28$ \\
\hline DEGEUFA BB Equity & & & & $-0,23$ & 0,08 & 0,04 & $-0,06$ & $-0,14$ \\
\hline DEGSUSA BB Equity & & 0,39 & 0,34 & & 0,02 & 0,30 & 0,17 & $-0,05$ \\
\hline DEGUSBA BB Equity & 0,83 & 1,13 & 1,49 & 0,66 & 0,42 & 0,59 & 0,73 & 0,26 \\
\hline ESPESCA LX Equity & & & & & 0,13 & 0,15 & 0,09 & $-0,08$ \\
\hline ESPRITE LX Equity & $-0,20$ & $-0,22$ & $-0,68$ & $-1,10$ & $-0,03$ & $-0,00$ & $-0,27$ & $-0,54$ \\
\hline HIEZX US Equity & 0,39 & 0,21 & & $-0,32$ & 0,26 & 0,20 & 0,02 & $-0,12$ \\
\hline JCJBFAA LN Equity & & & $-0,51$ & $-0,44$ & 0,18 & 0,05 & $-0,21$ & $-0,28$ \\
\hline JIISX US Equity & & & $-0,42$ & $-0,55$ & 0,07 & 0,10 & $-0,11$ & $-0,20$ \\
\hline JPGSX US Equity & & & & $-0,36$ & 0,09 & 0,14 & 0,03 & $-0,08$ \\
\hline JPIAX US Equity & & & $-0,24$ & $-0,31$ & 0,07 & 0,10 & $-0,02$ & $-0,09$ \\
\hline JPIVX US Equity & 0,16 & & & & 0,14 & 0,13 & 0,13 & 0,13 \\
\hline JPMJBAA LX Equity & 0,20 & 0,28 & 0,19 & & 0,10 & 0,15 & 0,00 & $-0,05$ \\
\hline KDHAX US Equity & $-0,16$ & $-0,23$ & $-0,64$ & $-1,10$ & $-0,02$ & $-0,01$ & $-0,23$ & $-0,49$ \\
\hline KDSAX US Equity & & & 0,28 & 0,24 & 0,13 & 0,19 & 0,25 & 0,21 \\
\hline LGTEQGS LE Equity & $-0,23$ & $-0,27$ & $-0,32$ & $-0,45$ & $-0,05$ & $-0,04$ & $-0,10$ & $-0,20$ \\
\hline LMVTX US Equity & $-0,37$ & $-0,49$ & $-0,96$ & $-1,52$ & $-0,12$ & $-0,14$ & $-0,39$ & $-0,70$ \\
\hline LOPEX US Equity & & & & & 0,06 & 0,07 & 0,02 & $-0,06$ \\
\hline LSVEX US Equity & 0,20 & & & & 0,16 & 0,15 & 0,10 & 0,10 \\
\hline LSVPX US Equity & & & $-0,26$ & $-0,25$ & 0,08 & 0,10 & $-0,06$ & $-0,12$ \\
\hline LSVVX US Equity & & & $-0,49$ & $-0,54$ & 0,03 & 0,07 & $-0,18$ & $-0,26$ \\
\hline NLCIX US Equity & & & & & $-0,25$ & $-0,29$ & $-0,23$ & $-0,32$ \\
\hline OSEUSBV BB Equity & 0,25 & 0,36 & & & 0,18 & 0,25 & 0,08 & $-0,01$ \\
\hline OSI9180 BB Equity & & $-0,19$ & $-0,33$ & $-0,66$ & $-0,00$ & 0,00 & $-0,12$ & $-0,33$ \\
\hline OSIBEPR BB Equity & & $-0,27$ & $-0,35$ & $-0,30$ & $-0,03$ & $-0,11$ & $-0,22$ & $-0,28$ \\
\hline SSLAX US Equity & & & & & $-0,04$ & $-0,01$ & $-0,04$ & $-0,12$ \\
\hline UBGAX US Equity & & $-0,34$ & $-0,47$ & $-0,75$ & 0,03 & $-0,04$ & $-0,11$ & $-0,28$ \\
\hline UBRLX US Equity & & $-0,29$ & $-0,40$ & $-0,61$ & 0,05 & $-0,02$ & $-0,08$ & $-0,21$ \\
\hline UBVLX US Equity & & 0,41 & 0,72 & 1,01 & 0,14 & 0,33 & 0,45 & 0,57 \\
\hline WOOPX US Equity & & & $-0,72$ & $-1,02$ & 0,16 & 0,13 & $-0,21$ & $-0,37$ \\
\hline \multicolumn{9}{|c|}{ CONTAGEM DE COEFICIENTES: } \\
\hline \multirow[b]{2}{*}{ Prazos (meses): } & \multicolumn{4}{|c|}{ Betas variáveis dummy } & \multicolumn{4}{|c|}{ Efeitos cross section } \\
\hline & 6 & 12 & 36 & 60 & 6 & 12 & 36 & 60 \\
\hline Positivos & 6 & 6 & 5 & 3 & 21 & 20 & 12 & 5 \\
\hline Negativos & 4 & 10 & 16 & 19 & 10 & 11 & 19 & 26 \\
\hline Líquido & 2 & -4 & -11 & -16 & 11 & 9 & -7 & -21 \\
\hline
\end{tabular}

Fonte: elaboração própria

Obs: * apenas betas significativos a $5 \%$ ** efeitos cross section somados aos interceptos das regressões de cada prazo.

Quanto à tendência de maior dificuldade para superar os Benchmarks nos prazos mais longos, os dados analisados neste estudo apontam para influência do período marcado pela crise internacional.

A observação da evolução da variável Fator Geral Excesso por intervalo ajuda a entender este comportamento. 


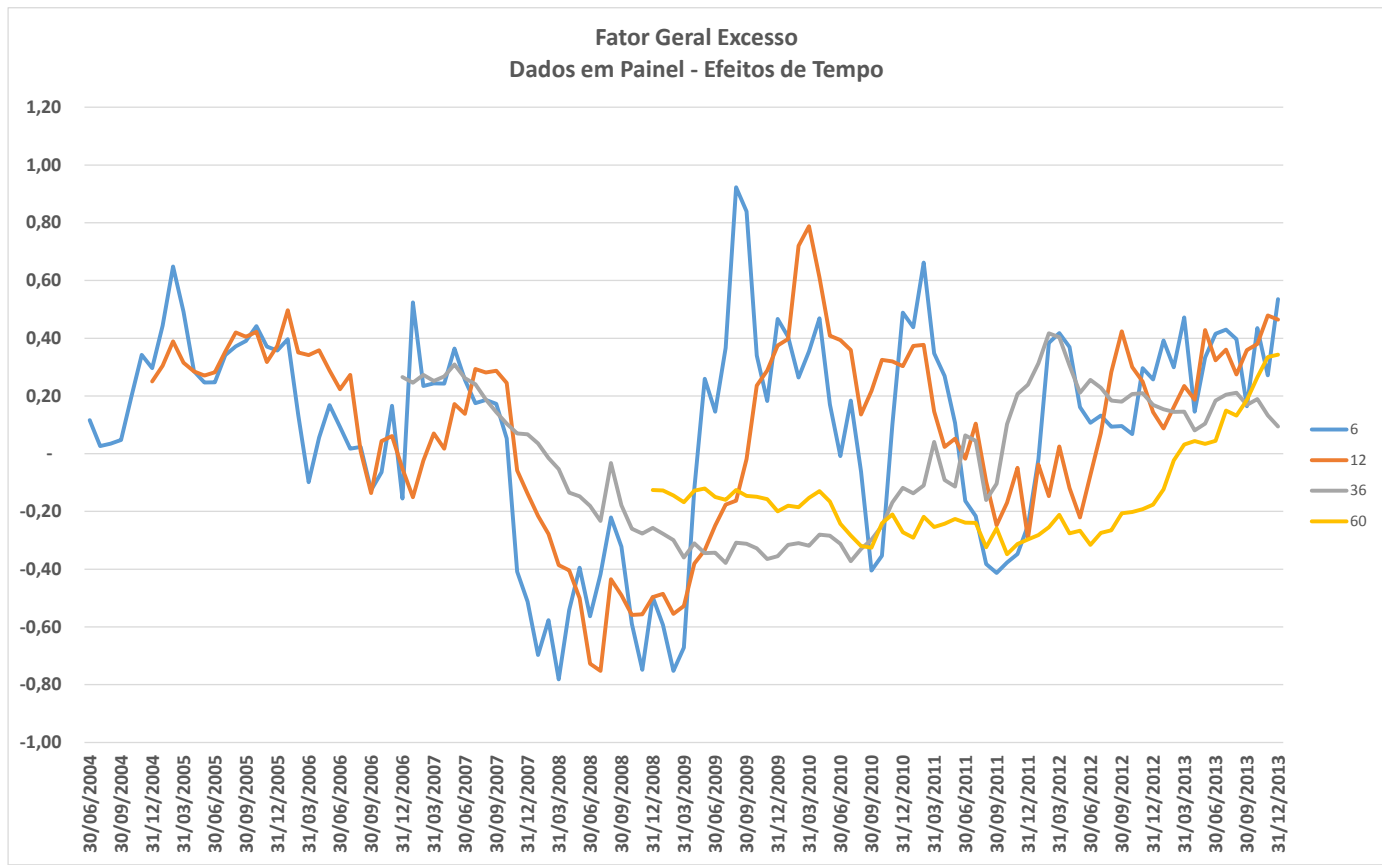

Gráfico 7: Regressão Fator Geral Excesso - dados em painel: efeitos de tempo.

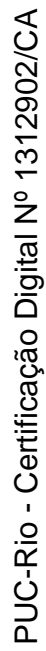

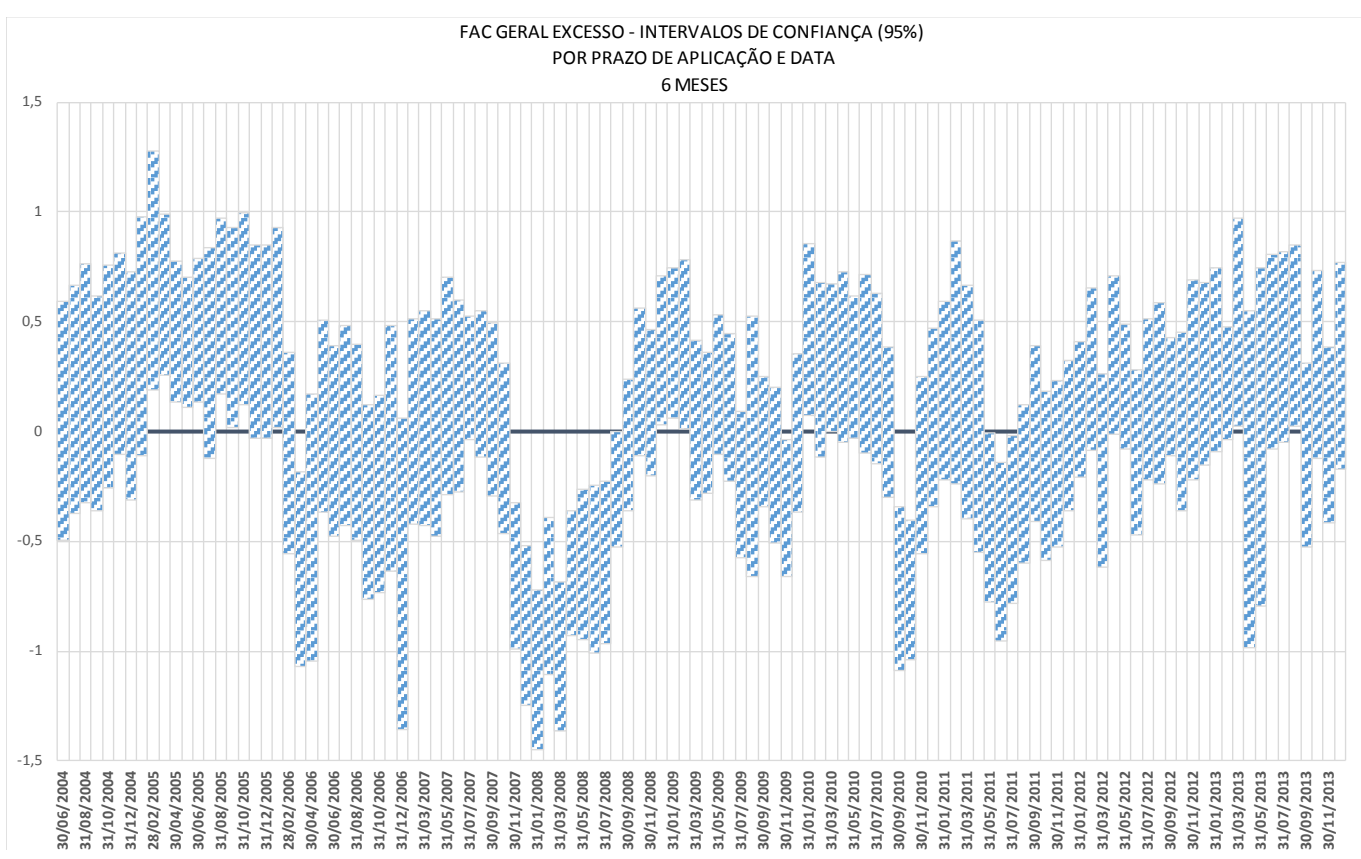

Gráfico 8A: Fator Geral Excesso - Intervalos de confiança (95\%) por intervalo (prazo e data) 6 meses. 


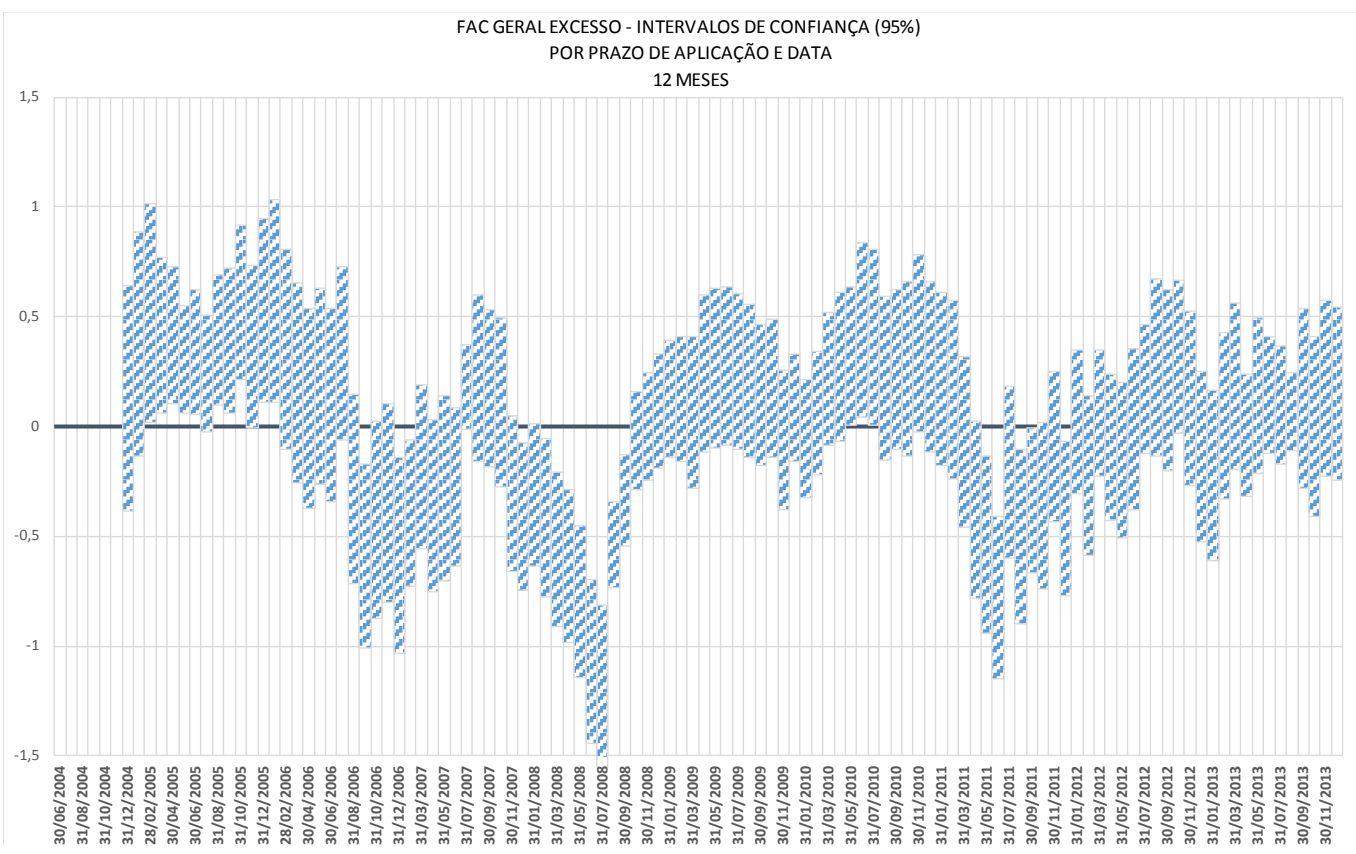

Gráfico 8B: Fator Geral Excesso - Intervalos de confiança (95\%) por intervalo (prazo e data) 12 meses.

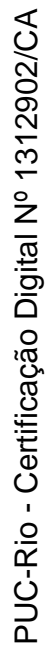

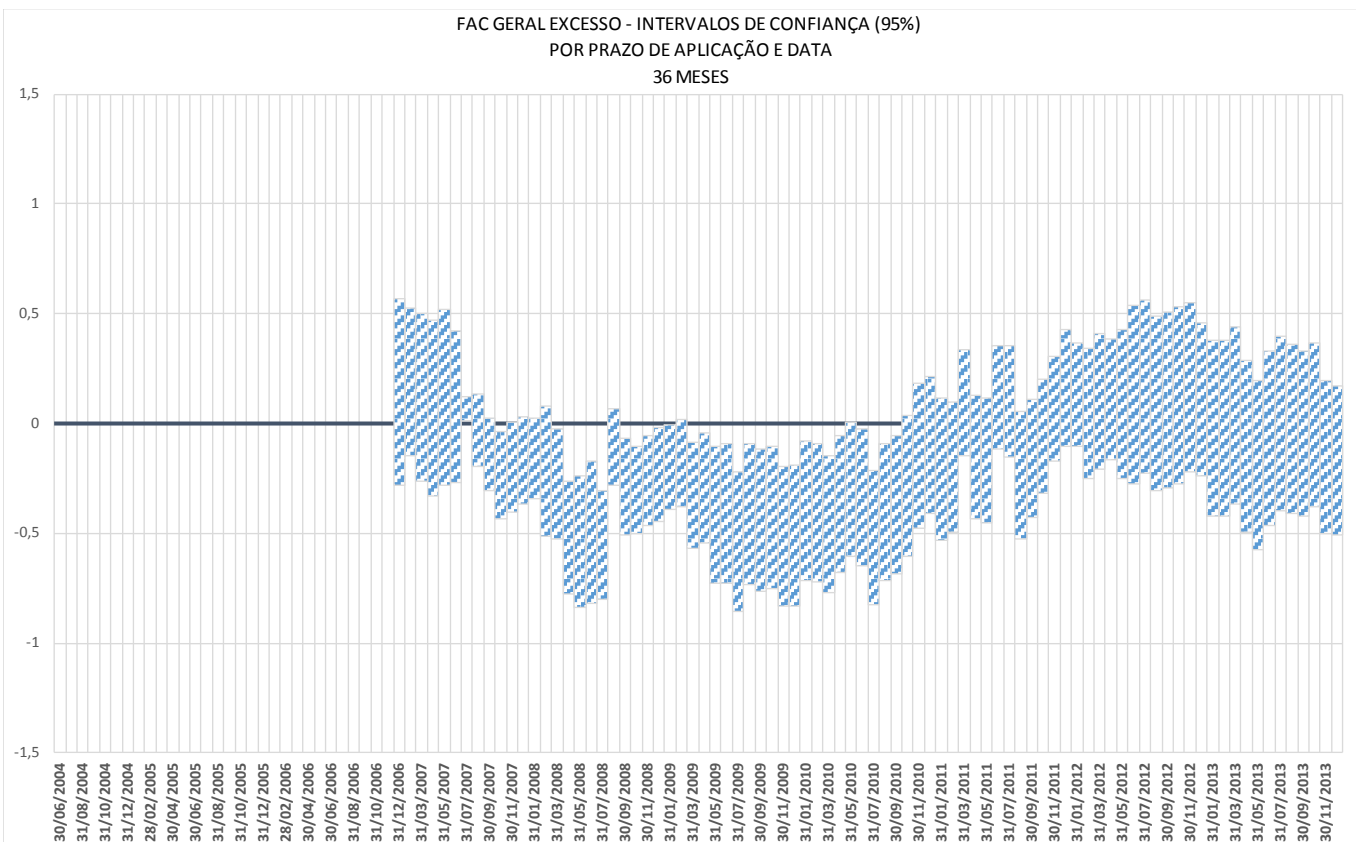

Gráfico 8C: Fator Geral Excesso - Intervalos de confiança (95\%) por intervalo (prazo e data) 36 meses. 


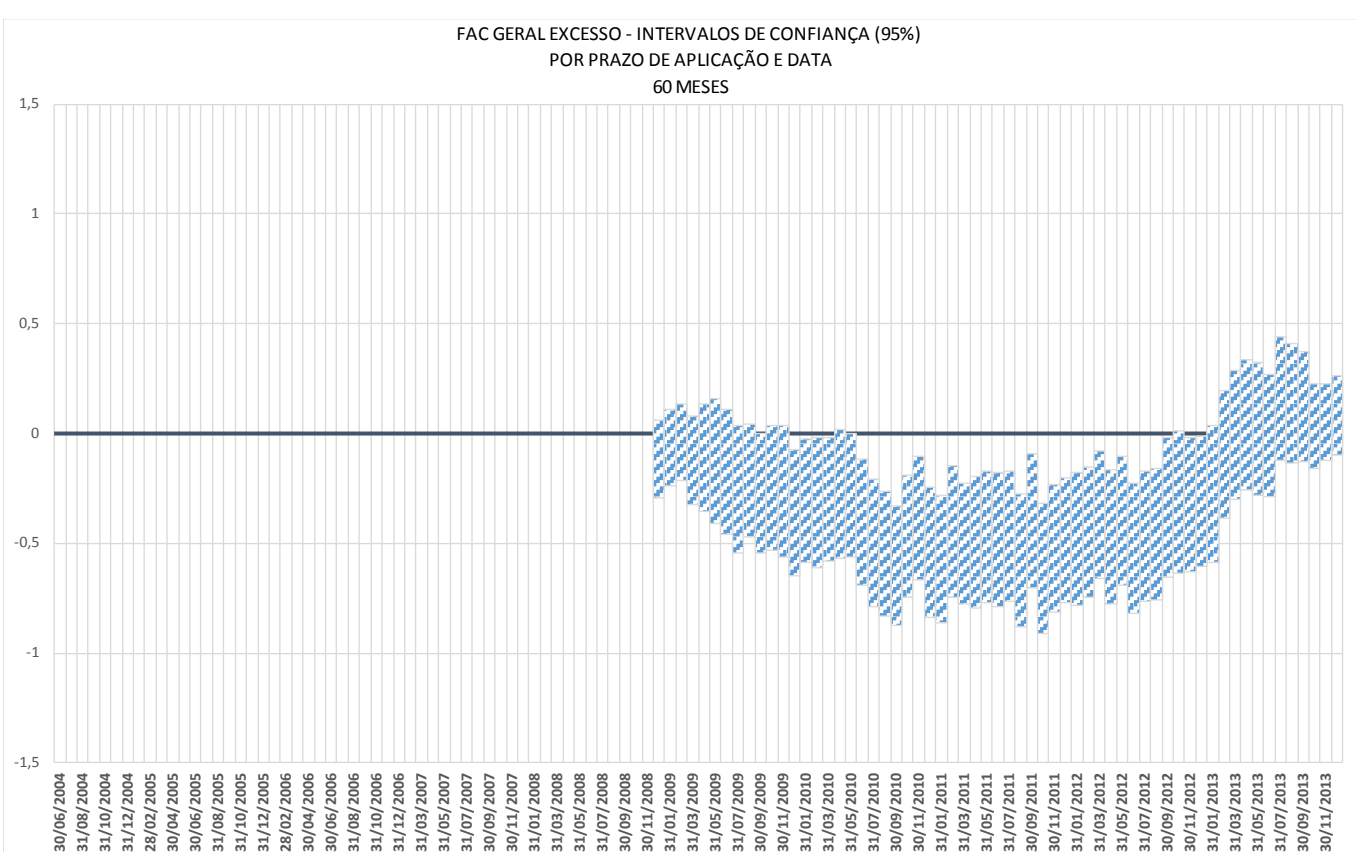

Gráfico 8D: Fator Geral Excesso - Intervalos de confiança (95\%) por intervalo (prazo e data) 60 meses.

O Gráfico 7 mostra os efeitos de tempo (já adicionados os interceptos) das regressões de dados em painel para cada um dos prazos de aplicação. A data de encerramento de cada intervalo de aplicação foi definida como série de tempo.

Os gráficos 8A a 8D mostram os intervalos de confiança (a 95\%) da média da variável Fator Geral Excesso por intervalo, segregados pela data de encerramento de cada intervalo para os prazos de 6, 12, 36 e 60 meses.

Por serem mais numerosos, a observação dos intervalos de 6 meses ajuda a entender melhor a tendência. Além disso, como os intervalos de prazos mais longos correspondem, em última análise, a aglomerados de intervalos de 6 meses, o comportamento dos fundos nos intervalos semestrais ajuda a explicar o desempenho abaixo dos Benchmarks observado nos prazos mais longos.

Pode-se observar que, para os intervalos de 6 meses, destacam-se 2 períodos em que os fundos apresentaram, na média, desempenho significativamente diferente do Benchmark: i) durante o ano de 2005 o desempenho foi superior ao Benchmark; ii) nos semestres encerrados entre o quarto trimestre de 2007 até o final de 2008 -- período de deflagração da crise internacional que deprimiu fortemente a rentabilidade de investimentos ao redor do mundo -- o desempenho foi inferior ao Benchmark. O impacto da diferença negativa em 2007/2008 foi cerca de 50\% maior que a diferença positiva em 2005. 
Fora destes dois períodos, em todo o restante do tempo da amostra analisada neste trabalho, o desempenho dos fundos comportamentais, na média, não diferiu significativamente dos Benchmarks, salvo exceções pontuais.

Embora os resultados negativos dos meses relativos ao período mais agudo da crise internacional tenham afetado o desempenho dos fundos de forma geral, o impacto se diferencia por prazo de aplicação de duas maneiras: i) os prazos mais curtos já haviam acumulado, desde o início da amostra até o início da crise, histórico de intervalos com desempenhos positivos que ajudaram a compensar os efeitos do período de crise; ii) nos prazos mais longos os resultados de um período se propagam por mais tempo, ou seja, afetam maior quantidade de intervalos, do que nos prazos curtos.

Quanto aos históricos positivos, do início da amostra até o terceiro trimestre de 2007, houve 9 intervalos de 6 meses e 10 intervalos de 12 meses com desempenho médio significativamente superior ao Benchmark. Este histórico positivo ajudou a compensar os intervalos negativos do período da crise de forma que, no total da amostra, o desempenho nos prazos de 6 e 12 meses não foi significantemente inferior ou superior aos Benchmarks. Já os prazos mais longos (36 e 60 meses), considerando o início da amostra em 2004, não se beneficiaram de históricos positivos: o primeiro intervalo de 60 meses se encerrou em dezembro de 2008, auge da crise, e o primeiro intervalo de 36 meses terminou em dezembro de 2006, pouco antes do início da crise.

Quanto ao efeito da persistência, de 2009 até o fim da amostra, os prazos de 6 e 12 meses tiveram, respectivamente, 50 e 48 intervalos livres da influência dos meses relativos ao período de crise de 2007/2008. Isto representa cerca de $40 \%$ do total de intervalos da amostra para estes prazos de aplicação. Para o prazo de 36 meses, este percentual de intervalos pós-crise cai para 28\% enquanto para o prazo de 60 meses cai para zero, ou seja, até o último intervalo de 60 meses da amostra ainda continha meses do período de crise. Logicamente, ao longo do tempo, este efeito vai se diluindo à medida que novos meses substituem os meses do período da crise nos intervalos mais recentes. Como prova desta substituição, desde o terceiro trimestre de 2012 os intervalos de 60 meses apresentam tendência contínua de alta.

A Tabela 22 traz um resumo em percentual da contagem dos intervalos de acordo com a significância (a 95\%) da média geral de desempenho dos fundos. 
Tabela 22: Percentual de intervalos quanto à significância (a 95\%) das médias da variável Fator Geral Excesso - Por prazo de aplicação

\begin{tabular}{|l|r|r|r|r|}
\hline \multicolumn{1}{|c|}{ Prazos (meses) } & \multicolumn{1}{|c|}{$\mathbf{6}$} & \multicolumn{1}{c|}{$\mathbf{1 2}$} & \multicolumn{1}{|c|}{$\mathbf{3 6}$} & \multicolumn{1}{c|}{$\mathbf{6 0}$} \\
\hline Significativos positivos & $13 \%$ & $12 \%$ & $1 \%$ & $0 \%$ \\
\hline Não significativos & $73 \%$ & $72 \%$ & $65 \%$ & $44 \%$ \\
\hline Significativos negativos & $14 \%$ & $16 \%$ & $34 \%$ & $56 \%$ \\
\hline
\end{tabular}

Fonte: elaboração própria

\subsection{5}

\section{Impacto do grupo econômico e região foco}

Também foi analisado o efeito dos grupos econômicos responsáveis pela administração dos fundos (parente companies) e dos países-foco dos investimentos dos fundos.

Tabela 23: Regressão Fator Geral Excesso: Retorno do Benchmark; dummy = grupo econômico, região foco

Variável Dependente: Fator Geral Excesso

\begin{tabular}{|l|r|r|r|r|}
\hline \multicolumn{1}{|c|}{ Variável } & Coeficiente & Erro Padrão & Estatística t & P valor \\
\hline RETORNO DO BENCHMARK & 0,025814 & 0,034341 & 0,075170 & 0,4523 \\
\hline AMERICAN INTERNAT (AIG) // U.S. & $-0,163869$ & 0,054353 & $-3,014919$ & 0,0026 \\
\hline BANQUE DEGROOF SA, // EUROP REGION & $-0,127018$ & 0,025559 & $-4,969641$ & 0,0000 \\
\hline BANQUE DEGROOF SA, // EUROP UNION & $-0,330770$ & 0,062332 & $-5,306580$ & 0,0000 \\
\hline BANQUE DEGROOF SA, // EUROZONE & $-0,278984$ & 0,027905 & $-9,997546$ & 0,0000 \\
\hline BANQUE DEGROOF SA, // U.S. & 0,544906 & 0,034661 & 15,720850 & 0,0000 \\
\hline DEUTSCHE BANK AG // U.S. & $-0,100053$ & 0,027569 & $-3,629127$ & 0,0003 \\
\hline JPMORGAN CHASE \&, // JAPAN & $-0,027472$ & 0,039179 & $-0,070119$ & 0,4832 \\
\hline JPMORGAN CHASE \&, // U.S. & $-0,077997$ & 0,016393 & $-4,757942$ & 0,0000 \\
\hline LEGG MASON INC // U.S. & $-0,721495$ & 0,044469 & $-1,622468$ & 0,0000 \\
\hline LGT GROUP FOUNDAT // GLOBAL & $-0,291844$ & 0,044958 & $-6,491417$ & 0,0000 \\
\hline SEI INVESTMENTS C // U.S. & $-0,090896$ & 0,027597 & $-3,293728$ & 0,0010 \\
\hline TIAA BOARD OF OVE // U.S. & $-0,199496$ & 0,184850 & $-1,079235$ & 0,2805 \\
\hline VIRTUS INVESTMENT // U.S. & 0,101459 & 0,045345 & 2,237516 & 0,0253 \\
\hline R2 Ajustado & $\mathbf{0 , 0 6 3 1 1 9}$ & & & \\
\hline
\end{tabular}

Fonte: elaboração própria

Com um R2 ajustado de 6\%, a combinação de região foco do investimento e grupo econômico do administrador (Tabela 23) não apresentou contribuição importante para explicar as taxas de superação dos Benchmarks pelos fundos, embora a quase totalidade tenha apresentado coeficientes significativos. Algumas observações merecem destaque, como por exemplo o elevado grau de 
concentração deste mercado: dos 31 fundos da amostra, 20 pertencem a 2 grupos: “Banque Degroof” e “JPMorgan Chase \&”, cada um com 10.

O belga “Banque Degroof” apresentou desempenho abaixo do Benchmark em todos os investimentos na Europa mas obteve resultados positivos com o fundo “DEGUSBA BB Equity” cujo foco é os Estados Unidos. Além dele, apenas o grupo "Virtus Investment”, com o fundo "HIEZX US EQUITY”, também norteamericano, conseguiu desempenhos superiores aos Benchmarks.

O grupo "JPMorgan Chase \&” foi o único representante da amostra com investimentos no Japão, atuando por meio de 2 fundos, sendo que um obteve resultado positivo e outro negativo, o que tirou a significância do coeficiente. 


\section{Conclusões}

\section{1}

\section{Desempenho dos fundos}

Os testes T mostraram que, para o período analisado, apenas três fundos apresentaram desempenho significativamente (sig. 5\%) superior a seus respectivos Benchmarks em todos os quatro indicadores de desempenho utilizados: “DEGUSBA BB Equity”, “JPMJBAA LX Equity” e “KDSAX US Equity”. Computando a média geral da amostra, os fundos superaram os Benchmarks nos indicadores MDC e Ômega mas não nos indicadores IS e ISO. Apenas 9 fundos apresentaram coeficientes positivos significativos a $5 \%$ para a variável consolidadora de todos os indicadores.

Considerando uma amostra de 31 fundos analisados, estes resultados apontam mais para sucessos individuais destes representantes do que propriamente uma tendência geral de superioridade dos fundos comportamentais: dentre os 31 fundos, 13 superaram o Benchmark em pelo menos um indicador enquanto 18 não superaram em nenhum indicador.

Este resultado corrobora as conclusões do trabalho de Santoni e Kelshiker (2010) que também não identificaram evidências suficientes para suportar hipótese de que os fundos comportamentais apresentam desempenho superior ao mercado.

A partir dos resultados dos testes post-hoc de ANOVA para diferenças de desempenho entre os fundos em relação ao respectivo Benchmark no período analisado, considerados todos os prazos de aplicação e todos os quatro indicadores de performance, os fundos foram ordenados e agrupados em 3 categorias: superiores, intermediários e inferiores, conforme segue:

- Superiores: $1^{\circ}$ ) DEGUSBA BB Equity; $2^{\circ}$ ) UBVLX US Equity; $3^{\circ}$ ) DEGSUSA BB Equity; $4^{\circ}$ ) KDSAX US Equity; OSEUSBV BB Equity; 
$6^{\circ}$ ) JPMJBAA LX Equity; $7^{\circ}$ ) JPIVX US Equity; LSVEX US Equity; $9^{\circ}$ ) HIEZX US Equity; $10^{\circ}$ ) LOPEX US Equity; $11^{\circ}$ ) ESPESCA LX Equity

- Intermediários: $12^{\circ}$ ) JPGSX US Equity; $13^{\circ}$ ) DEGEUFA BB Equity; $14^{0}$ ) JPIAX US Equity; LSVPX US Equity; $16^{\circ}$ ) SSLAX US Equity; $17^{\circ}$ ) JIISX US Equity; DEEMUBV BB Equity; $19^{\circ}$ ) JCJBFAA LN Equity; 20³) NLCIX US Equity

- Inferiores: $21^{\circ}$ ) OSIBEPR BB Equity; 22º OSI9180 BB Equity; LSVVX US Equity; $24^{\circ}$ ) WOOPX US Equity; UBRLX US Equity; UBGAX US Equity; LGTEQGS LE Equity; 28 ${ }^{\circ}$ DEGEMUA BB Equity; 29 ${ }^{\circ}$ ) ESPRITE LX Equity; KDHAX US Equity; $31^{\circ}$ ) LMVTX US Equity

O fundo "UBVLX US Equity” foi apontado por Santoni e Kelshiker (2010) como o de melhor desempenho e aqui aparece em segundo lugar, atrás de “DEGUSBA BB Equity”, que só começou a operar em jun/08, ou seja, 18 meses antes do fim do período analisado naquele estudo.

\section{2}

\section{Prazos de aplicação}

Na comparação de desempenho entre os fundos segregada por prazo de aplicação, duas tendências foram identificadas no estudo:

i) quanto menor o prazo de aplicação, menor a diferença de desempenho entre os fundos;

ii) quanto maior o prazo de aplicação, pior o desempenho em relação ao Benchmark.

A primeira tendência foi observada em diferentes análises: maiores níveis de variância dos desempenhos nos prazos mais curtos; maior quantidade de fundos em posições intermediárias nos prazos mais curtos; menor número de diferenças significativas entre os fundos nos prazos mais curtos; menor quantidade de coeficientes significativos nas variáveis dummy relativas aos fundos nas regressões nos prazos mais curtos. 
Esta tendência de maior semelhança entre os desempenhos dos fundos nos prazos mais curtos em comparação com os prazos mais longos era esperada. O retorno total do fundo é mais sujeito a oscilações quando o período de aplicação é mais curto do que quando o período é mais longo: um único mês com resultado muito superior ou muito inferior tem maior efeito sobre o retorno total de um período menor (6 meses) do que sobre um período maior (60 meses), o que contribui para tornar menos nítida a distinção entre os desempenhos dos fundos no curto prazo. Por isso, no estudo, foram identificadas poucas diferenças de desempenho estatisticamente significantes nos prazos de 6 e 12 meses, e mais diferenças nos prazos de 36 meses e 60 meses. Para o prazo de 120 meses, por se tratar de amostra única por fundo, não foi possível apurar significância estatística.

A segunda tendência verificada, de piora em relação aos Benchmarks nos prazos mais longos, também foi observada em diferentes análises: intervalos de confiança não significativos para a média dos desempenhos nos prazos de 6 e 12 meses e significativamente negativos nos prazos de 36 e 60 meses; número crescente, conforme o prazo de aplicação, de coeficientes significantemente negativos nas regressões para as variáveis dummy relativas aos fundos; número crescente, conforme o prazo de aplicação, de efeitos cross section negativos (variável 'fundos') nas regressões por dados em painel. Este resultado coincide parcialmente com o obtido por Santoni e Kelshiker (2010), que constatou desempenho inferior aos Benchmarks num horizonte de 3 anos (71\% dos fundos) e superior num horizonte de 1 ano (80\% dos fundos). Aqui houve evidências de desempenho inferior no prazo de 36 meses mas não de desempenho superior para o prazo de 12 meses.

Os dados analisados no presente estudo sugerem que este movimento foi influenciado pela crise internacional, especialmente entre final de 2007 e final de 2008. Neste período, os fundos apresentaram, em geral, desempenhos inferiores ao Benchmark, em linha com os resultados de Santoni e Kelshiker (2010): os fundos comportamentais apresentaram desempenho inferior aos Benchmarks em ciclos de baixa ("bear market”). Entretanto, considerando o período total da amostra, o desempenho nos prazos longos foi mais afetado uma vez que os prazos mais curtos apresentaram, antes e após o período agudo da crise, intervalos positivos suficientes para compensar os resultados negativos no cômputo total da amostra. Em resumo, nos prazos mais curtos os fundos tiveram mais 
oportunidades de recuperação dos efeitos negativos da crise do que nos prazos mais longos. Desta forma, é de se esperar que, com o passar do tempo, caso não ocorram novos períodos de quedas abruptas, despareça a tendência de desempenho inferior nos prazos mais longos observada neste estudo, à medida que os meses relativos ao período da crise vão sendo substituídos nos intervalos mais recentes.

\section{3}

\section{Impactos das variáveis}

A primeira variável analisada foi o retorno do Benchmark. Era esperado que o nível de superação dos Benchmarks pelos fundos fosse altamente relacionado com esta variável, de modo que, quanto mais alto o retorno do Benchmark mais difícil fosse para um fundo superá-lo e vice-versa. Entretanto, ao testar esta variável como explicativa do excesso de desempenho em relação ao Benchmark, o R2 obtido foi desprezível. Duas características ajudam a explicar este resultado: i) muitos fundos compartilham os mesmos Benchmarks (17 Benchmarks para 31 fundos); ii) os Benchmarks apresentaram retornos muito semelhantes ao longo do período da amostra. Consequentemente, as variações nos níveis de superação entre os fundos deveram-se mais aos próprios fundos do que aos Benchmarks: adicionando-se à regressão os fundos como variáveis dummy independentes, o R2 ajustado subiu para 14\%.

A variável prazo de aplicação, sozinha, teve pouco poder de explicação sobre o nível de desempenho dos fundos: R2 de 2\%. Entretanto, com a inclusão da interação entre os prazos e dos fundos, o R2 subiu para $18 \%$ e pôde ser observada a relação entre desempenhos negativos e prazos longos já discutida na seção anterior. Nas regressões por dados em painel para os prazos de aplicação de 6, 12, 36 e 60 meses, os valores de R2 obtidos foram de 19\%, 24\%, 38\% e 50\%, respectivamente.

A combinação de grupo econômico e região foco de investimentos como variáveis dummy independentes teve baixo poder de explicação dos desempenhos: R2 de 6\%. Destaque para a grande concentração dos fundos, com dois grupos ('JPMORGAN CHASE' e 'BANQUE DEGROOF SA') responsáveis cada um pela terça parte dos fundos. Apenas dois grupos econômicos apresentaram betas 
significativos positivos, ambos com foco de investimento nos EUA: grupo 'VIRTUS INVESTMENT' ('HIEZX US Equity') e 'BANQUE DEGROOF SA' ('DEGUSBA BB Equity’ e ‘OSEUSBV BB Equity’).

\section{4}

\section{Sugestões para estudos futuros}

Como sugestões para estudos futuros, propõem-se:

i) Análise do desempenho dos fundos comportamentais à luz de outras variáveis como, por exemplo, expectativas de taxas de juros, de inflação, de PIB, e outras medidas que sirvam de proxy de sentimentos e perspectiva dos mercados quanto ao cenário macroeconômico da região foco de investimentos. Os fundos comportamentais teriam rendimento melhor, pior ou igual diante de expectativas otimistas ou pessimistas dos agentes econômicos?

ii) Estender a análise de desempenho dos fundos comportamentais para períodos mais curtos, como por exemplo, mês, dia, intra-dia. Tais fundos conseguiriam se beneficiar de eventuais inconsistências do mercado em intervalos muito curtos, obtendo desempenho superiores?

iii) Investigar se existem, no Brasil, fundos que operem explorando vieses comportamentais a exemplo dos fundos analisados neste trabalho. Se existirem, analisar seu desempenho vis a vis os Benchmarks de mercado e/ou outros fundos. 


\section{Referências bibliográficas}

BAILEY, W.; KUMAR, A.; NG, D. Behavioral biases of mutual fund investors. Journal of Financial Economics: Elsevier. 102: 1-27 p. 2011.

BARBERIS, N.; THALER, R. A survey of behavioral finance. Handbook of the Economics of Finance: Elsevier. 1: 1053-1128 p. 2003.

BAWA, V.S.; LINDENBERG, E.B. Capital market equilibrium in a mean-lower partial moment framework. Journal of Financial Economics: Elsevier. 5: 189200 p. 1977.

BENARTZI, S.; THALER, R.H. Myopic Loss Aversion and the Equity Premium Puzzle. Quarterly Journal of Economics, v. 110, n. 1, p. 73-92, Feb 1995. ISSN 0033-5533. Disponível em: <<Go to ISI>://WOS:A1995QH36200004 >.

BERTRAND, P.; PRIGENT, J.-L. Omega performance measure and portfolio insurance. Journal of Banking \& Finance, v. 35, n. 7, p. 1811-1823, Jul 2011. ISSN 0378-4266. Disponível em: <<Go to ISI >://WOS:000291518300016>.

BLACK, Ken. Business statistics: for contemporary decision making. John Wiley \& Sons, 2011.

BROOKS, Chris. Introductory econometrics for finance. Cambridge university press, 2008.

BROWN, M. B.; FORSYTHE, A. B. ROBUST TESTS FOR EQUALITY OF VARIANCES. Journal of the American Statistical Association, v. 69, n. 346, p. 364-367, 1974 1974. ISSN 0162-1459. Disponível em: < <Go to ISI>://WOS:A1974T799200012 >.

CHAN, W.S.; FRANKEL, R.; KOTHARI, S.P. Testing behavioral finance theories using trends and consistency in financial performance. Journal of Accounting and Economics: Elsevier. 38: 3-50 p. 2004.

D'AVOLIO, G. The market for borrowing stock. Journal of Financial Economics, v. 66, n. 2-3, p. 271-306, Nov-Dec 2002. ISSN 0304-405X. Disponível em: <<Go to ISI $>$ ://WOS:000179256500004 >.

DEBONDT, W.F.M.; THALER, R. DOES THE STOCK-MARKET OVERREACT. Journal of Finance, v. 40, n. 3, p. 793-805, 1985 1985. ISSN 0022-1082. Disponível em: <<Go to ISI>://WOS:A1985ANR3000022 >.

DELONG, J. B. et al. Noise Trader Risk in Financial-Markets. Journal of Political Economy, v. 98, n. 4, p. 703-738, Aug 1990. ISSN 0022-3808. Disponível em: $<<$ Go to ISI $>$ ://WOS:A1990DQ48500002 >. 
FISHBURN, P.C. Mean-Risk Analysis with Risk Associated with Below-Target Returns. American Economic Review, v. 67, n. 2, p. 116-126, 1977 1977. ISSN 0002-8282. Disponível em: <<Go to ISI>://WOS:A1977DA61600010 >.

FROMLET, H. Behavioral Finance-Theory and Practical Application. Systematic Analysis of Departures from the Homo Oeconomicus Paradigm are Essential for Realistic Financial Research and Analysis. Business Economics: JSTOR, 63-69 p. 2001.

GONZALEZ FERNANDEZ, M.; GONZALEZ VELASCO, C. Is there a difference in the return and risk of non-conventional funds? Cuadernos De Economia Y Direccion De La Empresa, v. 16, n. 3, p. 194-204, Jul-Sep 2013. ISSN 1138-5758. Disponível em: <<Go to ISI>://WOS:000322427200004 >.

GOODFELLOW, C.; SCHIERECK, D.; WIPPLER, S. Are behavioural finance equity funds a superior investment? A note on fund performance and market efficiency. Journal of Asset Management: Nature Publishing Group. 14: 111119 p. 2013.

HAIR, Joseph F. et al. Multivariate data analysis. Upper Saddle River, NJ: Pearson Prentice Hall, 2006.

HARRIS, L.; GUREL, E. Price and Volume Effects Associated with Changes in the Standard-and-Poor-500 List - New Evidence for the Existence of Price Pressures. Journal of Finance, v. 41, n. 4, p. 815-829, Sep 1986. ISSN 00221082. Disponível em: <<Go to ISI >://WOS:A1986D795300003 >.

HAUG, M.; HIRSCHEY, M. The January effect. Financial Analysts Journal, v. 62, n. 5, p. 78-88, Sep-Oct 2006. ISSN 0015-198X. Disponível em: $<<$ Go to ISI $>: / /$ WOS:000240919500010 >.

JEGADEESH, N.; TITMAN, S. Returns to Buying Winners and Selling Losers Implications for Stock-Market Efficiency. Journal of Finance, v. 48, n. 1, p. 6591, Mar 1993. ISSN 0022-1082. Disponível em: $<<$ Go to ISI $>$ ://WOS:A1993KU06000003 >.

KAHNEMAN, D.; TVERSKY, A. Prospect Theory: An Analysis of Decision under Risk. Econometrica, v. 47, n. 2, p. 263-291, 03/01 1979. ISSN 00129682. Disponível em: < http://www.jstor.org/stable/1914185 >.

KANE, S.J. et al. Optimizing Omega. Journal of Global Optimization, v. 45, n. 1, p. 153-167, Sep 2009. ISSN 0925-5001. Disponível em: < <Go to ISI $>$ ://WOS:000268492700008 > .

KAPLAN, P.D.; KNOWLES, J.A. Kappa: a generalized downside risk-adjusted performance measure. Journal of Performance Measurement: TGS Publishing. 8: 42-54 p. 2004.

KEATING, C.; SHADWICK, W. F. A universal performance measure. Journal of Performance Measurement. 6: 59-84 p. 2002. 
KESELMAN, H. J. et al. The new and improved two-sample t test. Psychological Science, v. 15, n. 1, p. 47-51, Jan 2004. ISSN 0956-7976. Disponível em: <<Go to ISI $>$ ://WOS:000188846500008 >.

KLOTZLE, M.C. et al. Desenvolvimento de uma medida de desempenho comportamental. Revista Brasileira de Finanças. 10: 395-416 p. 2012.

LIM, T. S.; LOH, W. Y. A comparison of tests of equality of variances.

Computational Statistics \& Data Analysis, v. 22, n. 3, p. 287-301, Jul 151996.

ISSN 0167-9473. Disponível em: <<Go to ISI>://WOS:A1996UX53700005 >.

LOPES, L. Between Hope and Fear - The Psychology of Risk. Advances in Experimental Social Psychology, v. 20, p. 255-295, 1987 1987. ISSN 00652601.

LOPES, L.; ODEN, G. The role of aspiration level in risky choice: A comparison of cumulative prospect theory and SP A theory. Journal of Mathematical Psychology, v. 43, n. 2, p. 286-313, JUN 1999 1999. ISSN 0022-2496.

MARKOWITZ, H. Portfolio selection: efficient diversification of investments. Brasil Blackwall, New York 1959.

MEHRA, R.; PRESCOTT, E. C. The equity premium - a puzzle. Journal of Monetary Economics, v. 15, n. 2, p. 145-161, 1985 1985. ISSN 0304-3932. Disponível em: <<Go to ISI >://WOS:A1985AGB1900001 >.

MERTON, R. C. A Simple-Model of Capital-Market Equilibrium with Incomplete Information. Journal of Finance, v. 42, n. 3, p. 483-510, Jul 1987. ISSN 0022-1082. Disponível em: < <Go to ISI>://WOS:A1987H924400001 >.

MOORE, D. A.; HEALY, P. J. The trouble with overconfidence. Psychological Review, v. 115, n. 2, p. 502-517, Apr 2008. ISSN 0033-295X. Disponível em: < $<$ Go to ISI $>$ ://WOS:000255118800011 >.

NAWROCKI, D. N. A brief history of downside risk measures. The Journal of Investing: Institutional Investor Journals. 8: 9-25 p. 1999.

PEDERSEN, C. S.; SATCHELL, S. E. Small sample analysis of performance measures in the asymmetric response model. Journal of Financial and Quantitative Analysis, v. 35, n. 3, p. 425-450, Sep 2000. ISSN 0022-1090. Disponível em: <<Go to ISI $>$ ://WOS:000089449300010 >.

PHILIPPAS, N. Did Behavioral Mutual Funds Exploit Market Inefficiencies During or After the Financial Crisis? Multinational Finance Journal: Multinational Finance Society. 18: 85-138 p. 2014.

REINGANUM, M. The Anomalous Stock-Market Behavior of Small Firms in January - Empirical Tests for Tax-Loss Selling Effects. Journal of Financial Economics, v. 12, n. 1, p. 89-104, 1983 1983. ISSN 0304-405X. 
REINHART, W.J.; BRENNAN, M. Behavioral portfolios performance measurement. Working Paper, Loyola College, Timonium (USA) 2004.

RITTER, J.R. Behavioral finance. Pacific-Basin. Finance Journal: Elsevier. 11: 429-437 p. 2003.

ROZEFF, M.; KINNEY, W. Capital-Market Seasonality - Case of Stock Returns. Journal of Financial Economics, v. 3, n. 4, p. 379-402, 1976 1976. ISSN 0304405X.

SANTONI, A.; KELSHIKER, A.R. Behavioral finance: an analysis of the performance of behavioral finance funds. The Journal of Index Investing. 1: 5672 p. 2010.

SHARPE, W. F. Mutual fund performance. Journal of business: JSTOR. 119138 p. 1966.

SHEFRIN, H.; STATMAN, M. The Disposition to Sell Winners Too Early and Ride Losers Too Long - Theory and Evidence. Journal of Finance, v. 40, n. 3, p. 777-790, 1985 1985. ISSN 0022-1082. Disponível em: $<<$ Go to ISI $>$ ://WOS:A1985ANR3000020 >.

Behavioral portfolio theory. Journal of Financial and Quantitative Analysis, v. 35, n. 2, p. 127-151, JUN 2000 2000. ISSN 0022-1090.

SHLEIFER, A.; VISHNY, R.W. The limits of arbitrage. Journal of Finance, v. 52, n. 1, p. 35-55, Mar 1997. ISSN 0022-1082. Disponível em: < <Go to ISI>://WOS:A1997WM21300002 >.

SJØBERG, C. Performance evaluation of behavioral finance mutual funds: a comparison between behavioral finance mutual funds and conventional funds in the Norwegian fund market: Universitetet i Agder; University of Agder 2011.

SORTINO, F.A.; PRICE, L. N. Performance measurement in a downside risk framework. The Journal of Investing: Institutional Investor Journals. 3: 59-64 p. 1994.

THALER, R. H. From homo economicus to homo sapiens. Journal of Economic Perspectives, v. 14, n. 1, p. 133-141, Win 2000. ISSN 0895-3309. Disponível em: $<<$ Go to ISI $>$ ://WOS:000085807400010 $>$.

TVERSKY, A.; KAHNEMAN, D. Judgment Under Uncertainty - Heuristics and Biases. Science, v. 185, n. 4157, p. 1124-1131, 1974 1974. ISSN 0036-8075.

Advances in prospect theory: Cumulative representation of uncertainty. Journal of Risk and Uncertainty, v. 5, n. 4, p. 297-323, 1992. ISSN 0895-5646. Disponível em: < http://dx.doi.org/10.1007/BF00122574 >.

VON NEUMANN, J.; MORGENSTERN, O. Theory of Games and Economic Behavior: Princeton university press 1944. 
WILCOX, R. R. NEW DESIGNS IN ANALYSIS OF VARIANCE. Annual Review of Psychology, v. 38, p. 29-60, 1987 1987. ISSN 0066-4308. Disponível em: <<Go to ISI $>$ ://WOS:A1987F872200003 >.

WRIGHT, C.; BANERJEE, P.; BONEY, V. Behavioral finance. The Journal of investing, v. 17, n. 4, p. 82-90, 2008. ISSN 1068-0896.

ZAKAMOULINE, V.; KOEKEBAKKER, S. Portfolio performance evaluation with generalized Sharpe ratios: Beyond the mean and variance. Journal of Banking \& Finance, v. 33, n. 7, p. 1242-1254, Jul 2009. ISSN 0378-4266. Disponível em: $<<$ Go to ISI $>$ ://WOS:000266178100006 >. 